DISEASE GERMS. 


$$
6246
$$




\section{DISEASE GERMS:}

THEIR

REAL NATURE. 



\title{
DISEASE GERMS;
}

тиніR

\author{
REAL NATURE.
}

\section{AN ORIGINAL INVESTIGATION.}

BY

LIONEL S. BEALE, M.B., F.R.S., Fellow of the Royal College of Physicians; Physician to King's College Hospital; and
lately Professor of Physiology and of General and Morbid Anatomy in King's College, London.

TWENTY-FOUR PLATES CONTAINING MANY COLOURED ILLUSTRATIONS.

LONDON :

J. CHURCHILL \& SONS, NEW BURLINGTON STREET.

$$
\text { I870. }
$$

[All Rights Reserved.] 


$$
\begin{aligned}
& 515073 \\
& k 65 \mathrm{Mr})
\end{aligned}
$$

HARRISON AND SONS,

PRINTERS IN ORDINARY TO HER MAJESTY,

ST. MARTIN'S LANE.

WE C ki as collet onBerle

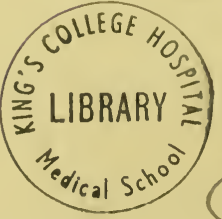

(A)

$$
\begin{aligned}
& 6246 \\
& 24.6 .55
\end{aligned}
$$




\section{THE RADCLIFFE TRUSTEES,}

WILLIAM STRATFORD DUGDALE, Eso., THE RIGHT HON. T. H. S. B. E. SOTHERON-ESTCOURT, THE RIGHT HON. W. E. GLADSTONE, M.P., HIS GRACE THE DUKE OF MARLBOROUGH, K.G., AND TO THEIR LIBRARIAN, HENRY W. ACLAND, M.D., LL.D., F.R.S., THIS WORK IS RESPECTFULLY DEDICATED. 



\section{P R E F A C E.}

THE conclusions concerning the nature of disease germs, now published for the first time in a connected form, were briefly sketched in the lectures I delivered at Oxford in 1868-9, by direction of the Radcliffe Trustees, and have been taught by me for many years past. Some of the facts will be found recorded in my Report on the Cattle Plague in 1866 , and in several memoirs and works published as early as I863.

The illustrations in the present volume are in advance of any yet published by me. By printing in three colours, very accurate copies of the specimens, prepared by the process of investigation I have long adopted, have been obtained. Although less clear and elaborate, and far less beautiful than the originals, the figures in the last few plates of this book really give with great accuracy the appearances of the specimens themselves. Although the result obtained may perhaps be scarcely considered commensurate with the time and labour expended I feel sufficiently encouraged to make further efforts in the same direction.

The time has now arrived when, I think, without impropriety, I may ask scientific observers, and the 
public interested in those branches of scientific investigation which I have now for many years prosecuted, to calmly examine for themselves the actual work which has been done, and not to allow their judgment to be unduly influenced against the conclusions arrived at, either by the circumstance that my researches have not been acknowledged by some scientific writers, or because my views have been very cursorily, and perhaps disparagingly noticed.

It sometimes happens that a leader of opinion, though professing to give the public in a manner the most disinterested and ingenuous, an impartial view of the general state of knowledge in a particular department of research, is led away by his enthusiasm, and perhaps almost unconsciously proclaims and advocates the tenets of his own particular belief; or, without intending it, constitutes himself the mouthpiece of a faction.

However damaging it may be to the interests of science, and however fatal to every other view, there is some excuse for such a course, for the main objects of a party, which has already agreed upon its principles, must necessarily be to force into notoriety, and make the utmost of those arguments which support the particular dogma to which its members have committed themselves, to the exclusion of every other idea. Observations which happen to be opposed to the prevailing propaganda must be ignored or disparaged, or put down by the force of 
authority. The individual opinion of a member must yield to the interests or necessities of the party to which he belongs, but he who desires to serve the interests of science and hopes to extend the bounds of natural knowledge, should endeavour to preserve his individuality, defend liberty of opinion, and strive to retain complete independence of thought and action.

L. S. B.

November, I870. 



\section{TABLE OF CONTENTS.}

\section{BIOPLASM AND ITS DEGRADATION.}

$\begin{array}{llllllllll}\text { Bioplasm... } & \ldots & \ldots & \ldots & \ldots & \ldots & \ldots & \ldots & \ldots & 7\end{array}$

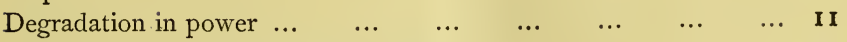

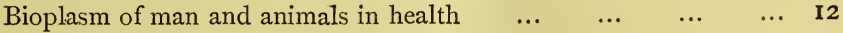

$\begin{array}{lllllllll}\text { Bioplasm of amœbæ } & \ldots & \ldots & \ldots & \ldots & \ldots & \ldots & \ldots & \text { I2 }\end{array}$

$\begin{array}{lllllllll}\text { Bioplasm of bacteria } & \ldots & \ldots & \ldots & \ldots & \ldots & \ldots & \ldots & \text { I4 }\end{array}$

$\begin{array}{lllllll}\text { Vital movements of bioplasm } \ldots & \ldots & \ldots & \ldots & \ldots & \ldots & \text { I4 }\end{array}$

$\begin{array}{lllllllll}\text { Bioplasm of mucus } & \ldots & \ldots & \ldots & \ldots & \ldots & \ldots & \ldots & \text { 17 }\end{array}$

$\begin{array}{lllllllll}\text { Embryonic bioplasm } & \ldots & \ldots & \ldots & \ldots & \ldots & \ldots & \ldots & \text { I } 8\end{array}$

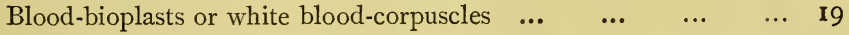

$\begin{array}{lllllll}\text { Bioplasm of the tissues of the adult } & \ldots & \ldots & \ldots & \ldots & \ldots & 26\end{array}$

$\begin{array}{llllllll}\text { From health to disease } . . . & \ldots & \ldots & \ldots & \ldots & \ldots & \ldots & 27\end{array}$

The pus bioplast derived from the germinal matter of all the

$\begin{array}{llllllllll}\text { tissues } & \ldots & \ldots & \ldots & \ldots & \ldots & \ldots & \ldots & \ldots & 30\end{array}$

$\begin{array}{lllllll}\text { Of retrogression in formative power } & \ldots & \ldots & \ldots & \ldots & \ldots & 3^{\mathbf{I}}\end{array}$

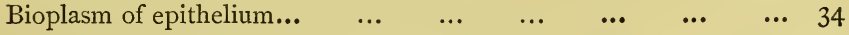

Multiplication of blood-bioplasts in disease $\ldots \begin{array}{lllll}\ldots & \ldots & \ldots & \ldots & 37\end{array}$

New observations on the growth and multiplication of pus $\quad \ldots \quad 42$

On the movements occurring in ordinary living pus $\quad \ldots \quad \ldots \quad \ldots \quad 44$

$\begin{array}{lllllll}\text { Death and decomposition of pus } & \ldots & \ldots & \ldots & \ldots & \ldots & 46\end{array}$

\section{DISEASE GERMS IN ANIMAL FLUIDS AND SECRETIONS.}

$\begin{array}{lllllll}\text { Germs in fluids and secretions... } & \ldots & \ldots & \ldots & \ldots & \ldots & 48\end{array}$

$\begin{array}{lllllllll}\text { Simple exudation } & \ldots & \ldots & \ldots & \ldots & \ldots & \ldots & \ldots & 50\end{array}$

Lymph capable of producing a poisoned wound $\quad \ldots \quad \ldots \quad \ldots \quad \ldots 5$

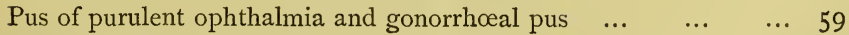

$\begin{array}{llllllll}\text { Germs in vaccine lymph } & \ldots & \ldots & \ldots & \ldots & \ldots & \ldots & 60\end{array}$

$\begin{array}{llllllllll}\text { Germs of small-pox } & \ldots & \ldots & \ldots & \ldots & \ldots & \ldots & \ldots & 64\end{array}$

$\begin{array}{llllllll}\text { Disease germs of fever } \ldots & \ldots & \ldots & \ldots & \ldots & \ldots & \ldots & 64\end{array}$

$\begin{array}{llllllll}\text { Syphilitic disease germs } & \ldots & \ldots & \ldots & \ldots & \ldots & \ldots & 65\end{array}$

$\begin{array}{lllllll}\text { Living disease germs in secretions } & \ldots & \ldots & \ldots & \ldots & \ldots & 67\end{array}$ 
$\begin{array}{llllllllll}\text { Living tubercle germs } & \ldots & \ldots & \ldots & \ldots & \ldots & \ldots & \ldots & 68\end{array}$ $\begin{array}{lllllllllll}\text { Cancer } g e r m s & \ldots & \ldots & \ldots & \ldots & \ldots & \ldots & \ldots & \ldots & 69\end{array}$

\section{INTRODUCTION OF DISEASE GERMS INTO THE BODY AND OF THEIR ESCAPE.}

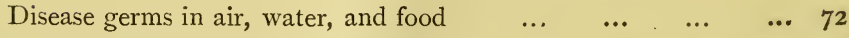

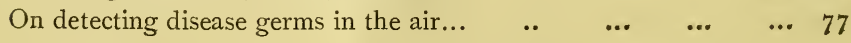

\section{Mode of Entrance of Germs.}

Of the passage of disease germs into the blood $\quad \ldots \quad \ldots \quad \ldots 80$ State of vessels favouring the entrance of disease germs $\quad \ldots \quad$... 84

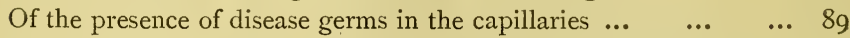
State of blood favourable to the multiplication of disease germs, ... 92

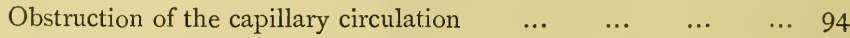

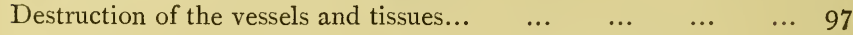
Multiplication of the disease germs in the infected organism $\quad \ldots \quad$ I03 Concerning the possibility of disease germs passing into the sub$\begin{array}{lllllll}\text { stance of normal living bioplasm } & \ldots & \ldots & \ldots & \ldots & 107\end{array}$

\section{Escape of Disease Germs from the Infected Organism.}

$\begin{array}{llllllllll}\text { On elimination } & \ldots & \ldots & \ldots & \ldots & \ldots & \ldots & \ldots & \ldots & \text { II } 5\end{array}$

The passage of disease germs through the vessels $\begin{array}{lllll} & \ldots & \ldots & \ldots & \text { I29 }\end{array}$ The constant phenomena of fever and inflammation $\quad \ldots \quad$... I 30 $\begin{array}{lllll}\text { The manner in which disease germs may occasion death } & \ldots & \ldots & \text { r } 38\end{array}$ Of the manner in which an organism may be "protected" from other attacks of the same contagious disease $\quad \ldots \quad \ldots \quad \ldots$ I4I

\section{OF THE NATURE OF THE CONTAGIOUS DISEASE GERM.}

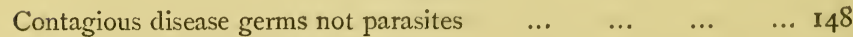

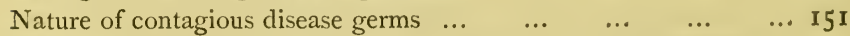

No difference to be detected in the appearance of different kinds of

$\begin{array}{lllllllll}\text { living matter } & \ldots & \ldots & \ldots & \ldots & \ldots & \ldots & \ldots & \mathbf{1} 62\end{array}$

Disease germs may long remain dormant though alive $\quad \ldots \quad \ldots$ I64

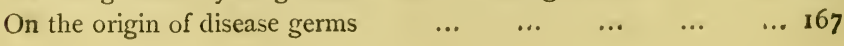




\section{TABLE OF CONTENTS.}

\section{PLATES.}

Plate I.-Fig. I. Bioplasm of bacterium. Figs. 2 and 3. Bioplasm of amœbæ. Figs. 4 and 5. Bioplasm of mucus

Plate II. - Fig. 6. Growing extremities of placental tuft. Fig. 7.

Capillary vessels opening into small vein ; Pia mater....

Plate III.-Fig. 8. Capillary vessels and small vein from the turtle's ovum, at an early period of development $\quad . . . \quad \ldots$

Plate IV.-Fig. 9. Capillary vessels; Frog's mesentery, Fig. Io.

Vessels, muscular fibres and nerves ; Bladder frog ... ...

Plate V.-Fig. I I. Deep layer of the cuticle; Newt Fig. I2. Superficial layer; Cuticle newt. Fig. I3. Cartilage rib; Kitten at birth. Fig. r4. Cartilage rib cat $\ldots$... $\quad \ldots$

Plate VI.-Fig. 15.-Epithelium from pharynx; Sore throat.

Fig. 16. Mucus cells from bronchial tubes of a cow, cattle

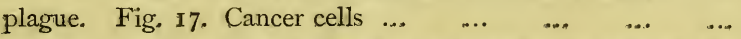

Plate VII.-Fig. I8. Epithelium of the tongue in a state of inflammation. Fig. 19. Formation of pus in epithelial cells of the mouth. Fig. 20. Division of bioplasm in cells of bladder

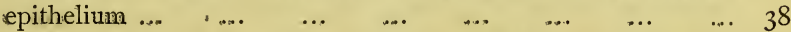

Plate VIII.-Fig. 2I. Portion of the pectoral muscle frog, 48 hours after being perforated by a thread $\quad \ldots \quad \ldots \quad \quad \ldots$

Plate IX,-Fig. 22. Portion of pectoral muscle frog, 96 hours after being perforated by a thread $\quad \ldots \quad \ldots \quad \ldots . \quad \ldots$

Plate X.-Fig. 23. Portion of pectoral muscle frog, 168 hours after being perforated. Fig. 24. Vein and capillary branches; Web of frog after inflammation has been set up by mustard .... Plate XI.-Fig. 25. Pus bioplasts from a case of chronic inflammation of bladder. Fig. 26. Portion of a living pus corpuscle from the bladder, very highly magnified. Fig. 27. Portion of a dead pus bioplast from the bladder. Fig. $27^{*}$. Different forms assumed by a minute mass of bioplasm from the bladder during five seconds 
Plate XII.-Fig. 28. Red and white blood-corpuscles in a drop of blood from the finger. Fig. 29. Minute particles of bioplasm from exudation. Fig. 30. White blood corpuscles and fibrin from a pale clot, human subject. Fig. 31. Capillary vessel with numerous masses of bioplasm in its walls ...

Plate XIII.-Fig. 32. Vallisneria spiralis, showing large and small cells. Fig. 33. Altered blood bioplast from the finger. Fig. 34. Lymph corpuscles from a vaccine vesicle. Fig. 35 . Part of a cell in vallisneria showing minute bioplasts which move round the cell, with other contents $\quad \ldots \quad \ldots \quad \quad \ldots$

Plate XIV.-Fig. 36. Bioplasts and bacteria in vaginal mucus, cow, cattle plague. Fig. 37. Bioplasts from small-pox vesicle. Fig. 38. Blood from intestinal capillaries, cattle plague. Fig. 39. Particles from vaccine lymph. Fig. 40. Bioplasts from a small vein. Fig. 4I. White and red blood-corpuscles, cattle plague

Plate XV.-Fig. 42. Bioplasts in milk, cattle plague. Fig. 43. Bioplasts and fungi in mucus, from vagina, cattle plague. Fig. 44. Smallest masses of bioplasm in milk, cattle plague. Fig. 45. Cancer cells from a case of cancer of bladder. Fig. 46. Tubercle in coats of a small artery ; Pia mater ... ... Plate XVI.-Figs. 47-51. Dr. Maddox's apparatus for collecting germ and solid particles suspended in the atmosphere... $\quad \ldots \quad 78$

Plate XVII.-Figs. 52-54. Vertical sections through mucous membrane of small intestines in cases of cholera. Fig. 55. Vessel with bulgings, consequent upon obstruction from a villus, cholera. Fig. 56. Cell-like mass, villus, cholera. Figs. 57-59. Villi and Lieberkuhn's follicles, in cases of cholera ... 100 Plate XVIII.-Fig. 6o. Summit of a villus, Jejunam, cholera. Fig. 6r. Part of summit• of villus, cholera; Impervious capillaries. Fig. 62. Altered capillaries of villus, cholera... … 102

Plate XIX.-Fig. 63. Summit of a villus, Jejunam cholera; Shrunken and wasted vessels. Fig. 64. Summit of villus, nearly healthy. Fig. 65. Capillary vessels containing pigment, granules and oil globules. Fig. 66. Capillaries and bodies external to the vessel, cholera. Fig. 67. Vessel from villus, $\begin{array}{lllllllllll}\text { cholera } & \ldots & \ldots & \ldots & \ldots & \ldots & \ldots & \ldots & \ldots & 102\end{array}$

Plate XX.-Fig. 68. Mucous membrane of fourth stomach, cattle plague; Vessels injected with Prussian blue. Fig. 69. Portion 
PAGE

of a vessel from fig. 68, more highly magnified. Fig. 70. Capillary vessels from surface of a villus, containing bioplasts. Fig. 71. Capillary loop from malpighian body (injected with Prussian blue) containing bioplasts $\quad \ldots \quad$... $\quad \ldots \quad$... IO4

Plate XXI.-Fig. 72. Fat vesicles invaded by bioplasts. Fig.

73. Loops of vessels from eruption of cattle plague. Fig. 74. Capillary from surface of a villus, cattle plague I04

Plate XXII.-Fig. 75. Section of pustule from eruption, cattle plague. Fig. 76. Fibrous tissue of the corium from the pustule (fig. 75). Fig. 77..The fibrous tissue (fig. 76) more highly magnified. Fig. 78. Particles of contagious bioplasm. Fig. 79. Capillary retina, calf, cattle plague. Fig. 8o. Bioplasts from $\begin{array}{lllllllll}\text { villus, cattle plague } & \ldots & \ldots & \ldots & \ldots & \ldots & \ldots & \text { IO } 4\end{array}$

Plate XXIII.-Fig. 8I. Vertical section of skin, cattle plague; Vessels blue, showing papillæ covered with their epithelium. Fig. 82. Papillæ beneath eruption, cattle plague. Fig. 83. Plan to show how contagious bioplasm may pass from the blood and reach the parallel layers of cuticular cells. Fig. 84. Young cuticular cells and masses of bioplasm. Fig. 85. Minute sporules of fungi, from superficial cells of cuticle ; Near eruption, cattle plague. Fig. 86. Cuticular cells under scab, cattle $\begin{array}{lllllllllll}\text { plague } & \ldots & \ldots & \ldots & \ldots & \ldots & \ldots & \ldots & \ldots & \text { I30 }\end{array}$

Plate XXIV.-Fig. 87. Connective tissue corpuscles healthy. Fig. 88. Enlarged connective tissue corpuscles, cattle plague. Fig. 89. Capillary from mucous membrane, fourth stomach, cattle plague, injected with Prussian blue. Fig. 90. Small artery, with large mass of bioplasm obstructing its cavity, in$\begin{array}{lllllll}\text { jected with Prussian blue... } & \ldots & \ldots & \ldots & \ldots & \ldots & \text { I34 }\end{array}$ 


\section{Dr. Lewis's Observations on Hallier's Cholera Fungus.}

Since the remarks on pp. 152-156 were printed, I have received from Calcutta, through the kindness of the author, a copy of the "Report on the Microscopic Objects found in Cholera Evacuations, \&c.," by Assistant-Surgeon Lewis, M.B., attached to the Sanitary Commissioner with the Government of India. By a series of most careful microscopic investigations it is proved for once and for all, that Hallier's views on cholera are erroneous. His cholera fungus is not peculiar to cholera stools. Dr. Lewis's Report is illustrated by nearly a hundred very careful drawings, exhibiting points of great interest and importance. Everyone studying the subject of disease germs should see this Report. Some of the questions referred to in the first part of my work are considered with great care, and several of the conclusions at which I have arrived receive support from Dr. Lewis's observations. To the correctness of his drawings, and remarks upon Bennett's and Pouchet's statements (p. 48 of Dr. Lewis's Report), I can bear testimony. See also p. 56 of "Disease Germs, their Supposed Nature." [Nov. 8th, I8jo.]

\section{Concerning Magnifying Powers.}

In order that some idea may be formed of the degree of magnifying power of the one-fiftieth of an inch olject glass, lately made for me by Messrs. Powell and Lealand, it may be stated, that if it were possible to see a human hair in its entire width under this power, it would appear to be nearly one foot in diameter, and an object an inch in height would be made to appear 250 feet high.

\section{CORRECTION.}

P. 55, insert at the beginning of the fifth line from bottom the words "in which." 


\section{DISEASE GERMS :}

THEJR

REAL NATURE.

MONG the most fatal diseases from which man and the higher animals suffer are those which are called contagious or infectious. These depend upon a poison, which, having entered the body, grows and multiplies there in a marvellous manner peculiar to matter which is alive. The living poison may be introduced into our bodies in the air we breathe, in the water we drink, or in the food we eat, and may possibly also gain access to us by the pores of the skin, or even by penetrating through the cuticle itself. No care on our part will insure us against invasion; but, though surrounded by infection, and living among contagious disease germs, it is by no means certain that we shall be attacked, indeed the probabilities of escape are very great. We might wear water-proof coats and water-tight boots, cover the head with mackintosh, protect the nostrils and mouth with a cotton wool respirator, and grease or varnish every particle of skin exposed, and, in spite of

II. 
all these precautions, the living germs might enter our bodies, grow and multiply there to our detriment, and perhaps destroy us; while a friend who took no such pains to protect himself, and may have been for hours exposed to the infected air, might escape altogether, and enjoy perfect health though surrounded by contagion on every side!

We shall have to consider in another part of this work what circumstances probably increase our liability to attack, and by what means we may improve our chance of escape.

The diseases in question are known as $Z$ ymotic $(\boldsymbol{Z} \dot{v} \mu \eta$, a ferment, leaven), but under this head have been also included affections due to malaria, maladies resulting from changes in the food, and diseases depending upon the introduction into the body of living parasitic animal or vegetable organisms. This classification is not altogether satisfactory, because diseases induced by the introduction into the organism of bodies so essentially distinct from one another, as for instance the poison of small-pox, and the tape worm, should scarcely be included in one class. At the same time, when the subject comes to be carefully considered, it must be admitted that there are many difficulties, while the classification in question possesses many practical advantages, and upon the whole has been found to work well. If the conclusions arrived at in this work are accepted, it will not be difficult to separate the fevers and allied diseases from others which are at present 
grouped together in the zymotic class, without introducing changes in nomenclature or classification, which might cause inconvenience in practice.

Some of the contagious fevers are among the most terribly fatal maladies which we are called upon to treat, but many of us feel convinced that these of all diseases are the most preventible, for this has been clearly proved by the great success which has already attended measures as yet but imperfectly carried out. Yet year after year, in consequence probably of those who make our laws being ignorant of the facts, and seldom brought face to face with actual cases of disease, little is done to reduce the virulence, or to arrest the spread of these frightful scourges, some of which, as scarlet fever, are almost as fatal to the children of persons in easy circumstances as they are to the children of the classes whose day's work seldom produces much more than is sufficient for the day's sustenance, and sometimes less than enough to preserve the body in a state fit for work.

The ignorance even of many very intelligent persons concerning the simplest practical requirements for limiting the spread of contagious diseases is deplorable, so that in epidemics the scourge is sometimes fostered and spread by the very persons in charge of the sick, sometimes by the patients being allowed to mix with the healthy and distribute far and wide the germs of disease. Heads of families are not always aware that a child who has completely recovered from scarlet 
fever and is in fact well, may communicate it to half the children with whom he comes in contact, unless he is placed in quarantine for two months, by which time there is reason to think all the active contagious particles will have died, or will have been removed.

From a return moved for by Mr. W. H. Smith, and printed by order of the House of Commons, we learn that the deaths from zymotic diseases in England and Wales amount to upwards of I I I,000 annually, out of a population of under $22,000,000$, the total deaths from all causes being under 500,000. Continued fever destroys upwards of 20,000 lives per annum; scarlet fever alone averages about 18,000 victims, and sometimes destroys 30,000 persons in a single year. The actual numbers are given in the accompanying table, which has been calculated from the Registrar General's return above referred to.

\begin{tabular}{|c|c|c|}
\hline & $\begin{array}{l}\text { Fve years, } \\
\text { I } 864 \text { to I } \$ 68, \\
\text { inclusive. }\end{array}$ & $\begin{array}{l}\text { Average } \\
\text { for } \\
\text { one year. }\end{array}$ \\
\hline Estimated population .. & & $21,210,431$ \\
\hline Total deaths ................ & $2,438,826$ & 487,765 \\
\hline Diarrhœa and Cholera ............... & 125,828 & 25,165 \\
\hline Fever $\ldots \ldots \ldots \ldots \ldots \ldots \ldots \ldots \ldots \ldots \ldots \ldots \ldots \ldots \ldots \ldots \ldots$ & 100,807 & $20,16 \mathrm{I}$ \\
\hline Scarlet fever $\ldots \ldots \ldots \ldots \ldots \ldots \ldots \ldots$ & 93,297 & I 8,659 \\
\hline Hooping cough ......... $\quad$.......... & 54,077 & Io, 815 \\
\hline Measles ............................. & 46,043 & 9,208 \\
\hline Small-pox .......................... & 21,689 & 4,337 \\
\hline Diphtheria $\ldots \ldots \ldots \ldots \ldots \ldots \ldots \ldots \ldots \ldots \ldots \ldots \ldots \ldots$ & I 8,222 & 3,644 \\
\hline Other zymotic diseases .............. & 97,127 & 19,425 \\
\hline Total Zymotic diseases $\quad$............ & 557,090 & III 4 I 8 \\
\hline
\end{tabular}

Being 22.84 per cent. of the total deaths. 
It would be too much to say that this frightful mortality represents the deaths from preventible diseases, but there can be little doubt that good sanitary regulations, combined with cleanliness and temperance upon the part of the people, would save at least 100,000 lives annually in England and Wales alone. But this eminently practical part of the subject has been well considered by others far better qualified for the task than myself. I therefore pass on to discuss the nature of the material concerned in the spread of contagious diseases. It was shown in the first part of this work that the active substance was not a lowly vegetable organism developed independently of man or the animals subject to disease. We have, therefore, now to enquire what is the material substance which passes from the diseased to the healthy organism in small-pox, in measles, in scarlet fever, and other allied contagious diseases from which man and domestic animals suffer so severely. The material in question grows and multiplies and produces its kind as all living things do, and as nothing that does not live has been proved to be capable of doing. We may therefore conclude that it is living matter. But it has been already shown that it is not a vegetable organism. What then is its nature? The arguments advanced against a vegetable germ theory of disease do not perhaps apply to some other forms of a germ theory, one of which will be considered. 
In order to make the conclusions at which I have arrived intelligible, it will be necessary for me in the first place to direct the reader's attention to some of the most important changes which occur in the living matter or bioplasm of the healthy tissues. 


\section{BIOPLASM AND ITS DEGRADATION.}

THOSE marvellous progressive changes which occur during the development of the embryo, while the structures which characterise the organism are being evolved, are still but very imperfectly understood. We know, indeed, that all the complex tissues and organs of man and the higher animals are dependent for their production upon changes occurring in a minute mass of perfectly colourless living matter, in which no indications of form or structure can be discerned, but how these changes are brought about we have not yet been able to ascertain; nor is it conveying much information to the student if the teacher informs him that the perfect organism, with all its marvellous apparatus, existed "potentially" in the little colourless living embryonic particle, since it would be impossible to distinguish the particle which was to develop a highly elaborate mechanism from that which was to produce a simple amœba, as its highest developmental product. Hence, while it cannot be said that the structures evolved "existed" in the original mass of living matter it will not make the assertion more correct if it be qualified by the term "potentially." All we know is that such and such structures result, but we know this from seeing them, not from a priori reasoning. For the characters and 
composition of the living matter do not enable us to premise anything whatever as to its formative properties.

In the formation of man and the higher vertebrata the primary mass of bioplasm or living matter absorbs nutriment, and grows, and then divides and subdivides into numerous masses, which are arranged in a definite manner, but what determines this is not known. From each of these in pre-ordained order, and with perfect regularity, more are produced, no doubt, according to "laws," but laws about which we know nothing, except that if physical, they are very different from any physical laws yet discovered. As this process of division goes on, the resulting masses produce various substances, some having wonderful structure and properties. But the power of each series to produce these peculiar materials, which did not exist before, and which cannot be extracted from the food supplied, differs from that of the series which preceded it, and so on until the complex structural basis of the organism is as it were laid down.

There are developed masses of bioplasm to form nerve, others to produce muscle, others glands, and so on, all of which have been derived from one common mass, but the bioplasm destined to take part in the development of a gland will, under no circumstances, produce muscle or nerve.

And yet with all this marvellous difference in power, which if not acquired is at any rate manifested 
as development advances, there is, as far as is known, no difference in matter which will account for the result. The nerve or muscle producing bioplasm is, as far as can be ascertained, the exact counterpart of the gland or bone forming bioplasm, and why one produces one tissue and the other a very different tissue cannot be explained; all these different forms of bioplasm have descended from one, which may be regarded as the parental mass, but in regular, definite, and pre-arranged order; so that if from any circumstance the bioplasm which is to form a gland or other organ, or a member, is not produced, and does not occupy its proper place at the right period of developmental progress, that gland, organ, or member will be wanting in the particular organism.

The manifestation of power or property to form special parts with special functions proceeds in regular order, progressively in one direction only as the germ advances towards the particular perfect form it is to attain. The power once lost can never be regained, although life may continue to be manifested nevertheless, and perhaps more actively than before. If the particles of bioplasm which were to take part in the development, say of the brain, do not receive at the proper period a supply of the right kind, or the proper proportion of nourishment; a well-developed healthy brain cannot in that case be formed. The particles may waste and die, or they may grow for a time and then cease to progress further; or they may 
grow, and live, and multiply, and form a great mass of matter, which however will never produce a brain or an organ capable of performing the functions which the brain was designed to discharge. They may multiply fast, and take up more nourishment than the brain cells would have appropriated, had they been formed, but the organ with its marvellously complex intricate structure, which for its formation requires gradually progressive changes, steadily proceeding during a length of time, will never be produced; and under no circumstances conceivable could any of these masses, or any of their descendants, develop one perfect brain cell. If progress towards the mature state be stopped at any point the perfect state of development can never be reached, and the organism if developed must be imperfect. The development of other complex organs may have proceeded with perfect regularity, but the organism must ever remain incomplete in structure, and incapable of performing all the functions it might have discharged.

But although developmental power may be lost for ever, power of a different kind may be acquired pari passu during the rapid multiplication of bioplasm. Progressive advance in the capacity to form lasting structures and elaborate organs is characterised by the comparatively slow but regular and orderly growth and multiplication of bioplasm. Rapid multiplication, on the other hand, involves degradation 
in formative power, which is at length entirely lost, never to be reacquired.

Degradation in power is commonly associated with increased rate of growth, increased faculty of resisting adverse conditions, and, in some cases, with such remarkable vitality of the living matter that it takes up more than the nourishment which should be appropriated by healthy parts. Consequently these last are at length starved and deteriorated or are completely destroyed. Nay, the actively living degraded bioplasm may retain its vitality although removed altogether and for some time from the living body, and it may grow and at length destroy other living organisms to which it gains access.

It is the main object of this work to show that a disease germ is probably a particle of living matter derived by direct descent from the living matter of man's organism, and I propose to give a sketch of some of the most important facts which have led me to adopt this view. The inquiry is of great interest, and affects the question of the nature of the material concerned in the propagation of contagious diseases. I shall also indicate how our views of treatment and more particularly how our efforts to extirpate the poison of contagious diseases and to prevent its production, will be influenced by the conclusions arrived at. In the first place I shall refer to the mode of multiplication of the bioplasm of man in health, and then endeavour to trace its degradation until a form 
of bioplasm destructive of healthy life and capable of infinite multiplication results.

\section{Bioplasm of Animals and Man in Health.}

Bioplasm of Amoba.-Among the lower, simplest living forms known are some very simple organisms consisting apparently of transparent structureless semifluid material. Seldom indeed as much as the $\frac{1}{100} \overline{0}$ of an inch in diameter, they vary much in size down to particles of extreme minuteness and tenuity only just visible under the highest power yet made, equalling about 5,000 diameters. These masses, apparently composed almost entirely of living matter, can move in any part, and in any direction (Figs. 2, 3, plate I.). Portions of the seemingly viscid or semifluid material may protrude in advance of the rest of the mass, and coming in contact with protrusions from other parts, join these, and thus may result a ring or a series of rings. The protrusion may be withdrawn and the whole assume the appearance of a perfectly smooth globular mass.

Such naked masses of living bioplasm or germinal matter may apply themselves to foreign bodies, and if these are small, completely invest them, so that the latter are at length seen in the interior of the mass embedded in its very substance. It is in this way that these simple forms of life are capable of effecting the solution of certain substances, and afterwards ap- 
propriating them as nutrient materials. They increase in number in a very simple manner. If one of the protrusions above referred to be detached, artificially or by accident, a new and independent organism results. So long as a pedicle remains between the two, though it be so thin as to be only just visible, the diverticulum may be withdrawn, and the whole form one single spherical mass of living, growing, moving matter. But if the communication be once completely severed two separate beings result, and these can never again be incorporated so as to form but one.

Any one can study for himself the most important of the highly interesting phenomena which have been observed in these wonderful and simple organisms. Amœbæ can be readily obtained from water which has been left for a few days in a warm light room. Their growth can be watched from day to day, and their movements can be seen without difficulty. With the aid of high powers it will be found that the moving material is clear, transparent, and as far as we are able to discover, destitute of structure, exhibiting no appearance which could be reasonably supposed to be due to the presence of " molecular" or any kind of " machinery." It appears like homogeneous matter of syrupy consistence which moves in all directions. No one has been able to offer anything like an explanation of these movements although every one can see and study them without difficulty. Authorities have expressed them- 
selves as if they had been able to give a full and sufficient explanation of the phenomenon, but there is nothing in their statements to justify the confidence which they seem to repose in the correctness of their views. The cause of these movements is unknown, if it is not unknowable. An attempt has been made to delineate the appearance of the moving matter in question in Plate I., fig. 3, which was examined under a power of 5,000 diameters. The difference in the shading indicates changes in thickness resulting from the movement.

Bioplasm of Bacteria.-If a large bacterium be. crushed, the very simply living matter may sometimes be expressed from the envelope without injury, and may be seen to exhibit vital movements, while in the field of the microscope, Fig. I. The progressional movements of many of the simplest organisms are effected by the bioplasm of their bodies protruding through the pores in their investing membrane or shell, by currents in the fluid caused by the movement of the living matter, and by the action of this same self-moving living material upon processes of the envelope or other passive organs composed of formed material projecting from different parts of the surface.

Vital Movements of Bioplasm.-These movements, which take place in every kind of bioplasm, or living matter, and which are to be observed so easily in the amœba, were formerly supposed to be peculiar to this organism. When it was discovered that the same 
sort of motion was to be observed in the case of many of the lower forms of life and in the white blood corpuscle, it was spoken of as amobiform or amoeboid, as if the movements in question were connected with some mechanism or action peculiar to the amœba and the lowest forms of life. And even now the formation of "amœboid corpuscles" is spoken of as if it were some very special and exceptional phenomenon. The movement is, however, characteristic of the whole living world; but it is strictly confined to living beings, and nothing like it has been shown to occur in non-living matter. In man and the higher animals it is not always possible to see the movements of the bioplasm, for a very slight change in the circumstances under which life is carried on may cause its death; but in some cases, and these not a few, they may be seen in the living matter taken from man's organism, and from animals, both in health and also in the diseased state. See Plates XI., XIII., figs. 25, 26, fig. 33, pp. 46,54 .

As I have endeavoured to show, these movements are invariably limited to living matter (bioplasm). I have called this movement vital and have endeavoured to show that it is distinct from muscular contractility, and from every other kind of movement known. The vital movements of bioplasm vary remarkably in activity, and the same kind of living matter may move quickly or slowly according as the surrounding conditions change. Living particles transport them- 
selves from place to place ; they may insinuate themselves through the narrowest apertures, or creep through very minute fissures and channels. They may climb through water, and there is even reason to think they may move upwards through perfectly still air by virtue of their capacity for vital movement. The division and subdivision of living matter, and hence the multiplication of living beings, are among the results of vital movements. These vital movements too are the cause of many phenomena which are characteristic of man and the higher animals. That is, a chain of changes, each being a consequence of an antecedent change, may be traced backwards until at last we arrive at the movements occurring in the living matter, beyond which we cannot go; for we cannot ascertain the cause of these movements, although we know it must be closely related to life itself, for life cannot be conceived of without movement. The growth and multiplication of disease germs, their introduction into the body, their passage into the blood, and their subsequent wanderings, are intimately connected with their capacity for vital movement. Their formation I shall endeavour to prove is associated with greatly increased activity of vital movements, and the undue nutrition of certain forms of the bioplasm of the organism. In order to render intelligible to the reader the grounds of my views, it will be necessary in the first place to offer some general remarks concerning the nature and 
BIOPLASM OF BACTIRIUM, AMEBA, AND MUCUS.

Fig. 1.

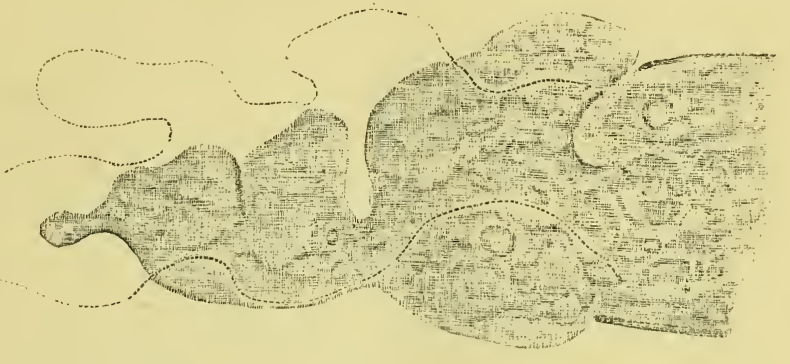

Bioplasm or living matter from a crusher bacterinm showing the changes in form which occurred during a few seconds. $x$ leov. p. 14 .

Fig. 2.

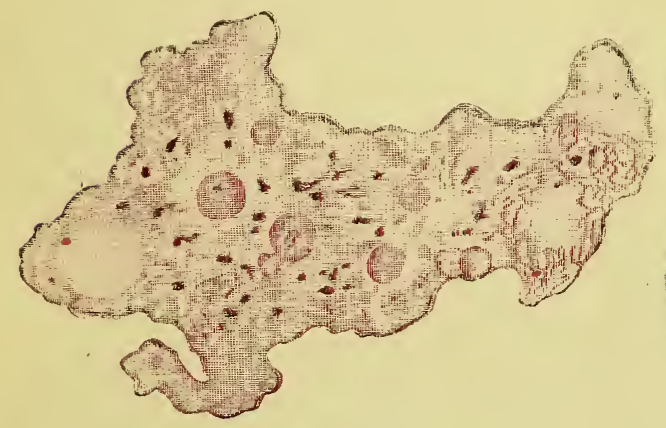

A small amœba, magnified by the $\frac{-1}{5} \frac{1}{10}=8800$ diameters. 1867. p.12
Fig. 4.

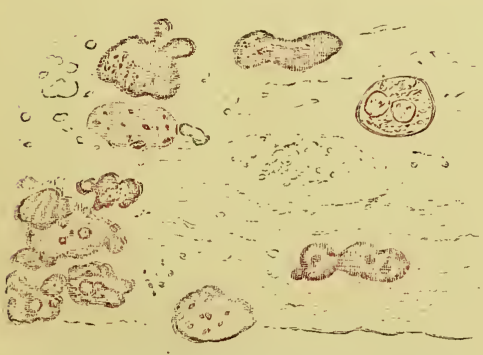

Mucus from the trachea during life, magnified 700 ciameters. p. $i 7$.
Fig. 3.

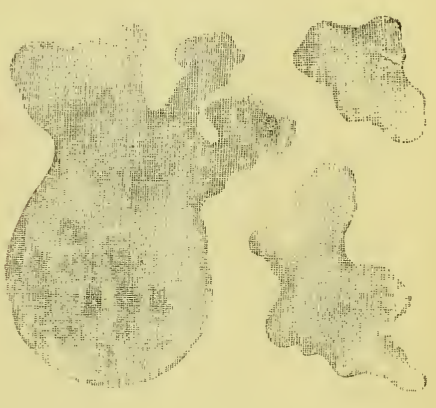

Very minute living amœbæ, magnified 5000 diameters, p. 12.

Fig. 5

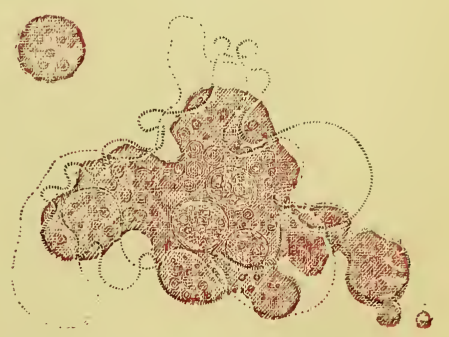

One of the living mucus corpuscles represented in Fig. 4, magnified by the $\frac{1}{50}=2800$ diameters. showing alterations in form during one minute. p. if

$$
\overline{\mathbf{1}} \overline{\mathbf{0}}, \frac{\mathbf{x}}{\overline{0}} \overline{0} \mathrm{0} \text { th of an inch - }
$$

L. S. B.] $\times$ r00 linear.
$\times 2800$

$\times 5000$. 

growth of the bioplasm of the higher animals and man.

The Living Matter or Bioplasm of Mucus.-If a little mucus which collects commonly enough upon the soft mucous membrane of the air passages be examined upon a warm glass slide, with the aid of a power magnifying 700 diameters, or upwards, little oval masses of germinal matter not unlike amœbæ will be seen in great numbers embedded in the viscid transparent material which gives to the mucus its properties, and which has been formed by the particles of the bioplasm, Fig. 4, plate I.

By attentive examination movements will be observed in many of these masses, not unlike those above described in the case of the amœba. Fig. 5 represents the changes in form in a living mucus corpuscle under a power of 2,800 . If the distribution of nutriment to the mucus be increased, the bioplasts enlarge, and divide and subdivide until vast numbers result. In some cases of inflammation of the mucous membrane all the viscid matter secreted upon the surface appears to consist of bioplasts ordinarily termed pus corpuscles, while on the other hand the proportion of formed material which was abundant in ordinary mucus is exceedingly small. The bioplasm has multiplied so fast that there has not been time for the production even of the soft mucus.

Vital movements resembling those which have been described in the amœba, in the bioplasm of mucus, II. 
and in white or colourless corpuscles may be seen, but not so easily, in the bioplasm of young epithelial cells, in that of cartilage, the cornea, connective tissue, and other textures, and there can be no doubt whatever that all bioplasm possesses the power of movement, and that by virtue of this power of movement the several masses are able to take up the positions they respectively occupy in all the different tissues which they form, and in the preservation and maintenance of which, in a state of integrity, they play so highly important a part as long as life lasts.

Embryonic Bioplasm.-The growth and multiplication of bioplasm at an early period of development may be studied in an embryo, and many highly important observations may be made if the growing tissues of the chrysalis of the common blow-fly be submitted to examination, especially when they have been successfully stained by the carmine fluid. A mass of formless bioplasm invariably represents the earliest stage of development of every tissue and organ. The bioplasm, which is concerned in the formation of the special tissues, emanates from this, and in many cases a sort of temporary structure is formed in the first instance in which the development of the higher tissue afterwards takes place. Some suppose that the particles of bioplasm are formed anew, but this is certainly not the case. They have been invariably derived from pre-existing bioplasm. In the formation of the tissues of the imago or perfect insect 
during the chrysalis state, each texture is developed anew from bioplasm, but this was derived from the bioplasm of the larva. If one of the growing extremities of a fotal tuft of the placenta be examined, it will be found that the material which advances first, which grows away as it were from the tissue which is already formed, is a mass of bioplasm, which is divided and subdivided into smaller portions, as represented in Fig. 6, plate II. The loop of vessels gradually increases in the wake of this little collection of living matter which continues to move onwards as long as the placenta continues to grow. These little collections of bioplasm bifurcate, and thus form branches into which vascular loops afterwards proceed. As in every other instance, the first changes are produced by bioplasm; and by this living matter every kind of growth and development is effected.

White Blood Corpuscles or Blood Blioplasts.-If a drop of blood be obtained from the finger by pricking it with a needle, and allowed to fall upon a glass slide slightly warmed, covered with thin glass, and carefully pressed, and then examined under a power of 700 dianeters or upwards, here and there, colourless slightly granular, apparently spherical bodies will be seen amongst multitudes of the well-known red bloodcorpuscles. These are the so-called white or colourless blood-corpuscles (Plate XII, fig. 28). They consist of living bioplasm or germinal matter, and exhibit movements like those referred to in the amœba and 
in the mucus corpuscle. The movements continue for many hours after the blood has been withdrawn from the body. The colourless as well as the red blood-corpuscles vary much in size, although they are often represented as if they were of uniform diameter. These bioplasts multiply by giving off little diverticula, which become detached, and then grow into complete corpuscles. In the blood there are, besides the white blood-corpusles, multitudes of minute masses of living matter, probably composed of the same material as the white blood-corpuscles. These were described and figured by me in I863, and I showed that when the capillary walls became stretched by distension they would escape through little longitudinal rents or fissures into the spaces external to the vessels, where, being freely supplied with nutrient matter, they grew and multiplied, giving rise to the numerous corpuscles seen in this situation in inflammation. These minute particles are indeed the most important constituents of inflammatory exudation, and are the agents by which the important changes occurring in the exudation are effected. They vary much in number in the blood and are very abundant in inflammation.

Whenever the circulation is carried on slowly in any part of the body the colourless or white bloodcorpuscles grow and multiply, and at an early period of development, before the heart and lungs are fully formed, the only corpuscles are these white or colourless 

TISSUES.

Fig. 6.

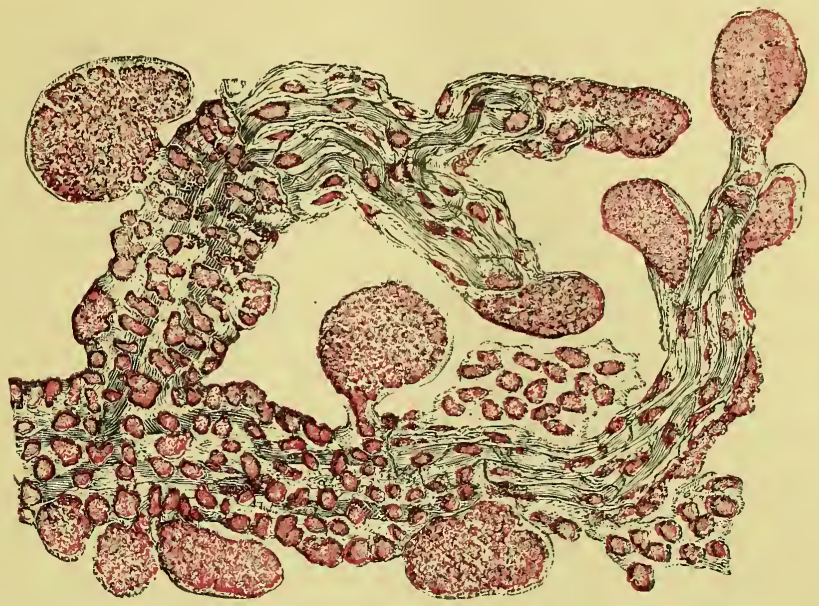

Growing extremities of foetal tufts fyom human placenta, 7 th month, $\times 21$; At every extremit $\nabla$ is seen a collection of small masses of advances, and the vessels and other structures srow in its wake rs it were. The masses of bioplasm of the capillaries and otluer structures entering into the formation of the tutt are also well seen. 1864. p. 19

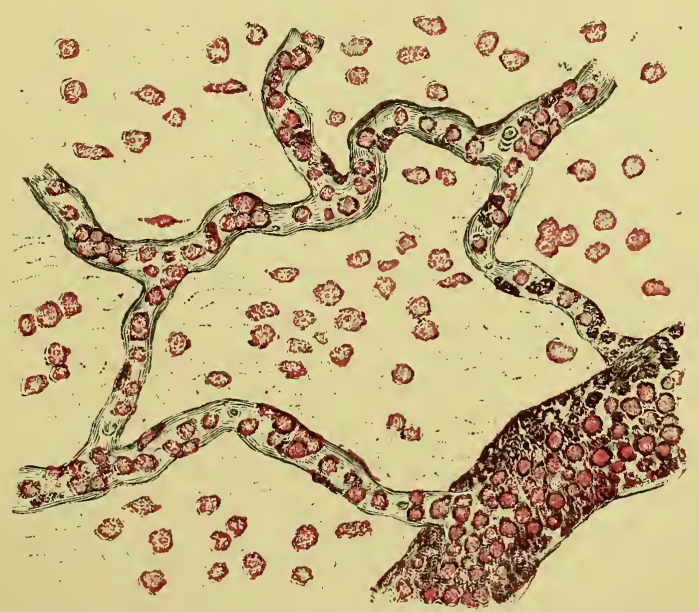

Capillary vessels openins into a small vein. Pia mater. Human fotus, fifth month of intra. uterine life. The capillaries contain numerous. white blood corpuscles (bioplasm) which are coloured by carmine, and the vein is completely filled with them Very few red blood corpuscles were present. $\times 215$, p 21

L. S. B.]

$\frac{1}{1000}$ of an inch $\times 215^{\prime \prime}$ linear. 

blood-corpuscles. This important fact may be easily demonstrated if the blood in any of the small vessels of the embryo of a vertebrate animal be examined. A very striking and beautiful example is represented in Fig. 8, plate III, from the ovum of the turtle. The capillaries are seen to be filled with living growing blood bioplasts (white blood-corpuscles) every one of which has been well coloured by carmine fluid, and can therefore be very distinctly seen in the specimen. Only here and there could a red bloodcorpuscle be discovered.

In Fig. 7, plate II, I have given a drawing of part of a small vein, with a few capillaries opening into it, from a beautiful specimen of the pia mater, covering the hemispheres of the brain of a human embryo at the fifth month of intra-uterine life. This illustrates the same fact. The little veins were quite filled with blood bioplasts, very few of which had as yet become developed into red blood-corpuscles. In the capillaries represented in this drawing will be seen many very minute bioplasts which have been detached from larger ones and are growing. The bioplasts seen in the capillary interspaces are those which take part in the development of the other textures of which the pia mater is constituted.

In animals which hybernate, or which have been kept inactive in confinement for some tine, and in man, under certain circumstances, many of the red blood-corpuscles in the blood-vessels are absorbed, 
just as they are from a clot formed in any of the smaller vessels, and in some instances from a clot situated external to the vessels, and the living bioplasts (white blood-corpuscles) grow and multiply at their expense. After a time, such is the increase of the latter that the capillaries in many tissues are almost entirely occupied by them. This fact is illustrated by Fig. 9, plate IV, which represents very small capillary vessels of the mesentery of the common frog in winter. The vessel is almost choked up with white blood-corpuscles, only one or two red ones remaining in the specimen from which the drawing was taken. Another illustration of this fact is given in Fig. IO, plate IV, which represents some of the capillaries from the bladder of a half-starved frog. The capillaries have much wasted, and contain no red blood-corpuscles whatever, their cavity being entirely occupied by fluid liquor sanguinis and masses of bioplasm, differing much in size, the largest particles having the ordinary dimensions of the white bloodcorpuscles, while the smallest are so minute that they cannot be demonstrated under a power magnifying much less than I,000 diameters. It is remarkable that in this case the white blood-corpuscles are still growing and multiplying, and are, indeed, probably the active agents in the absorption of the tissues. In this specimen taken from the most beautiful and delicate of all the tissues of the frog may also be seen the very fine pale nerve-fibres which I demonstrated 
BLOOD BIOPLASTS, OR, WHITH BLOOD CORPUSCLES IN VESSELS OF EMBRYO.

Fig. 8.

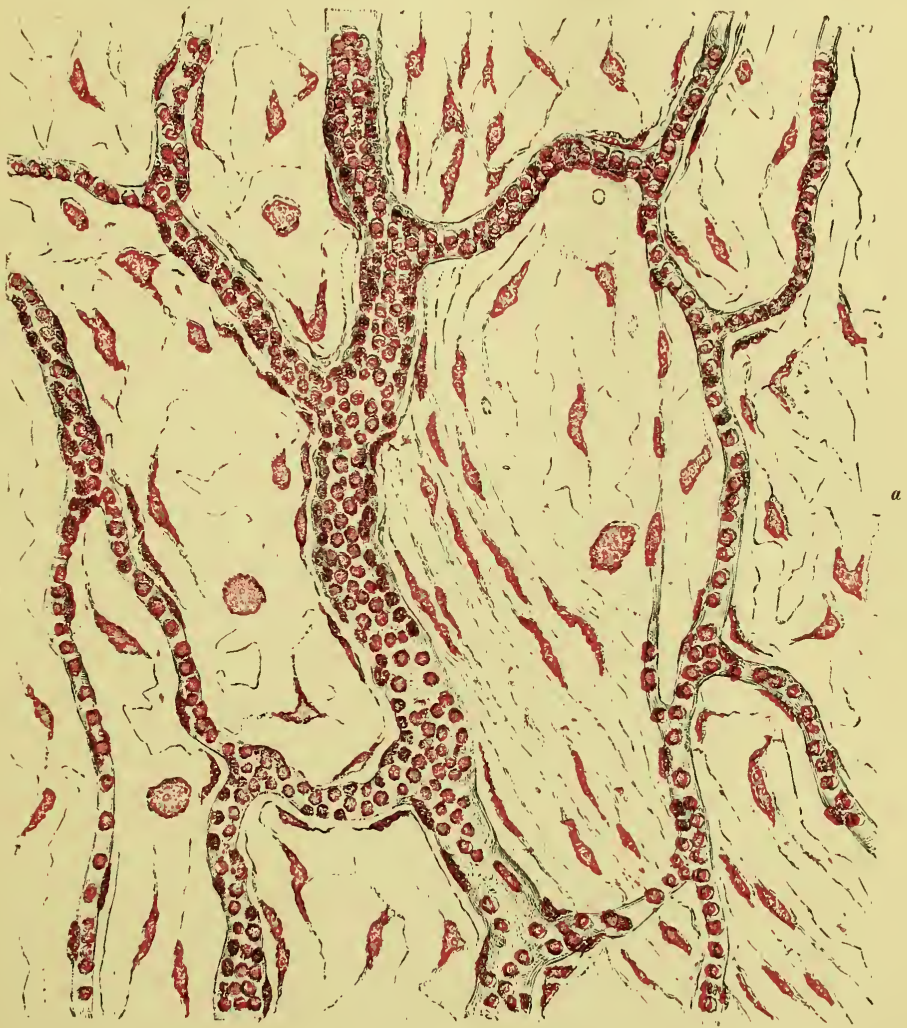

Capllary vessels and small vein from the ovurn of the Lurtle at an early period of development. The vessels were entirely filled with $w$ hite hlood corpuscles, and in some places the $y$ were completely distended with them. Developing convective tissue with connective tissue corpuscles, fat cells and perhaps nerve fihres are also seen. To the risht of the drawing at $\boldsymbol{a}$ will be observed a very young capillary, the tube of which is not yet wide enough to allow a blood corpuscle to pass through it. $\times 215$ 1864. p. 21 

some years. ago. A fine bundle is seen at $\alpha$, from which point it may be readily followed, as it divides into finer branches, ramifications of which are seen in every part of the drawing. The bundles of unstriped muscular fibres are marked $b$, while the bioplasm masses of the connective tissue corpuscles are represented here and there in the intervals.

So far I have endeavoured to show that the masses of germinal matter or bioplasm which are to be found in all parts of the tissues of man and the higher animals at every period of life, and suspended in the nutrient fluids, notwithstanding very remarkable differences in power, exhibit the same general characters as those manifested by the living matter of the lowest animals and plants. In all cases it is the bioplasm only which lives and grows and multiplies. Moreover, attention has been especially directed to the fact that the rate of growth of the bioplasm varies according to the scarcity or abundance of the nutrient material, and to the rapidity of its access. The bioplasts (white blood-corpuscles) of the blood increase in number, when the fluid in which they are suspended moves slowly as at an early period of life before the propelling apparatus is fully developed, or at any period of life when the circulation is retarded from any cause whatever.

This remarkable growth and multiplication of the blood bioplasts seems to be determined by the altered conditions under which life is carried on without any 
derangement of the health necessarily accompanying the change. The fact of the increase of the white blood-corpuscles in apparently opposite conditions of the system receives a simple explanation. A hybernating animal cannot be said to be suffering from disease, but nevertheless the blood in his capillary vessels contains a vastly increased number of bioplasts, and could hardly be distinguished from blood which was stagnating in consequence of something impeding the circulation-a state of things which would be rightly regarded as disease. In this part of the inquiry we seem indeed to be on the very confines of disease ; in a sort of border-land where the healthy process may so gradually and imperceptibly pass into the morbid process that it would not be possible to draw a distinction in words, nor would the appearances which may be demonstrated by the eye enable us to define with greater exactness the special condition. In fact, up to this point there is no real difference. The state of things I have described, if it continues, and if it leads to other changes, would be considered evidence of disease. If, on the other hand, the circulation soon returned to its normal rate, the increased number of white blood-corpuscles in the capillaries would soon pass into the circulation and become lost in the mass of the blood, where they would undergo further changes. There would be no stronger evidence of even a temporary disturbance of the healthy condition than was afforded perhaps by some trivial 
Fig. 9.

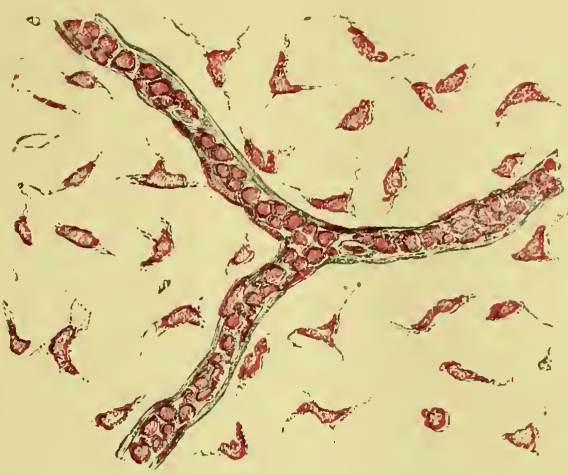

Capillary vessels and connective tissue, and connective tissue corpuscles Mesentery. Frog in winter. The capillaries are filled with numerous white blood corpuscles (bioplasm). Only one or two red blood corpuscles were present. $\times 215 . \quad$ p. 22

Fig. 10.

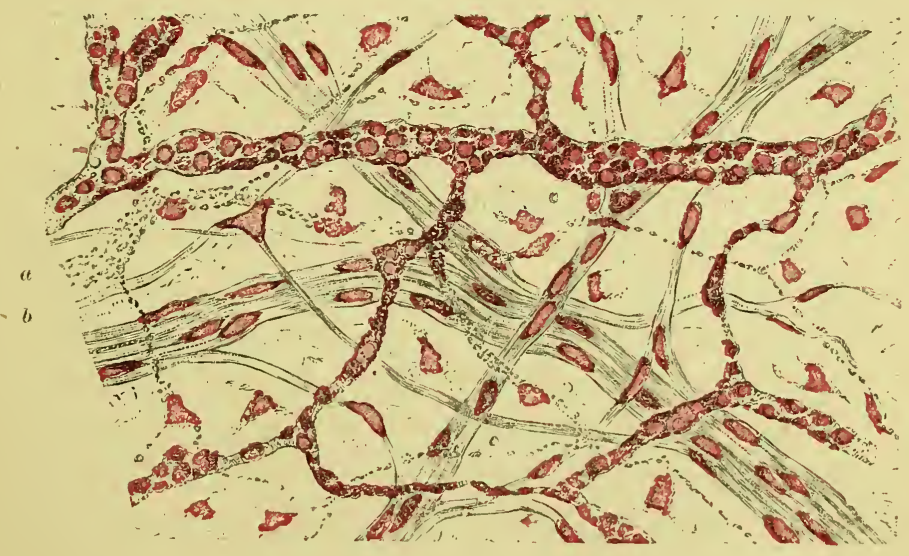

$b$

Bladder of a frog which was half starved. The capll aries are wasting, and contain bioplasm only. No red blood corpuscles coulâ ve detected. Bundles of unstmped muscle are seen ramifying over the field Some have fibres radiatins in three directions, and the bioplasm of these is triangular $\boldsymbol{b}$. At $\boldsymbol{a}$, a bundle of $\nabla$ ery fine nerve fibres is represented. Its ramifications may be followed over every part of the specimen. The bioplasm of the connective tissue is also represented. Thus, all the tissues of the thin bladder are demonstrated. $\times 215$. The drawing wistaken from a specimen mounted in 1862. $\times 215$, p. 22 

nervous derangement possibly, giving rise, in the case of man and the higher animals to slight pain, which might soon pass off, or perhaps escape notice altogether.

These blood bioplasts possess formative power of a very remarkable kind even in the adult. Not only are they capable of producing fibrin, but they or bioplasts directly descended from them, are capable of forming fibrous tissue which resembles the ordinary fibrous tissue developed in connection with several textures of the body. But, more than this, these bioplasts, poured out from the vessels suspended in fluid exudation, or their descendants growing and multiplying upon a surface wound of the skin or a mucous membrane may produce cuticular cells or the epithlial particles of a mucous membrane, not perhaps quite so perfect and well formed as those developed in situ, but nevertheless efficient as a protecting covering. The varied power of forming tissue possessed by these bioplasts is perhaps due to the circumstance that they have inherited formative powers from the bioplasts of the germinal area at an early period of development, for it must be remembered that the ancestral white blood-corpuscles from which all have directly descended, were developed at a time anterior to that when the various bioplasts taking part in the formation of the tissues diverged from their common progenitor. So that formative power of a more general character than is possessed by the 
bioplasts of the tissues might be expected to belong to the blood bioplasts. And in the case of some of the lower animals which exhibit the power of reproduction of lost parts and organs, it appears very probable that the agents directly concerned in the development of these are bodies resembling the blood bioplasts; and that from them result masses of bioplasm which take part in the formation of the several tissues of which the new member is constituted.

Bioplasm of the Tissues of the Adult.-As the tissues are formed by the conversion of the outer part of each bioplasm mass into the formed material or tissue, the distance by which the several masses of biopiasm are separated from one ancther becomes greater. This important fact may be demonstrated in almost any tissue of a young or adult animal. In Figs. I I and I2, plate $\mathrm{V}$, are represented young and fully formed cuticle of the newt from the very same spot of skin. The formed material of the cuticular tissue accumulates around each mass of bioplasm until the well known adult "cuticular cell" results, Fig. I2.

Again, in Figs. I 3 and I4, the appearance of sections of permanent cartilage from the same part of the body is given under a power of 700 diameters. At an early period of development "tissue" scarcely exists, and all that can be discovered is bioplasm. In young tissue, at all periods of life, the same fact is observed, but as the textures advance towards maturity the proportion of bioplasm in a given bulk of 
PLATE V.

BIOPLASM OF FULLY FORMLD TISSUES.

Fig. 11.

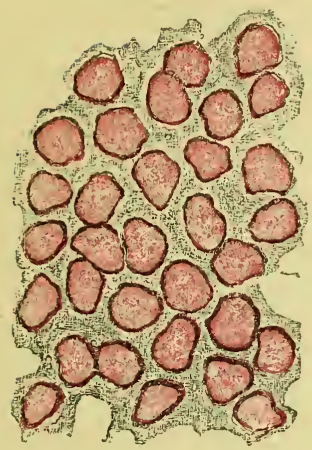

Cuticle. Newt. Deep layer, consistins of bioplasm with ver'y little formed material. $\times 215$. p. 26 .

F'iø. 13.

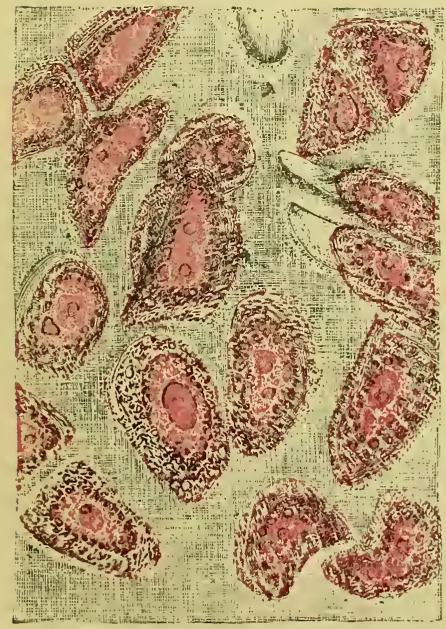

Cartilase rib of kitten at birth, showins large masses of bioplasm with very little formed material between them. $\times 700$. p. 26 .
F15. 12 .

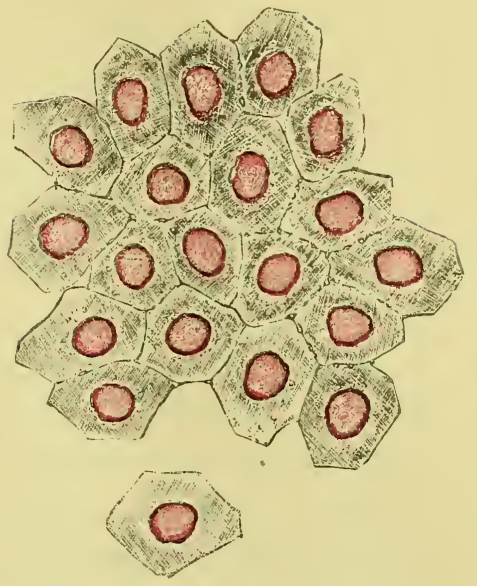

Cuticle. Newt. Superficial laver, showing earkt materia. $\times 2 \mathrm{i}, \mathrm{p} 26$

Fig. 14.

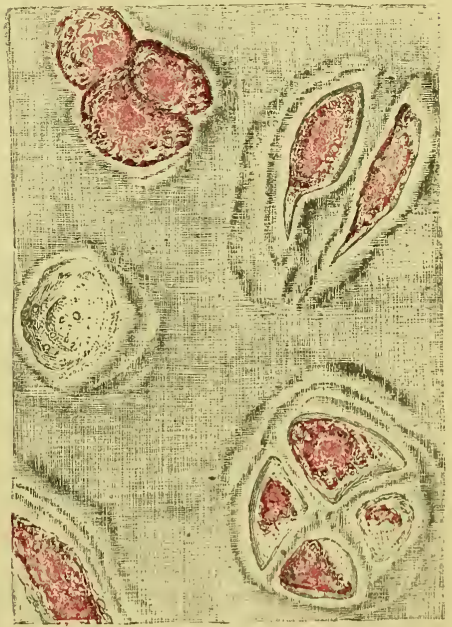

Cartilage rib of young cat, showing diminished size of masses of bioplasm and preat increase of matrix or formed material of cartilage. $\times ; 00$. 


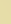


texture becomes less. Now in disease we shall find that in adult tissues the bioplasm increases, and that the general appearance assumed is that which embryonic tissue presents, indeed some "inflamed" textures might be mistaken for embryonic tissue.

\section{From Health to Disease.}

I have endeavoured to show that the only material in the organisms of living beings capable of growth and multiplication is that which I have recently named bioplasm, hitherto known as germinal or living matter. In fully formed tissues the proportion of this is very small. Still, all active change which takes place in the tissue depends upon this living matter, however little there may be. If there be none, the tissue is as incapable of undergoing active changes as if it did not form a part of the body. The smallest particle of bioplasm possesses active powers, and if supplied with proper pabulum, soon grows. Each little bioplast grows, that is, increases, by taking up material differing entirely from it in composition, properties, and powers, and converts certain elements of this into matter identical with that of which it consists. After the bioplasm-particle has reached a certain size, division occurs. Instead of growing larger and larger, and forming a continuous mass of enormous size, as some have fancifully supposed exists at the bottom of the ocean, portions are from time to time detached. 
These separate themselves and move away from the parent mass. Each of these little germs has properties in many respects like those of the parent mass, though it may possess the capacity for forming matters which the parent mass could not have produced. Each bioplasm particle lives and grows, attains a certain size, and may produce its kind in the same way.

Now, the whole human organism at a very early early period of its development consisted entirely of little masses of living bioplasm like those above referred to. Each of these grew and divided and subdivided, so that multitudes at length resulted from the division of a few. All were descendants of the first primitive germinal mass, which was itself derived from pre-existing germinal matter. After a time some of the bioplasm particles cease to multiply, though they still live and take up food. The living matter of which they are composed undergoes change. It dies under certain conditions, and "tissue" results. In this way muscle, and nerve, and fibrous tissue, and bone, and hair, and horn, and nail, and all other textures, are formed. In the adult, however, there remain some masses of germinal matter which go on growing and dividing just as all grew and multiplied in the embryo. Among these are the white or colourless blood-corpuscles, which possess formative power even in old age in greater degree than any other form of bioplasm in the adult, as has 
been already shown. At the deep aspect of the cuticle and below the fully formed epithelium of mucous membranes and some glandular organs, are masses of germinal matter, which continue to divide and subdivide in the same way throughout life. These, in the ordinary course, move towards the surface, and as they move, each gradually forms upon its surface the hard cuticular matter (cell-wall) to which the properties of the epidermis are due, see Plate V, fig. I2.

It has been already said that the bioplastic masses of different organisms, and those in different parts of the same organism, possess different endowments. For from one kind of bioplasm is formed muscle, from another nerve, from another fat, and so forth, but yet all these kinds have directly descended from one. They could not be distinguished from one another, nor from the primary mass from which they came, by any microscopical or chemical characters. Neither could one of these kinds of bioplasm in the adult develop a mass capable of producing the rest. A1though no one could distinguish one particle from the other, each will produce its kind, and that alone. It would be as unreasonable to expect an amœba to result from a pus-corpuscle, or from a yeast particle, or to suppose that by any alteration in food or management a cabbage would spring from a mustard seed, or the modern white mouse from the descendant of an ancestral white rabbit, as it would be to maintain 
that muscle, nerve, brain, gland, or other special tissue might be produced indiscriminately by any mass of bioplasm of the adult, supposing that the conditions under which it lived were changed to any possible extent. Its vital powers, which are within, and upon which the capacity to develop depends, cannot be thus changed by any mere alteration in external circumstances.

The Pus-Bioplast derived from the Germinal Matter of all the Tissues.-But it is certainly very remarkable that the many kinds of germinal matter of the organism of man and the higher animals, though differing so much in power or property that one pro-. duces nerve, another muscle, a third bone, a fourth fat, and so on, will each under certain conditions give rise to a common form of germinal matter or bioplasm differing in properties and powers from them all. This is the form of bioplasm known as pus, which may go on multiplying for any length of time, producing successive generations of pus-bioplasts, which exhibit remarkable vital properties, although they cannot form tissue, nor produce tissue-forming bioplasts of any kind whatever.

It is evident from this that the power is manifested in one direction only-onwards. Embryonic living matter or bioplasm gives rise to several different kinds, not one of which can produce matter having precisely the same endowments as that which existed immediately before it, and from which it sprang. And 
yet every kind of germinal matter exhibits powers of infinite growth:*

When bioplasm or germinal matter lives faster than in health, in consequence of being supplied with an undue proportion of nutrient material, a morbid bioplasm results; and if the process continues for a short time, changes familiar to those conversant with pathological alterations occur upon a large scale.

Of Retrogression in Formative Power.-In discussing questions of this kind, involving such minute details, we must be most careful to avoid too hasty generalization, and must proceed by very slow steps. This is more particularly necessary if it so happens that our inferences in some measure accord with the views of speculative and enthusiastic persons, who are always fancying that we are on the eve of some grand discovery which is to revolutionize thought. Many, from a consideration of the arguments I have advanced, would perhaps be led to look with favour upon the doctrine that the lowest living forms are capable of being produced by the retrograde development of higher forms, and that bioplasm even very high in the

* While, however, the process of division is proceeding, as has been described, in some cases a small portion of the germinal matter does not undergo division into masses of the next series, but retains its primitive powers. This remains in an embryonic condition after the tissue has been formed, and thus the development of new tissue, even in advanced life, is, in some cases, not only possible, but actually occurs. Many cancers and other morbid growths probably originate in these masses of embryo bioplasm which remain for a long time in a quiescent state embedded in some of the fully-formed textures of the adult. 
scale of organization, may give rise to forms of bioplasm approximating more and more closely to the lowest constant forms of life with which we are acquainted. A doctrine asserting that by continual retrogression through ages, the descendants of the highest forms would gradually deteriorate until their only remaining representatives were monads, would not be very easily disproved, and might be supported by many ingenious arguments. It is a view that doubtless would recommend itself to many minds in the present day.

But on the other hand it is obvious that cells and organisms might retrograde and produce various modified forms, without giving rise to any of those particular forms characteristic of the lower organisms which we are acquainted with. Nay, cells of different organisms might give rise to many different retrograde forms, and every one of these be very different from one another, and yet totally unlike any known organism. It is obviously possible that there should be infinite advance and infinite retrogression in multitudes of parallel lines, as it were, without the resulting forms of any one line becoming identical with those of another. Just as it is possible to conceive infinite advance in the features of the dog, without any resemblance whatever to the human face resulting, and retrogression and deterioration of the latter proceeding to any degree, and continuing for any length of time, without the production of the simian type of countenance. 
Sufficient allowance is not made by many thinkers for the infinity of difference even in structure, and variety of change, possible in living forms, without the production of two things alike, or any indication of the merging of one set of forms into another. It must not be forgotten for an instant that from such a marvellous storehouse of facts as is placed at our disposal in nature, we may with very little ingenuity select certain series of facts in favour of several very different general hypotheses; and however conflicting these may be with one another, it may not be possible to disprove any one of them in the present state of knowledge. The fact that masses of germinal matter, derived by direct descent from cells of one of the lower animals, may grow and multiply in man's organism, and vice versâ, might be adduced as an argument in favour of the original common parentage, countless ages back, of the predecessors of both; but there are, it need scarcely be said, facts and arguments tending to a different conclusion, and these must not be lost sight of in our attempts to ascertain the truth.

It is not improbable that the germinal matter of some of the lower, simpler plants and animals, when exposed to altered conditions, may give rise to morbid forms bearing a relation to their normal healthy living germinal matter, similar to that which pus bears to the germinal matter of healthy tissues, and it is possible that in our observations upon the lower forms of life we may be sometimes examining II. 
morbid instead of normal healthy organisms. It may be that the matter of the malarial poison may thus result, in which case it must be regarded as a morbid bioplasm of some low organism,--not as a species of any kind whatever,-but as a deteriorated form of living matter freely multiplying but incapable of producing healthy matter or of returning to its primitive healthy state.

I propose now to draw attention to the facts I have been able to observe in connection with the deterioration in power of bioplasm during that increased multiplication which results from the very free supply of pabulum, and which may at last lead to the production of diseased germs.

Bioplasm of Epithelium.-When the germinal matter of the epithelial cells of certain mucous membranes, or that of other tissues of the body, or the germinal matter of the white blood-corpuscles, lives faster than in health, in consequence of being supplied with an undue proportion of nutrient material, it grows and multiplies to an enormous extent; so that one mass may perhaps be the parent of five hundred, in the time which, in a perfectly healthy state, would be occupied in the production of two or three cells. And in some ordinarily very slowly-growing tissues, the germinal matter may in disease divide and subdivide very quickly, although in the healthy state it would undergo scarcely any appreciable clange in the course, perhaps, of several weeks or months. The 
increased rate of access of nutrient material to the living matter is the necessary condition of its increase. The living matter always tends to increase, but in the normal state of things it is only permitted to do so at a certain regular rate, which is determined by the even distribution and somewhat limited access of the nutrient material.

In certain cases in which an increased proportion of nutrient material is distributed to the epithelium of the mucous membrane,-as, for example, to that of the fauces,-the young epithelial cells grow and multiply so rapidly that the superficial layers of older and hardened structure become detached, and upon the free surface is produced a thick layer of soft, spongy, epithelial elements, with, in many instances, but faint indications of division into individual epithelial particles, Fig. I5, plate VI. In fact, under the circumstances alluded to, growth takes place too rapidly for the formation of the characteristic hardened epithelial texture, though the changes are not so rapid as to lead to the formation of actual pus. The spongy texture produced may be regarded as occupying a position midway between healthy epithelial tissue and the pathological bioplasm, pus. I have examined the young rapidly-growing, but as yet imperfectly-formed epithelial particles, in specimens taken from the surface of the pharynx in a case of slight sore-throat coming on in a person enjoying ordinarily good health; some of these are represented 
in Fig. 15 under a power magnifying 700 . The mode in which the masses divide and subdivide could be well seen, and the thick plastic character of the matter of which they are composed has been carefully given in drawings. The greater part of the material consists of living matter or bioplasm, some of which has probably undergone conversion into soft-formed material, which, however, still remains mingled with it. From any part of one of these masses diverticula might have been formed, and thus new bioplasts, each capable of undergoing conversion into an epithelial cell, would result. Many epithelial formations exhibit much the same changes in disease, and the transition from the healthy to the morbid state is beautifully indicated (Fig. I6). Nay, we may almost conceive that it is by unremitting continuance of this very process, combined with irregularity in the rate of multiplication of contiguous particles, that the remarkable pathological formation of epithelial cancer results (Fig. I 7, pl. VI.).

If, then, the bioplasts of a tissue receive an unusually abundant supply of nutrient matter, they grow and multiply just like the amœba, the white blood-corpuscle, the mucus-corpuscle, and the puscorpuscle, and they may give origin to pus. Masses of bioplasm which under ordinary circumstances would form cuticle, grow and live so very fast, that there is not time for their cuticle-forming property to manifest itself. The changes are well shown in Fig. 18, pl. VII., 
FROM HEALTH TO DISEASE.

F.ig. 15.

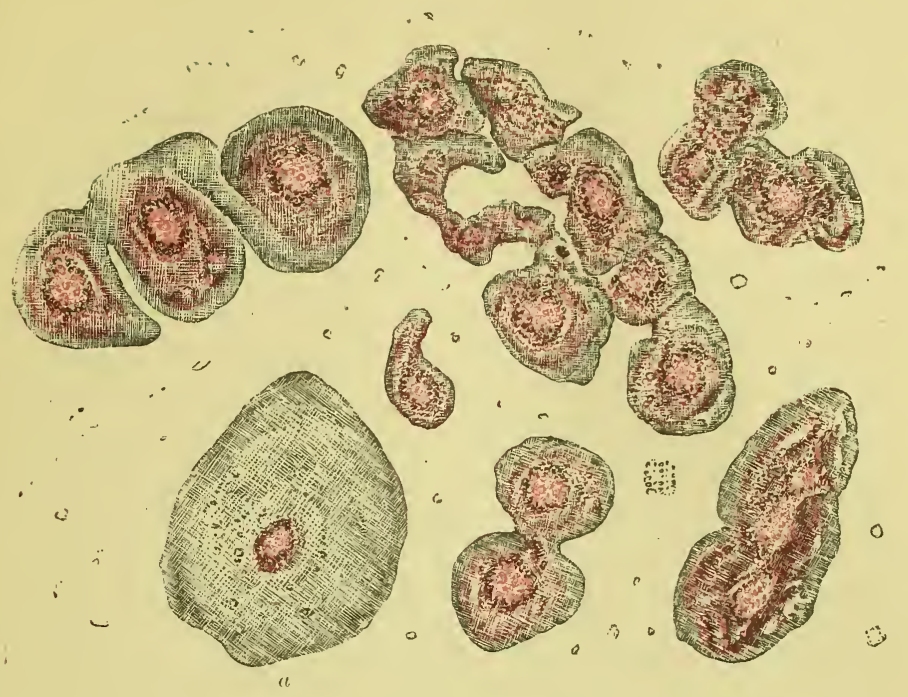

Epitheluum from the surface of the pharynx of a healthy person suffering from very slight sore throat, a day after "catchins cold." $a$ a normal full srown epithelial cell for contrastins with the other specimens in which the proport con material still plastic and containins very much bioplasm in some instances dependent upon very rapid growth. $\times 700$. p 35.

Fig. 16.

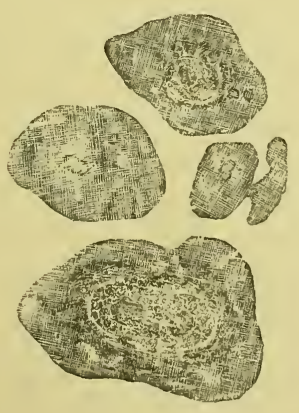

Sume of the emallest cells in white mucus from the smallest bronchial tubes of a cow which died from cattle plague. The bioplasm has increased in quantity. The animal was waim when examined. $\times 1800$. p. 35.

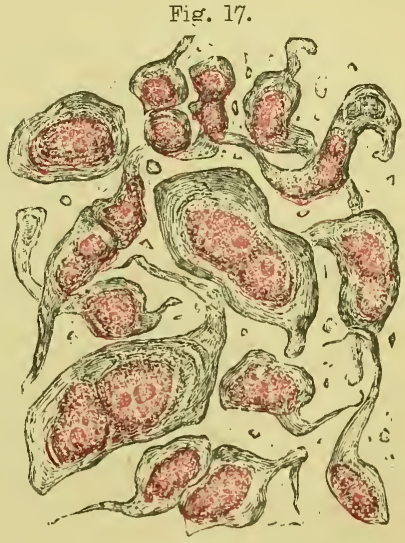

Cancer ctils from a case of epithelial cancer of the bladder, showinos srowth and multiplication of the bioplasm which exists in large quantity $\times 215$ p. 36 ,

$\times 700$ linear.

$\times 1800$. 
to the left of which, at $a b c d$, are represented separate cells, the bioplasm of which is growing and dividing and subdividing. The cells multiply faster than any cuticle cells, and the numerous descendants they produce are pus-corpuscles, Figs. 19, 20. From these pus-bioplasts, diverticula, proceed, and particles are from time to time detached which are extremely minute, and by their movements may pass through'very narrow chinks in tissues, and thus spread from the point where they were first produced : not only so, but some of these are so minute, that, like the little germs detached from the yeast cells and other microscopic fungi, the amœba germ, and many others, air will support them ; they may thus be carried long distances from the spot where they were developed. If exposed to great heat or cold, or to the action of certain gases and vapours, they will be killed, but in warm, moist air they will live; and if they fall in a favourable place, that is, where there is proper food for them, they will grow and multiply a thousandfold like yeast. But the yeast germ is essentially different from these, and will not produce amœba, or the latter pus. The pabulum suitable for the first would kill the last.

Multiplication of Blood-bioplasts in Disease.-Next, then, let us consider whether the multiplication of the bioplasts (masses of germinal matter) of the blood which occurs in the capillary vessels in disease, differs from the process which we have seen going on in the vessels of all animals at an early period of develop- 
ment, and throughout life at a certain time of the year in the case of hybernating animals, and in man under physiological conditions which cause the blood to circulate very slowly, or to stagnate for a time in the smaller vessels of the body. As will be inferred from the remarks made in pp. 24,35 , it is not possible to draw any distinct line of demarcation between physiological and pathological changes. In inflammation, the phenomena above referred to proceed a stage further, and then are unquestionably pathological. But even if this stage be reached, it by no means follows that the texture involved should not regain its normal condition and the previous healthy state be perfectly restored.

On the other hand, it is quite certain that if the state of things now to be described continues for a time, and proceeds to any great extent, destruction of tissue is inevitable and return to the original condition is rendered impossible. Repair may follow the injury, but this repair involves serious alteration in structure, with corresponding deterioration in action, without capacity for improvement and without the possibility, under any circumstances, of return to the former state.

When the circulation through the capillary vessels is impeded in many cases of fever, inflammation, and other diseases, the blood bioplasts (white blood-corpuscles) multiply, and the capillaries often appear to be filled with them. The vessels and their 
FROM HEALTH TO DISEAS

Fig. 19.

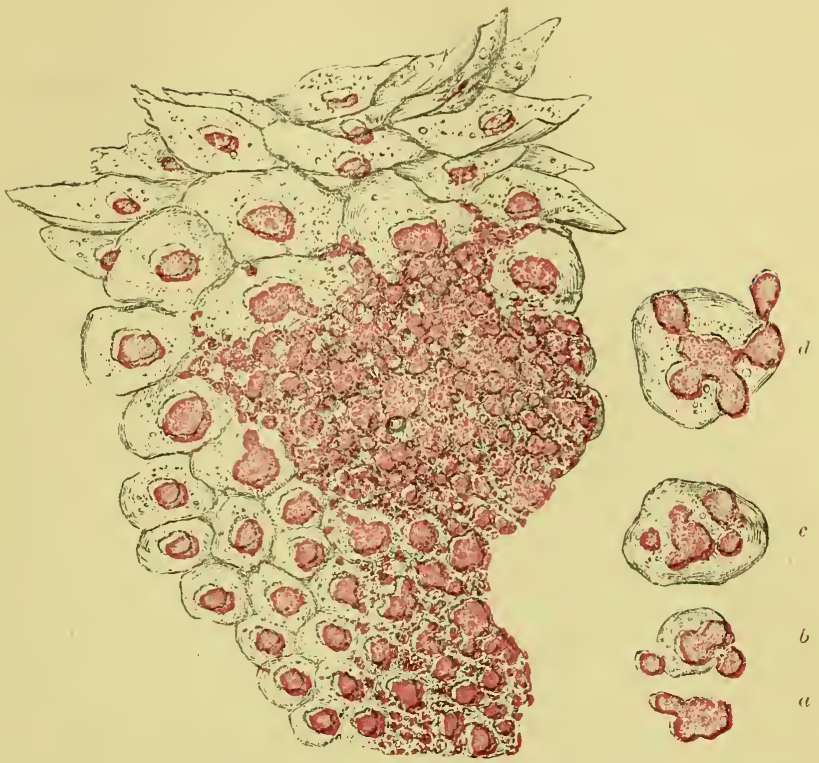

A portion of the ep:thelial covering of the tongue in a state of inflammation The bioplasm at the A por part is srowino and multiplyins vern rupidly 'The changes takins place in individual cells or elementary rarts are represented on the iipht, at $\boldsymbol{a}, \boldsymbol{b}, \boldsymbol{c}, \boldsymbol{d}, \times 700$. This drawing has not been copied from a single preparation, but has been completed from tue appearances observea in several different specimens, p 3is.

Fig. 17.
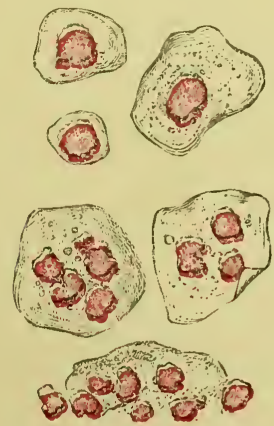

Increase of bioplasm and formaticn of pus in individual epithelial cells of mucols meznbrane. Mouth. $\times 210$ p, 37 .
Fig. 20.

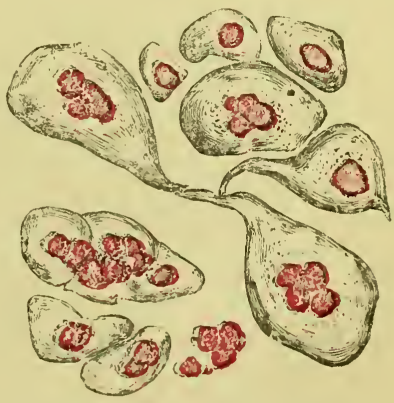

Divisiou of bioplasm in cells of blad. der epithelium. From a case of inflammation of the bladder. $\times 2 i 5$. 

contents then very closely resemble those of an animal during the early period of its development. This state of things always exists in inflammation, and the multiplication of the bioplasts often proceeds to a wonderful extent. The appearances seen are certainly not due simply to the accumulation of white blood-corpuscles, as some have held, but only in part to this, and mainly, as I pointed out many years ago, to their actual growth and increase. "If in any capillaries of the body the circulation is retarded from any cause, an increase in the white blood-corpuscles invariably takes place. In congestion and inflammation of the vessels of the frog's foot, the number of the white blood-corpuscles soon becomes so great as to impede and ultimately to stop the circulation through the vessel. Although the great majority are merely corpuscles that have been retarded in their passage, there can be little doubt that the corpuscles actually multiply in number in the clot that is formed."* In Fig. 24, plate X, p. 44, a very small vein with two capillaries from the frog's foot a few hours after inflammation had commenced, is represented under a magnifying power of 215 diameters. The white bloodcorpuscles form a thick layer all round the vessel, the circulation had quite ceased, and the entire tube would soon have been entirely occupied by white blood-corpuscles. The little capillaries are quite

* "On the Germinal Matter of the Blood, with Remarks upon the Formation of Fibrin," December 9th, 1863, 'Trans. of the Mic. Soc.' 
occluded. The liquor sanguinis is transuding through their walls, and in a very short time the minute vessels would have appeared quite filled with bioplasm, and the growth of the living matter from the minute particles of bioplasm which escaped when they were distended, would soon have commenced as in Figs. 21, 22, 23, plates VIII, IX, X. The fact of the increase of the white blood-corpuscles appears to have been overlooked in consequence of the preparation of the specimens not having been conducted with sufficient care to permit of examination being made with powers of high magnifying power.

Whenever a capillary vessel is distended, its walls necessarily become much reduced in thickness, and in extreme distension which occurs in inflammation, little longitudinal rents or fissures are here and there produced. Through these, serum, holding in suspension very minute bioplasts probably detached from the larger ones growing and multiplying in the vessel, pass. Having thus extravasated, these particles, resulting directly from the subdivision of the white blood-corpuscles, make their way by vital movements into the interstices of the surrounding tissues, and being nearly stationary, and abundantly supplied with nutrient pabulum, grow and multiply in the new locality, and at an increasing rate. The phenomena here described will be understood if the figures given in Plates VIII., IX. and X. be carefully studied. These have been copied from preparations which were pre- 


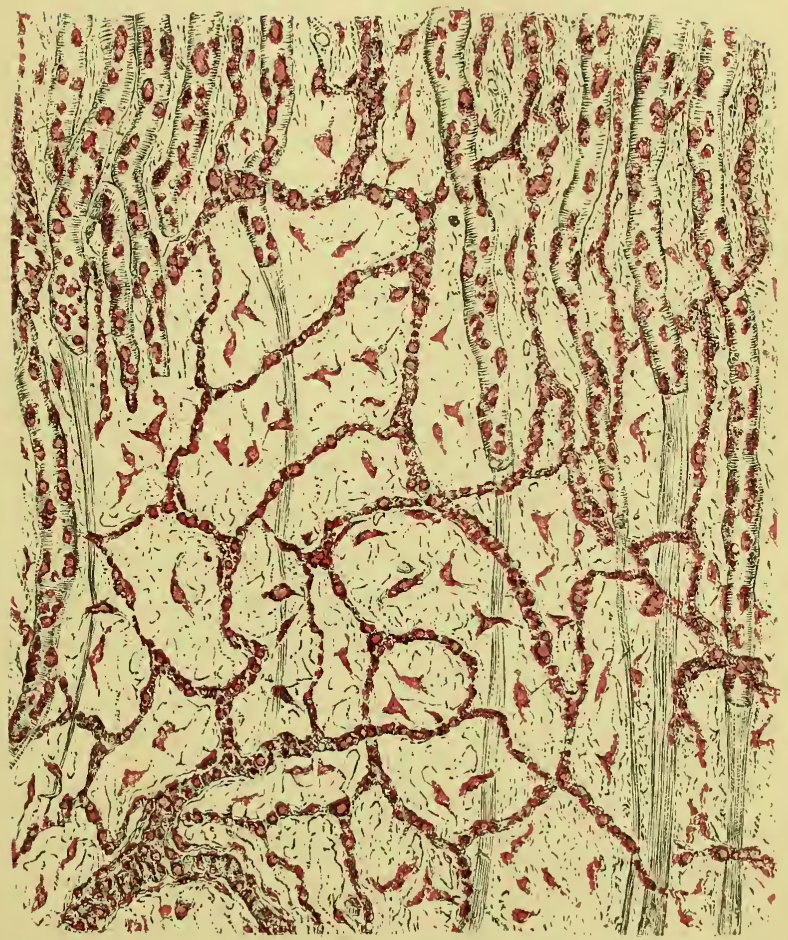

Fortion of pectoral muscle, fros. forţ eişht hours after beiné pertorated. × 50. Sbowing increaserl growth of bioplasm in all the tissues. The vessels contain an increased number of white blood corpuscles (bioplasm), and the bioplasm masses of the muscles are already dividing aud sub. diridıug. The elementary muscular tibies have iu several instances ruptured and contracted within the tube of the sarcolemma. From a specimen raounted w1 1863 . p. 40.

I⿳亠ेष 0 of an inch $-\times 50$ linear.

L. S. B.]

1570. 

pared in the year 1863 . But the facts demonstrated were well known to me, had been described in my lectures before 1863 , and were particularly referred to in a paper presented to the Royal Microscopical Society in that year, I did not come to the conclusion which has since been adopted by Cohnheim, that an individual white blood-corpuscle passed through the wall of the vessel, and then changed its characters and became a pus-corpuscle, an idea which had been previously advanced by W. Addison and also by Waller; but my observations led me to believe-and of the correctness of the conclusion I am fully satisfied -that the particles of germinal or living matter seen in such great numbers outside the vessels in cases of inflammation, result for the most part from the growth, division, and subdivision of minute particles of germinal matter which have passed through the vascular wall suspended in the fluid exudation. Many of the masses of germinal matter represented in Fig. 23, pl. X., are the descendants of white blood-corpuscles, but they are not the white blood-corpuscles which were previously in the blood, and which were circulating in that fluid. They may continue to grow and multiply like other kinds of germinal matter, until at last that rapidly-growing form of bioplasm, the common result of the greatly-increased growth and multiplication of every form of bioplasm in the living body, may be produced. In inflammation of a texture going on to pus-formation,- of the pus-corpuscles in 
the abscess, some are descendants of white blood-corpuscles, others of the bioplasm of the tissue, vessels, and nerves. The pus-corpuscle may therefore be a descendant of the white blood-corpuscle, as well as of the germinal matter of epithelium, and of other tissues. We may, indeed, trace back its parentage to the original embryonic bioplasmic mass, which must be regarded as the primitive ancestor of all.

New Observations on the Growth and Multiplication of Pus.-The researches upon which the conclusions here briefly expressed, are based, have proved, I think, as I showed in the first course of lectures which I gave at the Royal College of Physicians, I $86 \mathrm{I}$, that the pus corpuscle is not formed by the breaking up of the tissue, and the aggregation of lifeless particles resulting therefrom. Nor is pus produced by the precipitation of particles from a clear exudation and their subsequent aggregation to form masses, as Dr. Bennett of Edinburgh supposes. Pus, as I have endeavoured to show, is a form of living germinal matter, and has descended uninterruptedly from the normal germinal matter of the body. Virchow concluded that pus was formed in connective tissue corpuscles and in epithelial cells only. But there is little doubt that pus may be derived by very rapid growth from any germinal matter in the body.

The pus corpuscles usually figured and described are dead, not living. These spherical granular corpuscles have no longer the power of growth or multipli- 


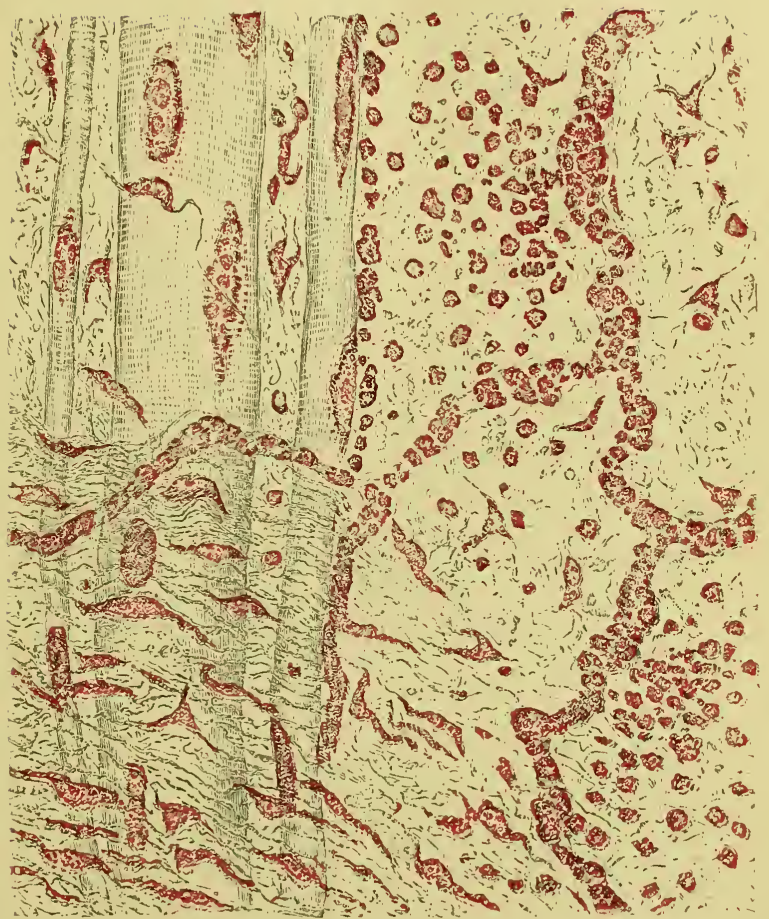

Tuscular fibres and connective tissue of the pectoral muscle of the fing in a state of inflammation fom the inmediate neighbourhcod of the seat of inimy FOOR days aiter the muscle had ium transfixed by a fine thread. The vessels are seen to be filled with whice blood corpuscits. Some of the bucplasm narticles, probably derived from the wlite blo $0^{-4}$, orpuscles (pase 40 ) liave escapeil from the vessel at two points. The bioplasm of the connective tis $* 1$ th and also that of the muscular fibres is much increased. $\times$ '215. From a specimen muluted in 1s63. p. 40. 
cation. In many coagulation has taken place on the surface, and thus a sort of "cell wall" has been formed. Within this are granules and minute oil globules, resulting from the disintegration of the living matter, of which the corpuscle originally consisted, and germs of bacteria. Such pus corpuscles do not alter their form of their own accord. After a time they undergo further disintegration. If the pus remains in a cavity in the tissues, the fluid products may be absorbed, while a small quantity of cheesy matter, rich in oil and cholesterine is all that represents what was once pus.

But how different is the living corpuscle. This may be seen to change its form under the microscope. Diverticula, which are from time to time detached, are seen to be formed at every part of the circumference, and thus give rise to new pus-corpuscles. The living pus-corpuscle is a mass of living, growing germinal matter, derived from matter like itself, or from the normal bioplasm matter of the organism. Plate XI.

As I stated in I863, the white blood corpuscle, the minute masses of germinal matter which I have described as existing in the blood, lymph corpuscles, chyle corpuscles, the masses of germinal matter in the spleen and other ductless glands, those found in connection with the walls of capillaries, germinal matter of nerve, muscle, and other tissues of the body, may give rise to pus if placed under conditions in which they are too freely supplied with pabulum. 
On the Movements occurring in ordinary living Pus. --I propose now to bring forward evidence which seems to me conclusive as to the mode of growth and multiplication of pus corpuscles, and which, I think, goes far to show how living particles, so minute that they may be transferred considerable distances without loss of vitality, may be produced.

There is certainly no true cell-wall in the case of living pus, for protrusions of the matter of which pus corpuscles consist may occur upon every part of the surface, and not only so, but some of these protruded portions, after moving a considerable distance away from the mass, become disconnected from it, and thus new pus corpuscles are produced. It is in this way that the very rapid multiplication of pus corpuscles is effected.

In pus from the bladder, movements even more active than those in the mucus corpuscle are very easily observed, and when fresh, not a single spherical corpuscle can be found. See Fig. 25, plate XI, representing some of the many different forms of pus corpuscles present in a very small quantity of pus. Every corpuscle exhibits a great number of these protrusions, and every protrusion might be detached and form a free pus corpuscle, Figs. 25, 26. Little particles are sometimes detached, and these are often so minute (less than $\frac{1}{10000}$ of an inch in diameter) that they might be supported by the atmosphere and thus transported to a distance while yet alive. 


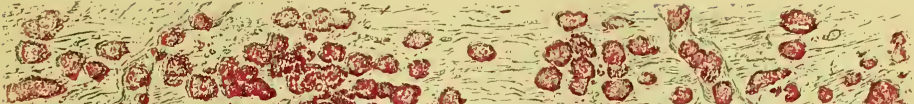

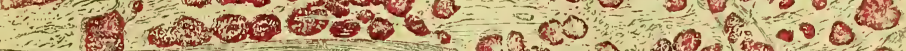

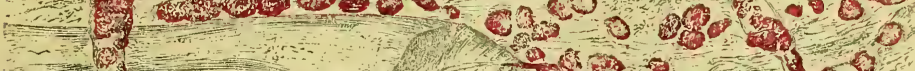

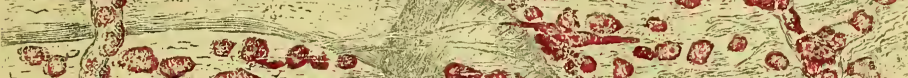

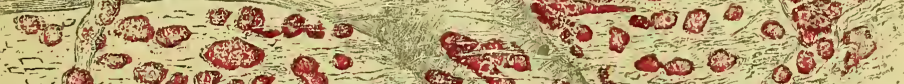

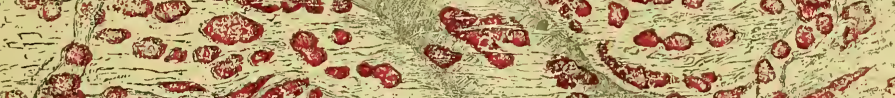

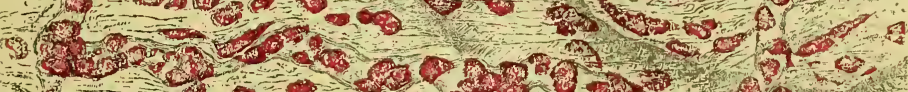

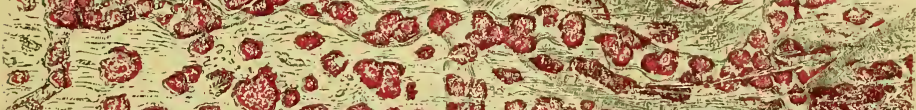

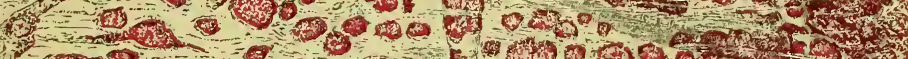

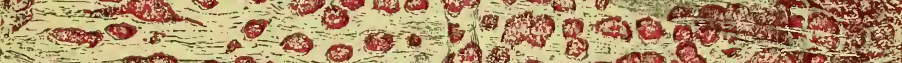

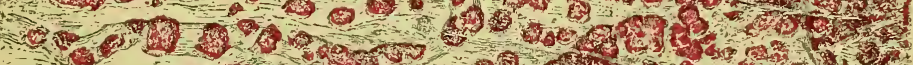
-

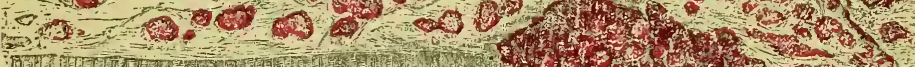

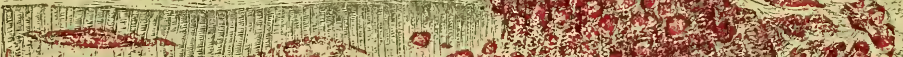

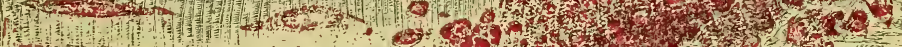

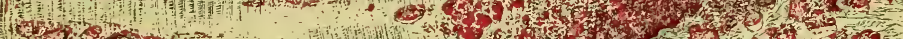

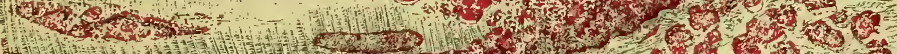
I1.

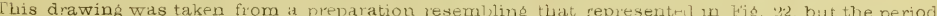

llowed to elapse after the inflammation had been exciced was longer, The Fros was killed sEVEN days after the pectoral was perforated by a threaci. $\times 215$. p. to

\section{Fig. 24.}

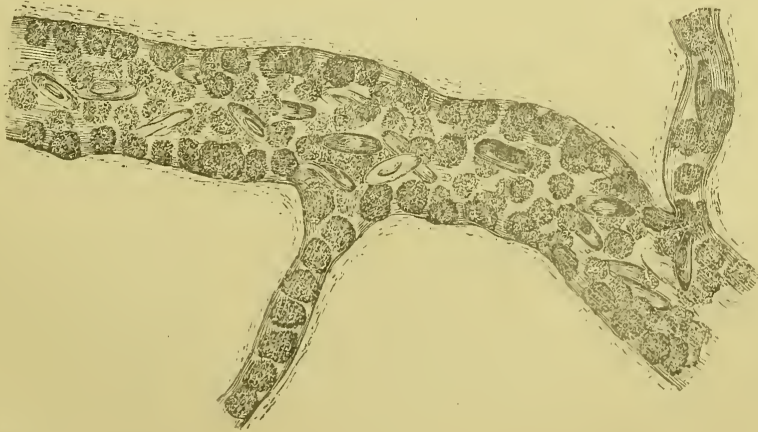


-

. 
(Fig. 27*) In warm weather, I have known the movements continue in pus corpuscles in urine containing little of the ordinary urinary constituents, for forty-eight hours or more after the urine had left the bladder.* The very phenomena which take place upon the surface of the mucous membrane of the bladder may in fact be watched for hours under the microscope, and there are few things more beautiful or more instructive.

The conditions required for the maintenance of life being more complex in the case of some forms of germinal matter than in others, we should conclude that such movements would continue for a considerable period of time in particles after their removal from their natural habitat, only in the lowest and most degraded forms. This is actually the case, just as some simple creatures are capable of supporting life under a great variety of conditions, while comparatively

* It is probable that careful observations upon this transparent living moving material will teach us much concerning the nature of life. I think that this subject merits far more attention than it has hitherto received, not only from physicists, chemists, and physiologists, but from philosophers. I do not think that what will be learned from the study will favour the notions now most popular, but that is no reason why it should any longer be wholly neglected, especially by those who profess to desire to carry their enquiries to the utmost possible limits, but who really carry them a very little way, who, if successful in destroying, are certainly obstructive. Some of those who profess to be most liberal in science strongly object to enquiry being carried beyond the limits they have arbitrarily and without sufficient reason laid down. 
slight alterations would be fatal to others higher in the scale.

It is not possible to distinguish many pus corpuscles from lymph corpuscles, white blood corpuscles, and many other masses of germinal matter; indeed, if the developing brain of an embryo be examined at an early period, it will be found that this important structure consists of nothing more than a number of spherical cells, which could not, by any means we are yet acquainted with, be distinguished from many forms of pus corpuscles. See "The Microscope in Medicine," Plate XX, figs. I55, I 56. If we carefully reflect upon many observed facts, we shall be compelled to admit that masses of germinal matter which resemble one another in every character we can ascertain, differ nevertheless remarkably in power, as is proved by the results of their living. Few recent writers seem to have fully recognized the remarkable truth that living things may agree in physical and chemical characters, but nevertheless differ wiclely in power; that transcendent difference in vital power may be associated even with similarity of composition, so that we are quite prepared for the discovery that the powers of certain forms of morbid bioplasm are very different from those of the normal living matter from which they have descended, although no difference whatever can be detected in their chemical composition.

Death and Decomposition of Pus.-When pus bio- 
PUS BIOPLASTS-THEIR VITAL IMOVEMENTS.

Fig. 25.

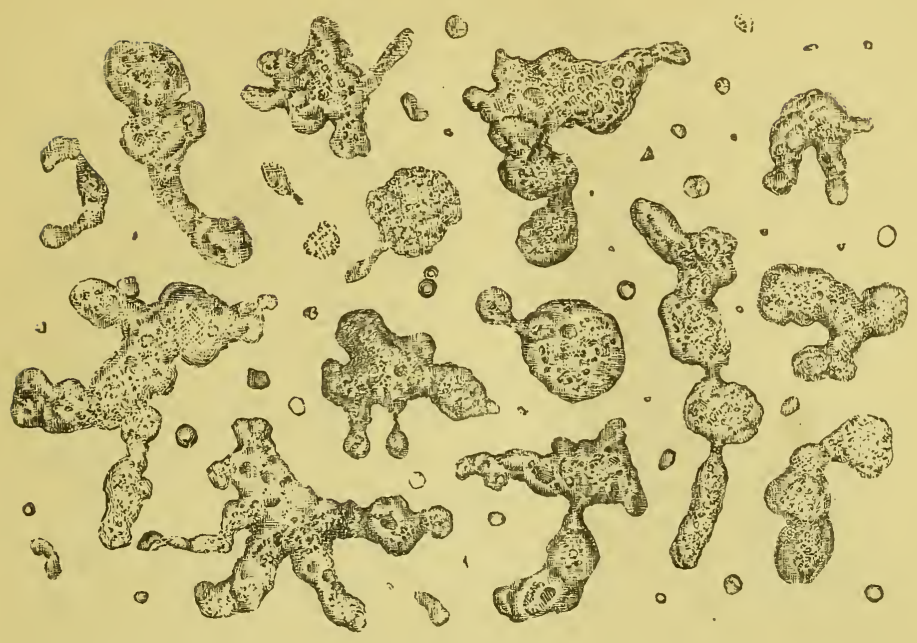

Pus bioplasts or corpuscles in active movement, from the urine of a case of chronic intlammation of the bladder. $\times 700$. p. 44 .

Fig. 26.

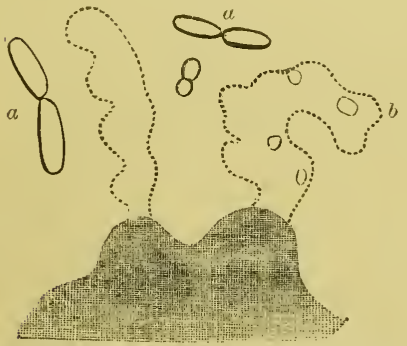

Portion of a living pus bioplast or corpuscle from the bladder The portion marked $b$ moved out in four seconds, and was then retracted. The other portion was extended in about the same time, $\times 2,800$. p 45 .

a. Baulein:

Fig. 27.*
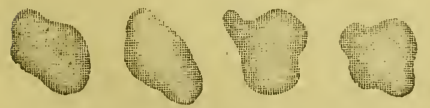

Different forms assumed by the same minute mass of bioplasm of pus from the bladder. during five seconds. $\times 2,800$. p 45 .
Fig. 27.

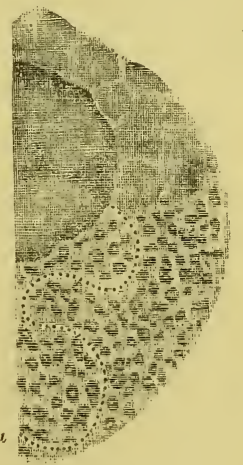

A portion of a pus corpuscle from the bladder of man, the thirc day after the urine containins it had been passed The vital morements had ing it had been passed Terimorent At a little particles (13acteria) were oscillating in take the course indicated by the couted line during the fraction of a second. $\times 2,800, p .47$.

$\overline{\mathbf{1}}^{3} \overline{0} \overline{0}$ of $\mathrm{an}$ inch $\times 700$

$$
\overline{\mathbf{1}} \mathbf{2} \boldsymbol{\mathbf { 0 }} \overline{\mathrm{o}}, \text {, , }
$$



plasts die, and their death occurs when they are placed in any fluid which is not adapted for their nutrition, the vital movements cease and the corpuscles invariably assume the spherical form. Not unfrequently a change occurs in the outer part, and a sort of membrane like a cell wall is produced; the contents become more granular, and they assume the appearance usually given in published drawings. After a short time the matter of which they are composed undergoes change, and is invaded by bacteria germs, which grow and multiply as represented in Plate XI, fig. 27. These bacteria are not formed directly from the matter of the pus which once lived, but it is quite possible that bacteria germs existed in a living but perfectly quiescent state amongst the oldest particles of the living matter on the surface of the pus corpuscle when it was yet alive. 


\section{DISEASE GERMS IN ANIMAL FLUIDS AND SECRETIONS.}

BEFORE I proceed to describe the characters of the particles suspended in animal fluids, having virulent contagious properties, it is very desirable to draw attention to the minute particles of bioplasm, which may be demonstrated in many specimens of simple exudation. From this subject we shall pass on to the consideration of other forms of "exudation" which possess specific disease-producing properties. We shall find that by a careful microscopical examination of fluids which experience has proved to us have contagious properties, facts of great interest are disclosed which have an important bearing on the question of the nature of the poison of contagious diseases. Many such fluids are clear like water, and quite as transparent when examined by the unaided eye only. When we come to subject them to examination with the aid even of the highest powers yet made, although solid particles are detected, and sometimes in great number, we observe nothing peculiar to these fluids alone-nothing which would enable us to form any conception of the wonderful properties they possessnothing that would attract the attention of the chance observer, or excite the interest of any one who had not long and carefully studied the matter. Nevertheless, 
what we are able to demonstrate is of vast importance, and with the aid of other observations and experiments, we may form, I think, clear notions of the nature and origin of these morbid poisons, and of the manner in which they produce their marvellous and oftentimes disastrous effects. Much yet remains to be disclosed, but we shall soon learn more if we will but work and think independently, and accept the teaching of facts of observation and experiment, while careful to avoid being misled by the dogmatism of those who obstinately persist in asserting that all vital phenomena are to be explained by physics and chemistry, and try to make people believe that living organisms are mere machines constructed by force. For all truly vital phenomena must necessarily be altogether out of the range of mere physical investigation; nevertheless, to such extravagant lengths has the opposite view been carried of late, that it has even been seriously stated that he who refuses to look upon life as mere inorganic force opposes investigation, and looks upon the structure of man's organism as a subject unsuitable for scientific exploration. It would be as reasonable to assert that a man who is to be a scientific investigator must commence by confessing his belief in the truth of a conclusion which has long been proved to be false by reason and observation.

The evidence that the wonderful properties of the fluids about to be considered are due to the presence II. 
of extremely minute particles of living matter will, I think, be admitted to be conclusive, while the effects produced by these in a living organism cannot be explained by physics or chemistry, or imitated artificially. Few persons will in these days be so deluded as to accept as an explanation the assertion that vital phenomena are "molecular," or admit that it conveys any more information than the announcement that the phenomena of living beings are due to the molecular changes in the basis of physical life. Such "explanations" explain nothing, and are but impertinent fictions of the imagination.

Simple Exudation.-The transparent colourless fluid which moistens the surface of a superficial wound after it has ceased to bleed, is poured out from the capillaries, or from the lymphatic vessels, or from both sets of vessels. This fluid, besides containing albumen in solution, contains multitudes of minute particles of bioplasm, which grow and multiply upon the surface. These form fibrin and matters more or less allied to it, and perform an essential part in the healing process, or in the formation of pus, as the case may be. These minute particles of living matter are present in the blood and lymph in countless numbers. They are concerned in the production of fibrous tissue outside the capillaries, which takes place in many pathological processes, and also in the production of pus-corpuscles, and other "corpuscles" in the same situation, in disease. All "exudations" 
contain these particles of living matter. The following paragraphs are taken from a paper written by me in $1863^{*}:-$

"When the capillary vessels are distended, as in that extreme congestion which soon passes into inflammation, a fluid which possesses coagulable properties transudes through the stretched capillary walls. It is probable that in such cases minute and narrow fissures result, which, however, are too narrow to allow an ordinary white or red blood-corpuscle to escape, but, nevertheless, wide enough to permit many of the minute particles of the living or germinal matter (the existence of which in the blood has been already referred to) to pass through. The small protrusions upon the surface of the white bloodcorpuscle might grow through the capillary walls, become detached, and pass into the tissue external to the vessels. Such minute particles of living matter external to the vessels being surrounded with nutrient pabulum, and stationary, would grow and multiply rapidly, while a similar change would of course go on in the now stagnant fluid in the interior of the capillary. The result would be exactly that which is observed, viz., the presence of a vast number of cells like white blood-corpuscles in the interior of the capillary vessel, and immediately around its external

* "On the Germinal Matter of the Blood, with remarks upon the Formation of Fibrin." Microscopical Society, December, 9th, I863.See Trans. Mic. Soc., April, I864. 
surface, and sometimes these extend for some distance in the substance of the surrounding tissue, and they increase in number.

"I venture, then, to conclude that many of the clear fluids which have been considered as 'exudations' from the blood, really contain a multitude of extremely minute particles of living matter, which are intimately related to the white blood-corpuscles, and that these grow and become one source of the small granular cells or corpuscles which are so familiar to all who have studied morbid changes in the tissues as they occur in man and the higher animals.

"Some of these active living particles may be so small as to be invisible by a power magnifying 5,000 diameters. I'have seen such particles, less than the 50,000 of an inch in diameter, and have no reason whatever for assuming that these are really the smallest that exist."

These minute particles of bioplasm multiply freely; but they may also be derived from the white bloodcorpuscles, and from other forms of bioplasm. The general appearance of such minute particles is represented in a minute portion of recently drawn blood in Fig. 28, plate XII. As the blood coagulates they undergo change, die, and help to form the non-living fibrin. In every clot numerous white blood-corpuscles, also composed of living matter, can be detected, Fig. 30. In coagulation it is probable that the most minute particles of bioplasm change first, and become 
LIVING BIOPLASM FROM THE BLOOD.

Fig. 28.

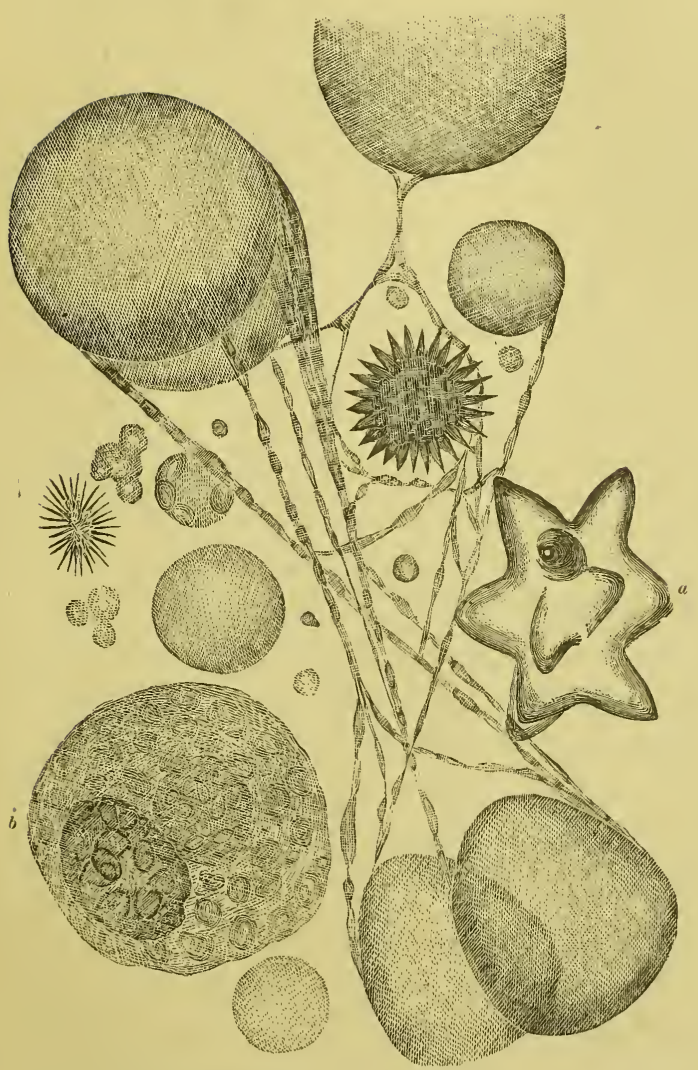

Red and white blood corpuscles in a drop of blood which har just been removed from the fing $\times$ r $\times 2,800$ 'The large smooth circular bodies are the red corpuscles. Three very small red corpuscles are less than the 1 th of an inch in diameter. The smallest particles are composed of matter like that of which the white blood corpusole or blood bioplast $(b)$ consists. Threads of fibrine are being formed by the coagulation of the minute particles of bioplasm of the blood These are seen between the corpuscles in the upper and lower part of the field a red corpuscle exhibiting ansular projections Abors ic and to the left is another with still more pointed processes septumber, 1863. p. S:
Fig. 29.

$$
\begin{aligned}
& \text { 3. } \\
& \text { (t) }
\end{aligned}
$$

Very minute particles of bioplasm from exudation. $\times 5,000$. p. 52 .

Fig. $3($ ).

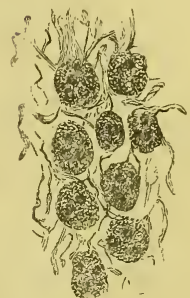

From a pale clot in the heart of a patient who died of exhaustion, showing white corpuscles, or blood bioplasts, and fibres of fibrine $\times 700$ p. 53 .

F1g. 31.

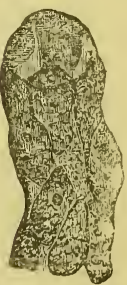

Capillary vessel, from the mucous membrane of the epiolotis shc in numerous masses ing numerous masses of bioplasm situsted projecting into the cavity of the vesse? $\times 700$ p. 53 . 

fibrin. After a time the white blood-corpuscles also die, and thus the coagulum of fibrin continues to increase for a short time after coagulation has commenced. The diverticula from a white blood-corpuscle undergoing conversion into fibrin are represented in Plate XIII, fig. 33. The lines round the red blood-corpuscles seen stretching from one to the other in Fig. 28, represent the earliest stage in the formation of fibrin, and the minute particles of bioplasm are seen actually undergoing change. The bioplasm of the blood is derived from the bioplasm originally found in the vessels of the germinal area at a very early period of development, from the bioplasm of the capillary walls, which is very abundant in some capillaries, and projects into the cavity, Plate XII, fig. 3I, and from the lymph and chyle bioplasm which is being continually poured into the vascular system and mixed with the blood.

If the clear transparent material which moves round the cells of Vallisneria (Fig. 32, pl. XIII.) and other plants be carefully examined under very high powers magnifying upwards of 2,000 diameters, it will be discovered that this is not a simple fluid like water containing the nucleus and chlorophyl (Fig. 35). But the apparent fluid has suspended in it an infinite number of particles of living matter like those of which the amœba, white blood-corpuscle, and other forms of living matter consist. With high powers the slightly opalescent appearance may be detected, and 
by careful foccussing minute particles of living matter will be brought into view. The movements of the fluid may therefore be compared with the movements of the living bioplasm of an amœba. In the circulating juice of many plants similar appearances may be observed, and in the blood and circulating fluid of all animals, and in man himself, minute particles of living matter are to be demonstrated in immense multitudes. These are diffused through the fluid, and to them is probably due the movement of the contents of the finer vessels and spaces. This constituent of the blood, seen with such difficulty that its presence is not yet admitted by observers, is probably the most important, for its increase or diminution may occasion serious disease or death. This almost impalpable living moving matter is the seat of many very important changes, and is perhaps influenced before any other constituents of the body when certain poisons and disease germs find their way into the blood. "Protection," after successful vaccination, and the escape from a second attack, which is the rule in the case of many contagious fevers, is most likely brought about by changes induced in the living matter under consideration.

In health it is upon this material that the coagulable property of the blood is mainly dependent, and it is this which in great part undergoes conversion into what we call fibrin, when the blood is removed from the living vessels or "dies." If destroyed it may, 
PLATE XIII.

BIOPLASM, BLOOD; VACCINE LYMPII; VEGETABLE CELIS. Fig. 32.

Fiś. 33

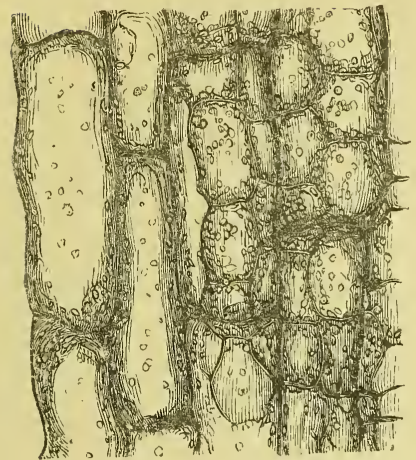

Vallisneria spiralis, showing large and small cells with livius coutents which rotate. $\times 130$. p. 33.

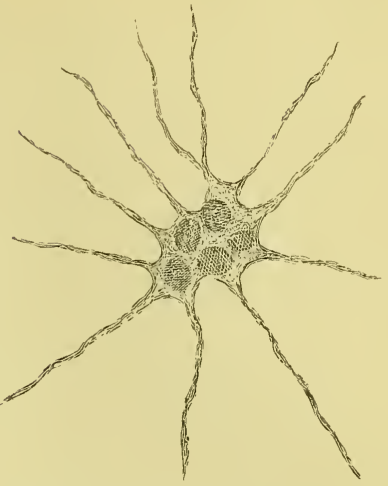

Alterea blood bioplast or corpuscle. Bodies of this form were common in the blood an hour after it had been drawn from the finger. The projecting processes consist of serminal matter which is sradually undergoinó change into fibrin. $\times 1,800$, p 53

Fig. 34.

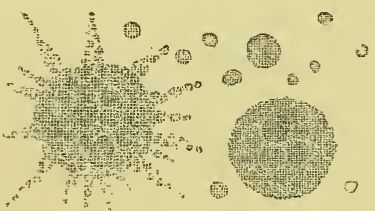

Corpuscles consisting of germinal matter or living bioplasm in the "lymph. froin a $\nabla$ acciue $v$ esicle, showing changes in form whichoccurea a few minutes after the lymph had been transferred to a warm slide. $\times 1,800$. pp. $60,62$.

Fig. 35.

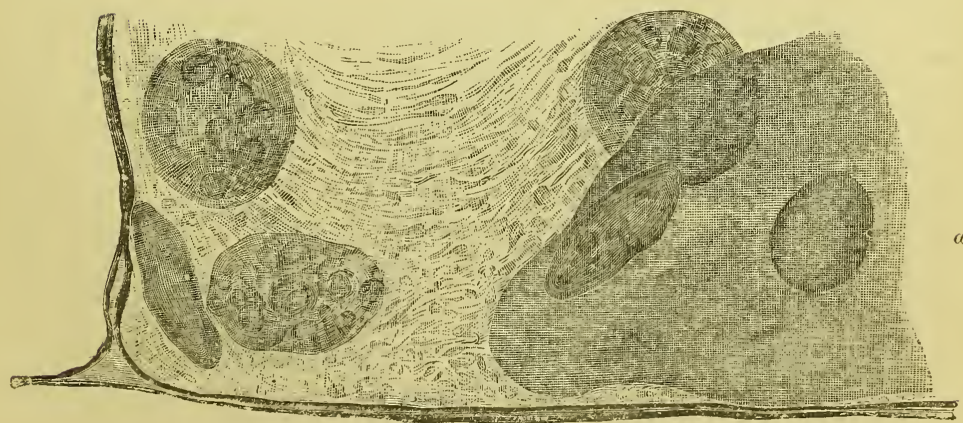

c

Part of it cell in vallisneria, showing circulation. The laree mass a with nucleus, is colourless, and consists of bioplasm. The smaller farticles (under $b$ ) are also composed of livins matter or bioplism. The movements of the entire contents round the cell are probably due to these. After death they are transtormed into fbmn. The round bodies, $c$, are masses of chlorophyl, which are
dich in process of formation. $\times 2,800 . \mathrm{pp} 53,55$.

$$
\begin{aligned}
& \overline{1} \overline{0} \frac{1}{0} \overline{0} \text { of an inch } \times 1800 \text {. } \\
& \overline{1} \overline{0} \text { iñ }, \text {, } \times 2500 \text {. }
\end{aligned}
$$


under favourable circumstances, be renewed by the appropriation of nutrient matter by the white bloodcorpuscles which are intimately related to this living bioplasm and take part in its formation. I believe they bear to it the same relation as the "nucleus" in the cell of Vallisneria bears to the living particles suspended in the fluid, Fig. 35, pl. XIII., while the red blood-corpuscles of the blood correspond to the chlorophyl particles in the rotating fluid contents of the vegetable cell. In this work attention will be drawn to the vast importance of this living fibrin-forming matter in various exudations, and it will be found that a simple explanation of many most important morbid phenomena may be given. Now in the fluid exudation or virus which produces a "poisoned wound" when inoculated we also find minute particles of living bioplasm.

Many arguments will be advanced in this treatise in favour of the view that the virulence of the poison is due entirely to the living particles, and not to the fluid in which these are suspended. In the case of some of these poisonous fluids we are able to study the production of the contagious virus, and we may even in some cases succeed in tracing out the manner the material with the wonderful poisonous property originates.

In some forms of inflammation of serous membranes the process may be made out, and a conception formed of the several changes which occur, and at 
last end in the development of the poison. The morbid change is sometimes limited to the effusion of serum and the production of "inflammatory lymph," but in other instances the inflammation proceeds to a further stage, and actual pus is generated. Peritonitis is an example of an inflammation which much more frequently proceeds to the formation of pus than inflammation of other serous membranes. The greater vascularity of the peritoneum as compared with allied textures may perhaps account for this fact. It is interesting to discuss briefly the characters of the different "inflammatory products," as they are called, resulting from peritoneal inflammation, varying in intensity.

In slight inflammation there is great vascular distension, accompanied, as in other cases, by the escape of exudation in which are suspended particles of bioplasm. The exudation coagulates upon the surfaces of the serous membrane, perhaps glueing them together. The fluid portion is gradually absorbed, and if the case progresses to recovery, much of the coagulated matter is also taken up, a little being transformed into fibrous tissue, resulting in a few " adhesions," or mere thickening of the serous membrane, as the case may be.

When, however, the intensity of the inflammation is more marked, the little particles of bioplasm originally derived from the white blood-corpuscles, grow and multiply, and with the fibrinous matter in which they are entangled, form transparent flocculi, which 
are suspended in the serous part of the exudation, or adhere here and there. loosely to the peritoneal surface. Many of these flocculi are found to contain multitudes of bioplasm particles, and oftentimes a vast number of these are suspended in the fluid, and congregated here and there, forming little collections, upon the surface of the delicate serous membrane, to which they adhere, and where they grow.

If the inflammatory process still continues, and increases in severity, the vascular congestion becomes more marked, and the exudation is poured out from the blood more abundantly; the masses of bioplasm increase in number yet faster, and the exudation in consequence appears nearly opaque. The flocculi are of a yellowish colour, and look very like pieces of clotted cream which stick here and there to the peritoneum covering the intestines and the inner surface of the abdominal parietes. Not unfrequently the surface is smeared over in places with whitish pasty masses of soft cream-like matter, in the intervals between which the highly-injected vessels stand out with great distinctness. The masses of bioplasm would now be called pus-corpuscles. Here then is an interesting example of the production of pus-corpuscles by the rapid growth and multiplication of particles of bioplasm which were once in the blood, and intimately related to the white blood-corpuscles.

But further: if, as is well known, a little of this material were to be introduced into the body, as may 
unfortunately happen from a dissection-wound in the course of making a post-mortem examination, terrible inflammation may be excited in the person inoculated. The most tiny morsel of this virulent, rapidly-multiplying morbid bioplasm may give rise to a dreadful form of "blood-poisoning," which may end fatally and in a very short time.

In some cases similar poisonous particles which have been derived from a diseased organism are so very light that they are supported by the air, and may find their way into the blood of a healthy (?) person through his respiratory organs, or may gain access to his circulating fluid by traversing the narrow chinks between the epithelial cells of the cuticle.

Now, what is the nature of the matter inoculated, which produces these dreadful results? The virulent poison which sometimes destroys life in cases of dissection-wounds cannot, as was remarked in Part I, be attributed to the presence of vegetable germs, for the period of its most virulent activity is very soon after death, but before the occurrence of putrefaction, when the vegetable fungus germs multiply. A punctured wound is not dangerous if putrefactive decomposition has taken place, because, although bacteria are developed in immense numbers, the rcal contagious virus is dead. The vegetable germs in fact grow and flourish upon the products resulting from the death of the dangerous animal living poison. In short this material is living and very actively growing germinal 
matter; living matter which retains its life after the death of the organism in which it was produced has occurred ; living matter which has descended directly from the living matter of health, but which has acquired the property of retaining its life under new conditions ; living matter destroyed with difficulty, and possessing such wonderful energy that it will grow and multiply when removed from the seat of its development and transferred to another situation, provided only it be supplied with suitable nutrient pabulum,and it is to be feared the ordinary nutrient fluids of a perfectly healthy organism are eminently adapted for the nutrition of this destructive virus.

The Germs of Purulent Ophthalmia-Gonorrhoal $P u s$.-Such is the vitality of these forms of bioplasm that they will grow and multiply upon certain mucous surfaces if placed there; not only so, but the living particles will retain their vitality for some time after their removal from the surface upon which they grew. They may even be transported long distances by the air, or they may remain for some time in moist cloths without being destroyed. When once a room has been infected with such particles, some weeks may elapse before the death of all the specific diseasecarrying germs has taken place.

The characters and vital movements of pus and minute pus germs, have been already described in p. 44 .

The pus possessing specific contagious properties 
cannot be distinguished from ordinary pus. It differs indeed from this last, but not in appearance, chemical composition, or physical properties. It differs in vital power.

Vaccine Lymph.-Vaccine lymph which has been just removed from the growing vesicle wiil be found to contain a great number of extremely minute particles of bioplasm, which may be well seen under a power magnifying from I,000 to 2,000 diameters. In I 863 I made a drawing of the appearances I observed in the bioplasts from a drop of perfectly fresh lymph which had been transferred to a warm glass slide, and carefully covered with very thin glass, under the $\frac{1}{26}$ object glass, which magnifies about I,800 diameters. The results are represented in Fig. 34, plate XIII, which was published in the "Quarterly Journal of Microscopical Science” for April, I864.

In vaccine lymph which has been kept for some time in glass tubes, multitudes of very minute particles are observed, and these exhibit the most active molecular movements. These particles have often been termed debris, and have been regarded as quite unimportant elements of the lymph. To them, however, the active properties of the lymph are entirely and solely due. And I should be no more inclined, in the absence of the most positive evidence to the contrary, to regard the fluid portion of the vaccine lymph as the active material, than I should be to assume that the fluid in which the spermatozoa were 
suspended was the fertilizing agent, and that the spermatozoa themselves were merely epithelial débris, and quite unimportant; or to infer that the fluid in which the yeast fungi or bacteria were growing, was the active agent in exciting fermentation while the actually growing, moving and multiplying particles were perfectly passive. The germinal particles in all cases are, without doubt, the active agents, and it seems to me as much opposed to the facts of the case to maintain that the materies morbi of cattle plague and other contagious fevers is a material that can be dissolved in fluid, and precipitated and reformed, or sublimed as a volatile substance, as it would be to look upon any living organism as the result of the concentration of an albuminous solution, and capable of resolution and precipitation.

The little particles represented in Plate XIV, fig. 39, could not be distinguished from the minute particles of pus, Plate XI, fig. $27 *$, or other germs of living germinal matter, and I think they consist of a peculiar kind of living matter, the smallest particle of which, when supplied with its proper pabulum, will grow and multiply, giving rise to millions of little particles like itself, each having similar properties and powers.

I consider it to be almost certain that the material of which these particles are composed has the power of forming matter like itself from pabulum around it, which differs from it in properties and composition. 
Such living germs may pass from the organism on which they grew to another, and will grow and multiply there if they meet with the proper pabulum. The only condition in which matter is known to exhibit these powers of self-multiplication is the living state.

M. Chaveau (Comptes rendus, February, I868) described these same bodies in I868. It is evident he had not seen my observations, published in the Cattle Plague Report, or my previous researches published in the Microscopical Transactions for I863.* Fig. 34, plate XIII, was appended to this paper, which was read December 9th, I863. Chaveau showed that the active particles subsided after forty-eight hours, and that no effects were produced by inoculating the albuminous supernatant fluid, while the full effects were produced by vaccinating with the deposit. As would be supposed from the excessive minuteness of these bodies, they are not to be separated by ordinary filtration, but if the fluid containing them also contains a trace of coagulable fibrin diffused through it, this by contraction after coagulation would filter off the little bioplasts, and leave a serum perfectly free. Dr. Farr calls the living particles biads ( $\beta \iota a$, force, $\beta$ เos, life), and speaks of the vaccine particles as

* "Beale had, before Chaveau, declared that the 'active properties of vaccine lymph are entirely and solely due' to these corpuscles. He has figured them."-1)r. Farr, "Report on the Cholera Epidemic of IS66," p. Ixviii. 
raccinads.- "Report on the Cholera Epidemic of I866," p. 1xx.

The circumstance that vaccine lymph retains its activity if kept in a tube for several weeks, seems conclusive as to the possibility of the particles retaining their vitality for a considerable time after they have been removed from the place where they grew; the arguments advanced as proving that the active power resides in the particles and not in the fluid, being admitted. It is not more difficult to explain the fact that such living particles may be dried without losing their power, than that an amœba or rotifer should exhibit the same peculiarity. As this property is observed in connection with many of the lower forms of life, we might almost anticipate that the living matter from the highest organisms, if reduced to a degraded condition, would retain its vitality under circumstances which would cause its death in its normal condition. Yet it must not be supposed that these particles any more than the "dried animalcules" are really dried. Some moisture is retained by the particles within the imperfectly dried mass. Complete desiccation will destroy life in both cases. Since it has been shown that the active powers of vaccine lymph reside in the minute particles of living germinal matter, and it has been proved that these may be dried (imperfectly) without loss of power, it is surely not too much to conclude that the materies morbi of other and allied contagious diseases is probably com- 
posed of living particles which have the same property of living for some time in a state of partial desiccation.

Living Germs of Variola.--l have examined the contents of the little vesicle which rises in small-pox at different stages of its development, and find, as in allied pathological changes, vast multitudes of minute particles of living matter or bioplasm, but, as will have been anticipated from what has been already said, these present nothing peculiar or characteristic, nothing that would enable us to say if we saw these particles under the microscope that they had been obtained from a small-pox vesicle, and would certainly give rise to that disease. I have made a drawing of some of the varioloid bioplasts from a well-developed vesicle on the fifth day of the disease, and also from a vesicle which was just making its appearance. Plate XIV., fig. 37.

Living Germs of Fever.-As was shown experimentally of Dr. Sanderson, a mere trace of blood serum was sufficient to progagate cattle plague. A very small portion of blood or of the tissues of an infected animal had the same effect. Nay, the contagium is so subtle that in this as well as in many other contagious diseases, the breath of the diseased organism contains numbers of the potent particles of poison, and in this manner the very air of a considerable space or even district may become infected. 
BIOFLASM OF SMALL POX VESICLE, AND BLOOD IN FEVER.

Fig. 36.
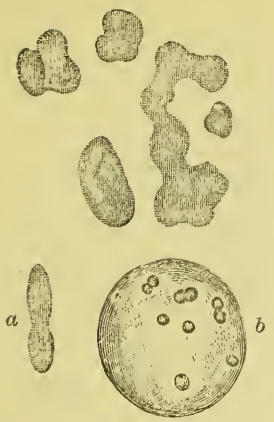

Bioplasts from the $\nabla$ aginal mucua of a cow. Cattle Plague, $a$ bacterium amonst these. $b$, a mass of serminall matter con. taining minute particles like bacteria. These are also seen in the white blood and pus corpuscle, \&c. $\times 2,800$. p. 64
Fig. 37.
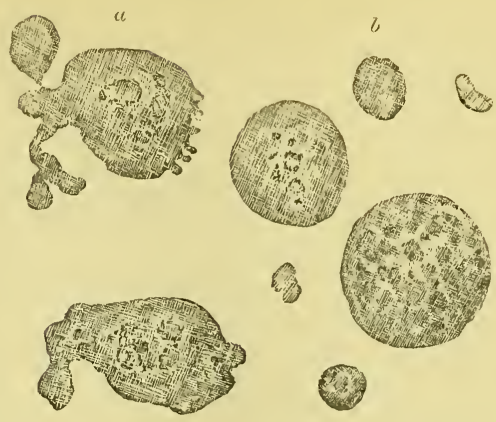

Bioplasts from small pox vesicles on the fifth day of the disease The two bodies under a from one of the younsest vesicles summit. 'The six bodies under $b$ from a fully formed veaicle. $\times 1,800$, p. $6 \pm$.

F1g. 33.

b

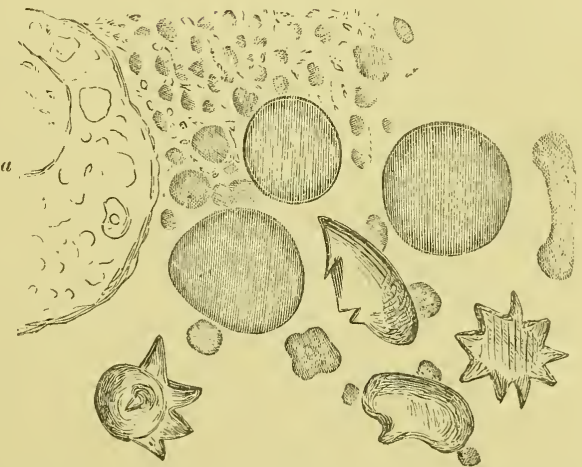

Blood from intestinal capillaries and small mesenteric vein Cattle Plaśue. The serum was reddish $a$, part of white blood corpuscle in outline; $b$. minute particies of bioplasm (disease germs) in immense number in all parts of the field. The smooth round bodies are youns red corpuscles, The anśular corpuscles are old and altered reâ bloodi corpuscles. $\times 2,600$, p 65 ,

Fig. 39.

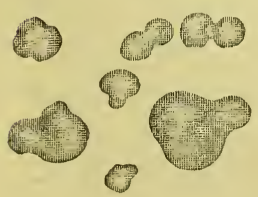

Particles from vaccine $1 \mathrm{ymph}$ which had been kept in a tube, exhibiting very active move ments. $\times 5,000$. pp. 60,61 .
F1g. 40.

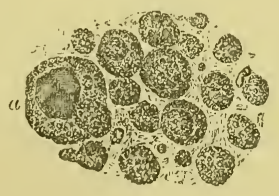
minal matter and white blood corpiscle $(a)$ trom small vein as in Fig. 38, $\times 2,800$, p. 65.
Very small masses of ger-

Fig. 41.

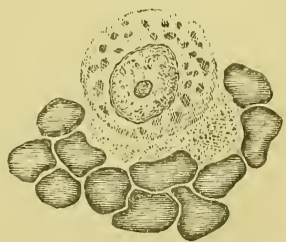

White and red blood corpuscles from a branch of the pulmonary vein. Cattle Plaśue. A quantity of germinal macter or bioplasm in a verv minute state of divi. sion is seen arolind the lower part of the white corpuscle. $\overline{\mathbf{1 0}}, \frac{\mathbf{3}}{0} \overline{0} \mathrm{o}$ of an inch $-\times 1800$.

$$
\times 1,800, \text { p. } 65 \text {. }
$$



In the blood removed from the smaller vessels, in the mucus secretions of the mouth, intestinal canal, and in the milk of animals suffering from this disorder, I have found multitudes of minute particles of bioplasm, which, as long as they remain alive, are, without doubt, disease-carrying particles. Disease germs are figured in Plates XIV and $\mathrm{XV}$, and in Plates XX to XXIII. Their characters will be further discussed in the Section on the "Nature of Disease Germs," p. I6I.

The disease germs of many contagious fevers will retain their vitality in water and other fluids for a length of time, and there is reason for concluding that some of these poisons not only grow and multiply in fluids different from any in the organism, but that in the course of such growth and multiplication, they acquire still more virulent properties. Dr. C. Macnamara has discovered that cholera poison in water after exposure to the sun for a few hours, becomes extremely virulent, and that this period corresponds with the development of multitudes of vibrios; but that after the lapse of a day or two, when the vibrios will have disappeared and given place to ciliated animalcules, the fluid may be taken with impunity.

Syphilitic Disease Germs.-The syphilitic germ is another of those remarkably special living poisons which may be suspended in serum and other fluids, and retain its vitality for a length of time.

II. 
There is reason for thinking that a single epithelial cell may carry multitudes of active particles of syphilitic poison, one of which introduced into the blood or lymph of a healthy person would probably grow and multiply, and give rise to pathological changes characteristic of, and quite peculiar to this particular poison.

We know that the syphilitic poison may retain its specific characters in the organism for years, from time to time giving rise to local pathological phenomena, which are characteristic of this kind of morbid bioplasm. It is impossible from the facts of the case to arrive at any other conclusion than this: that a certain portion of the living matter remains in the organism, and that under certain favourable circumstances this grows and multiplies, producing disease. Particles of this virulent poison may be transferred from the infected organism to a healthy one, and contaminate it, even many years after its introduction into the first had taken place. Of syphilitic bioplasm there are different kinds, giving rise to different pathological affections belonging to the syphilitic class. Indeed, some facts render it probable that there are several different species or varieties of syphilitic poison, instead of only one or two.

One very remarkable property of the poison of syphilis is, that it may be re-inoculated into the same organism over and over again, until inoculation ceases to produce any specific effect. As soon as this is the 
case, the organism is said to be "protected." But such protection sometimes cannot be procured until successive inoculations have been practised during several months, and, as has been remarked, the remedy is in many respects worse than the disease, besides being, and on many grounds, quite unjustifiable.

Living Disease Germs in Secretions.-The living germs of many fevers pass from the blood into the secretions. The urine, the secretions from the mucous membrane of.the nose, mouth, stomach, and intestinal canal, contain them in large numbers. There is reason to think they may also escape in the secretion of the sweat and sebaceous glands. In the excrements there can be no doubt disease germs exist in vast numbers in typhoid fever, in cholera, and in some other diseases. Even in the milk, in the tears, in the saliva, they are present. Some of the living particles in the milk from a cow suffering from Cattle Plague are represented in Figs. 42 and 44, plate XV, and in Fig. 43, particles of bioplasm as well as fungi are seen in vaginal mucus from another animal suffering from the same disease. The particles of bioplasm in which I believe the contagious properties reside, are situated immediately under the letter $d$ in Fig. 43. Below and to the left of these particles are sporules of fungi, which cannot be mistaken. Their spherical form, sharp, well-defined outline, and the high retractive power of the envelope, positively distinguish them from disease germs. 
Living tubercle germs will not be considered as very closely related to the contagious particles which are the active agents in the propagation of contagious fevers. There is, however, reason to think that particles of living growing tubercle exist sufficiently minute to be supported by the atmosphere and carried long distances; while there are many facts which are considered by some sufficiently conclusive to justify the opinion that tubercular disease of the lungs is at least in some instances contagious. And it is certain that the most recent observations in connection with the question of the nature and mode of propagation of tubercle, so far from militating against this view, tend rather to support it. That tubercle is not eminently contagious is certain, while the probabilities of minute particles of living growing tubercle escaping into the air while it remains in the air-cells of the lungs, or rising in a living state into the atmosphere from the sputum after its expectoration, are not great. At the same time neither circumstance can be regarded as impossible, neither view can be held to be untenable.

The manner in which the bioplasm of tubercle multiplies is represented in Fig. 46, pl. XV, where it is seen extending round a small artery in the areolar tissue of the external coat. The living particles obstructed in the vessel make their way through its lining membrane and between the fibres of the muscular coat, until they reach the arcolar tissue 
BIOPLASM, EVER, CANCER, TUBERCLI.

Fig. 42.

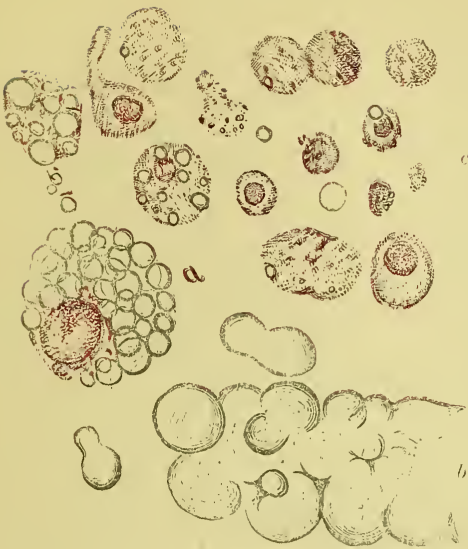

Nilk, $a$, Colostrum corpuscle with bioplasm; $b$, oily matter forming cplindrical masses ; $c$ s srow serminal matter or bioplasm, the so-called puslike corpuscles in the milk of a cow suffering from cattle plague. $\times 700$. p. 67.

Fig. 44.

(x)

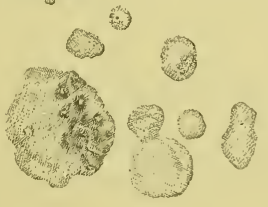

sine o: the smallest mitsses of bioplasm (uct colvured, in milk in cattle plague. $\times 2,800$. p. 67 .
Fig. 43.
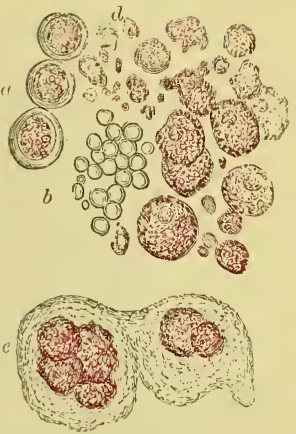

Wuoplasm from visima. cialle plisit. rapialy, $a$. Sporales of fungi; $b$, sinall sporules of fungi; $\boldsymbol{c}$, corpuscles aud pus like cells The manner in which th. rapid multiplication of imperfectly formect epichelial ceils takes place is represented at $e$. Observe the concentric layer's of the imperfectly hardened formed material $\times 700$. p. 67 .

Fig. 45.

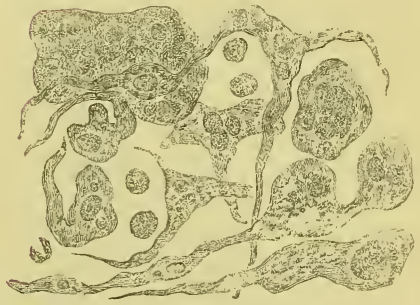

Bioplasm (not coloured) in cancer cella from a case of cancer of the bladder. $\times 215 . \quad$ p. 67 .

Fig. 46.

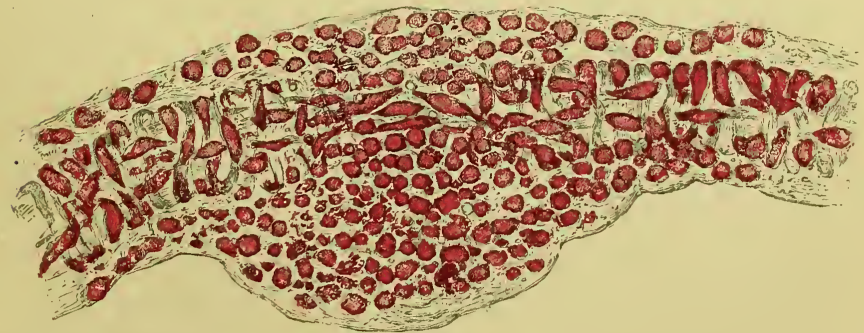

I'ubercle bioplasm in the coats of a small artery of the pra nater, thom a cist of ucheruth intiulu maliom. Death three weeks after the commencement of the attack. $x 215 . p$ is. זัญ

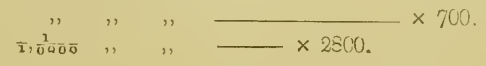



outside, where they grow and multiply. By their accumulation, the pressure upon the vessel becomes greater, and at last its calibre will be completely obliterated. From such tubercle collections minute bioplasts may be readily detached, and after having found their way into a pervious lymphatic vessel, or blood capillary, might be carried to distant parts and grow there. In this way tubercles are developed in many different parts of the body and in the substance of many different tissues and organs. If a particle of fluid, holding living tubercle-germs in suspension, were introduced by inoculation into a weakly organism, the disease might be produced.

Cancer Germs.-Whilst it is almost certain cancer could be introduced by direct inoculation into the organism of a healthy person, many circumstances render it in the highest degree improbable that living germs detached from the growth, could, under any circumstances, gain access to another organism through the air breathed, or in any other manner pass into the blood or tissues, as long as the surface remained uninjured. Cancer germs would probably live for some time in animal fluids out of the body, and it is by no means impossible that we may succeed in growing them in glass vessels away from their natural seat of growth, and watch the changes which occur under our microscopes ; but it is exceedingly doubtful if these germs would long retain their vitality if removed from the fluid which nourished them. Some 
cancer germs are represented amongst the large cancer cells figured in Plate VI, fig. I7, and in Plate XV, fig. 45. Between the cancer germ, which cannot be conveyed by the air from the diseased organism to one not infected,-and the germ of scarlatina, which will retain its vitality for weeks after it has escaped from the organism in which it was produced, and may readily gain access to healthy organisms in the air they breathe,-we have examples of living disease germs manifesting powers of retaining their vitality when free in many different degrees. In other words, these poisons differ remarkably in the facility with which they are propagated, or spread from person to person. All exhibit the same appearances, though they differ remarkably in power. The capacity for resisting death, due to some inherent power and not to their chemical composition, varies much, some being capable of living for weeks or months away from the fluids of the body, while others die within a very short time of their removal from the seat of growth.

In this section a number of remarkable forms of contagious matter or virus have been referred to. These resemble one another in general appearance. Neither by its form, chemical composition, or other demonstrable properties, could the vaccine germ be distinguished from the small-pox germ, or the pusgerm from either. All are like the minute particles 
of bioplasm of the blood from which they differ so remarkably in power. Of the conditions under which these germs are produced, and of the manner in which the rapidly-multiplying matter acquires its new and marvellous specific powers, we have very much yet to learn. Those who have committed themselves to physical views of life, undisturbed by the signal failure of all their attempts to demonstrate facts in favour of their hypothesis, must needs resort to the wretched expedient of suggesting that differences of form, structure, and composition, may be discovered at some future time. These, when discovered, they prophecy will fully account for the marvellous differences in power manifested by the different kinds of formless, structureless, living matter, healthy and morbid, which has hitherto defied chemical analysis. Yet it is imagined that the difference between the chemistry of the small-pox germ, and that of the ordinary pus germ, will be found sufficient to fully account for the different actions of the two. When chemical science shall have progressed sufficiently to enable chemistry to demenstrate the highly complex chemical phenomena of these germs, their marvellous collocations and combinations will, doubtless, be exhibited to the public. In the meantime chemists and physicists. await with confidence the fulfilment of their prophecies, and decline to take notice of any facts that have been, or that may be advanced, against their untenable doctrines. 


\section{INTRODUCTION OF DISEASE GERMS INTO THE BODY AND OF THEIR ESCAPE.}

Disease Germs in Air, Water, and Food.-Such minute particles as those described in the last section are liable to be suspended in the air we breathe, or they may be disseminated through the water we drink, or hidden in the food we eat. Not only so, but there is reason to think that some kinds of these contagious disease germs even grow and multiply outside the body. Indeed, it appears probable that a few actually acquire their virulent properties after they have left the organism in which they have been developed, while they remain immersed in some extraneous medium containing the proper elements for their nutrition and further development.

That such particles as those represented are sufficiently light to be supported in the air and carried long distances by air currents, is proved by the fact that the scales of the wings of insects and starch corpuscles, each of which weighs more than a hundred times as much, are supported by the slight currents of air in our ordinary rooms, deposited upon shelves, and even transported long distances. The careful examination of the particles suspended in the air as seen in a sunbeam, renders all further remarks upon this part of the question superfluous. 
It is well known that many contagious diseases may be propagated by the breath. Of this we have direct proof as regards the poison of cattle plague, small-pox, scarlet fever, and some others. Küchenmeister made a sheep breathe, during one hour, air which was made to traverse the shirt worn for twelve hours by a patient who was suffering from small-pox. Five days afterwards the disease commenced, and by the eighth day a well-marked eruption of variola was developed upon the sheep. Glanders is another contagious disease, and of a most fatal kind, which is propagated through the air, and, although direct inoculation is usually necessary for its communication to man, in one case which fell under my observation, the evidence that the fatal disease was communicated by the air was very strong indeed, if not perfectly conclusive.

I have endeavoured to ascertain if such particles as I have described could be actually demonstrated by microscopical investigation with the aid of the highest powers, in the air which was known to contain a form of contagious poison. Mr. Crookes made some investigations upon this part of the subject in connection with the Cattle Plague Inquiry, and he obtained some very interesting and important experimental results. He was good enough to give me a tube which contained a piece of cotton wool that had been exposed to the breath of a diseased animal, and was fully impregnated with contagious 
matter, and another tube through which the breath of an animal, dying from the disease, had been passed. I carefully moistened the wool and the tube with perfectly pure glycerine, and subjected the fluid to examination with the $\frac{1}{5} 0$ th.

Although in each case I have seen particles resembling those already many times referred to, I do not attach much importance to these two isolated observations, or look upon them as conclusive, for in the first place the number of minute particles of various kinds present makes it impossible to identify with any certainty the supposed particles of contagium; secondly, as there are undoubted sporules of fungi, I could not prove that the very minute particles which I should be inclined to regard as the contagium had not been developed from these; and, thirdly, in such an enquiry it would be wrong in principle to place much reliance upon only one or two observations.

At the same time it is only right to state that the piece of wool in one of the tubes, through which the breath had been passed, exhibited a much greater number of minute particles, resembling those which I regard as particles of contagium, than were obtained from the second piece of wool at the other end of the same tube, by which the air was subjected to a second filtration. It does, therefore, appear possible to determine the question from this experimental side. The microscopical part of the investigation presents 
many practical difficulties, and any one entering upon it should perform, in the first instance, a great many preliminary experiments in order to determine the most convenient and most delicate methods of examination.

Many disease germs will retain their vitality in water, and there can be no doubt that many are introduced into the organism in this medium only. From the evidence that has been adduced, it is certain that both typhoid fever and cholera are disseminated by drinking water, and almost as certain that if pure wholesome water had been supplied to the victims instead of the disease-carrying fluid, many lives would have been saved. That some disease germs will live for a considerable time in water, may be proved by experiment. Pus-corpuscles from the bladder may be kept alive in water, to which a very little albumen or serum has been added. The gonorrhœal poisongerm, as well as the bioplast capable of producing purulent ophthalmia, will also retain their vitality in water, and probably even in water containing soap and other things dissolved in it. Much of the water containing disease-producing germs is very rich in organic matter, and the products of the decomposition of organic matter. Hence it is alu'ays desirable to discard such water for drinking or culinary purposes. Although there can be no doubt that many bad specimens of water are perfectly harmless, as we are unable to say whether disease germs are actually 
present or not in any given specimen, the only safe course is to condemn all water rich in dissolved and suspended organic matter, and to subject all doubtful specimens to the action of Condy's fluid, boiling and filtration, before its use is permitted.

Various kinds of food afford a nidus for disease germs. Articles of diet should never be kept in the sick room longer than necessary, and the healthy should never be permitted to partake of food which had been left for some time exposed to the air of the sick room. In milk and weak soup it is probable some disease germs might retain their vitality for a length of time, and perhaps in warm weather grow and multiply to a great extent; and although a number of persons might perhaps take these fluids with impunity, or be in other ways exposed to the influence of disease germs, the probability that but one here and there would be attacked, renders the slightest carelessness on the part of the attendants highly culpable, and deserving of severe punishment.

As is well known, the poison of scarlet fever, smallpox, and some other contagious diseases, may be retained for a length of time, in a living state, in the clothes of the sick, in the bedding, hangings, furniture, on the paper of the walls, and even in the floor, of the sick room. It is probable that in these cases the living germs are embedded in a portion of the poisonous matter itself or the secretion in which it 
was present, or in some other kind of organic matter which has dried up. Thus some of the germs become protected in the same manner as the living germs of vaccinia and of variola are preserved in the partially dried lymph. In this way, as is well known, they will retain their vitality even for many weeks upon the point of a lancet or upon a glass or ivory plate.

On Detecting Disease Germs in the Air.-Various methods for detecting germs in the air have already been referred to when the subject of vegetable germs was under consideration. It remains now only to describe the apparatus recently devised by Dr. Maddox, for collecting from the atmosphere all foreign particles suspended in it. A full account of the instrument in question is given in the "Monthly Microscopical Journal” for June Ist, I870, p. 286. The arrangement will be understood, if the figures in Plate XVI, copied from those illustrating Dr. Maddox's paper, be referred to.

In Fig. 47, the instrument is so placed as to be used like a vane outside the house. By slipping off the vane, and placing the rest of the apparatus in a vertical instead of horizontal position, and attaching to it another short tube (Fig. $5 \mathrm{I}$ ) with a metal pipe terminating in a small funnel, it can be used over a cesspool, in any nook or corner, in an ordinary room, in a cow-shed or stable, or in a ward near a patient suffering from any infectious disease. A draught of 
air is produced by placing a lighted lamp under the funnel, as shown in the drawing.

When the apparatus is to be used vertically, the extra brass tube (Fig. $5 \mathrm{I}$ ) is to be slipped over the end, and the whole is to be supported by one of the retort-holders of the laboratory, or in any convenient way, and beneath the open end of the little funnel is to be placed a lighted oil or spirit lamp, in order that a current of air may be generated. Its position above the surface of the ground may vary from a few to many inches or feet, according to choice. Dr. Maddox thinks about 3 feet the proper height. If it be desired to test the efficacy of various vapours or fluids as disinfectants for the purpose of destroying the living germs, an extra nozzle (Fig. 50) made as a flat box having a small nozzle projecting from the cover, looking towards the thin glass, can be screwed on the ordinary one. "If this narrow box, which should be platinized inside, be packed with fine cotton wool, damped at one part with any article, as creosote, tincture of the muriate of iron, or solution of quinine, or a particle of hypochlorite of lime placed at one part, the particles from the air may be supposed to be entrapped amongst the fibres; but the cotton-wool should, before use, be soaked in absolute alcohol for half an hour, and squeezed dry between heated plates of glass; or gun-cottoin might be used if thought more free from error. The wool from opposite the nozzle might, in each case, be 
DR. MADDOX'S GERM COLLECTING APPARATUS.

Fig. 47.

$b$

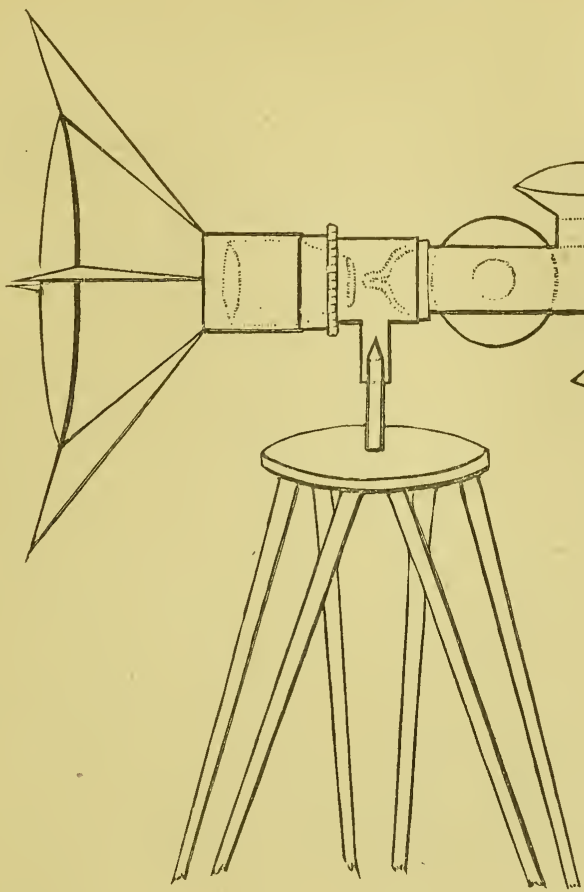

Dr. Maddox's apparatus for collecting germs and solid particles suspended in the atmosphere The anr enters at $a$ and through the smaller fuunels above ind below, it passes throue he narrow

nozzle in the central part of the figure and strikes against the thin glass placed imme-<smiles>CCCCCCCCCCCCCCCCC</smilesdiately beneath This is smeared with slycerine or purified treacle and to it all olycerine or purified treacle and to it all
foreisn particles adhere. The air then escapes through some holes at the circum. ference of the glise and then passes away. p. 77 .

Fig. 51.

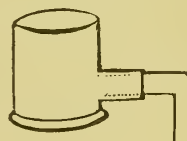

The spring for retaining the thin glass in position, seen in eection.

Fin. 49.

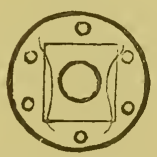

Fig. 50.

I he trir slass on its plate with holes around the circumference, through which the air escapes.

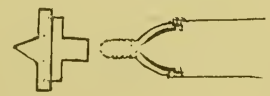

Screwed pipe witk fine extra nozzle for experiments with disinfectants. p 78.

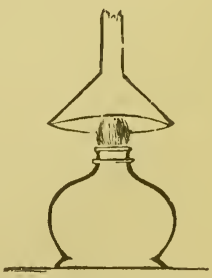

Tube and lamp for causing a drausht throush the apparatus when it is used in a room or confined sface. The vane is removed and the a pparatus arranged vertically. p. 78 .

[To face pase 78. 

removed with a pair of fine scissors and forceps, placed in a deep growing slide with some medium, and set aside for observation."

The advantages claimed by Dr. Maddox for this apparatus are ready application at any spot, the collection of the atmospheric particles into a small space in such a manner that they may be at once microscopically examined with a $\frac{1}{16}$ th or $\frac{1}{20}$ th objective, placed in some form of cultivating apparatus for further observation, or mounted permanently.

Dr. Maddox has found besides particles of various organic and mineral matters, pollen grains, minute germs of various fungi or protophytes, and excessively minute bodies, "molecules," "globules," \&c. These varied in number according to the force of the wind, dryness of the ground, and other circumstances.

At the close of his paper Dr. Maddox remarks :"The examination of the collections made over forty days has shown that in this immediate locality (Woolstone, near Southampton), at this period (May), the air cannot be considered as loaded with microscopic germs; the largest number visible and counted as such on one cover being twenty-one (not including bacteroid bodies). A few only have germinated; they are under observation." 
Mode of Entrance of Disease Germs.

Of the Passage of the Disease Germs into the Blood. -In all cases in which disease germs produce their characteristic effects, they reach the blood. Until they have entered this fluid there is no possibility of their exerting any deleterious effects upon the system. Having entered the blood, they grow and multiply, and, as we shall see presently, become obstructed in the smaller capillary vessels, in and around which those changes occur, which give to each particular contagious fever the characteristics peculiar to it, and enable us to recognize and define it.

With regard to the manner in which the minute particles of contagious germinal matter gain access to the blood, there has been much difference of opinion, but many circumstances render it certain that they may reach it from many different surfaces.

Suspended in the air, they may pass towards or into the air-cells of the lung at every inspiration. Some of the lightest particles might reach the ultimate aircells where an exceedingly delicate membrane easily penetrated by living particles alone separates them from the blood.

If living disease-germs fell upon the soft mucous lining of the air passages, they would there find a material if not adapted for their nutrition, at least favourable for preserving them in a living state. Through this they would gradually make their way 
into the capillary vessels or lymphatics, ramifying in the tissues beneath. But besides gaining access to the blood of man's organism through the breathing apparatus, the particles of contagious germinal matter may pass into the stomach with the food, and make their way into the blood after traversing the delicate mucous covering of that organ. They might get into some of the mucous follicles, and after growing and multiplying there, some of the particles might reach the vessels which lie just beneath.

As has been already mentioned, some diseasegerms, like the lower vegetable and animal organisms, will live for a considerable time in water. But it must not be concluded that this fact tends in any way to favour the view that disease-germs are in fact animal or vegetable particles, for pus-corpuscles will not only live for a considerable period of time in water, holding in solution a very small quantity of animal matter, but they will grow and multiply. Of all media taking part in the wide diffusion of diseasegerms, and facilitating. their introduction into man's organism, water, there is reason to think, is the most general, and, perhaps with the exception of air, the most effective.

Lastly, the particles of contagious bioplasm or germinal matter may enter the body through the skin. In some states of the cutaneous surface, the epidermis is swollen, softened, and moist, and living particles would easily insinuate themselves in the

II. 
slight chinks which exist between the epithelial cells, and gradually make their way into the capillary vessels beneath.

I have heard that a well-known physicist has said, that if his mouth and nose were protected by a cotton-wool respirator, he would not hesitate to sleep in a bed which had been occupied by a patient suffering from scarlatina. Although we are much in want of information concerning the precise mode of ingress of poison-germs, I trust that so foolish and utterly useless an experiment will not be made. If the experimenter took the disease, the fact would add nothing whatever to our knowledge, while if he escaped scathless, the fact could be more satisfactorily explained than by attributing it to the efficiency of the vaunted cotton-wool respirator. Germs so minute as those of contagious diseases will find their way into the blood by other channels than the air passages or alimentary canal. The mucous membrane of the conjunctiva, covering the front of the eye, is soft and moist. and they could easily worm their way between the soft epithelial-cells, and thus reach the blood. They might readily make their way into a hair-follicle, or pass down the tube of a sweat-gland. There are also many passages opening upon the external surface of the body by which such minute living, moving particles might gain access to the moist tissues, and make their way into the blood. 
In some instances it seems that the disease-germs gain access to lymphatic vessels, and grow and multiply there, causing abscess in some of the lymphatic glands. The blood is sometimes infected as well, while in some cases, in which there is serious inflammation of lymphatic glands, it appears to escape contamination.

The living particles of contagious germinal matter readily find their way into the blood if there is an open wound upon any part of the body, and if, as is not unfrequently the case in patients suffering from wounds, the blood is not in a healthy state, the poison grows and multiplies rapidly. To introduce cases of contagious fever into a ward where a number of persons who have undergone surgical operations are iying, would be a cruel and, though not so in law, a criminal act. To place a surgical case in a medical ward in which fever cases of any kind are admitted, is most dangerous. Even slight wounds like those made in operations upon the eye do not heal readily, and out of a number of such cases a large percentage will certainly go wrong. Accoucheurs are well aware of the horrible fatality of contagious poisons when introduced among lying-in women, and are but too often painfully familiar with the dread certainty with which these minute germs make their way into the blood, poison the living matter of the body, and destroy life in the puerperal state. For this reason lying-in wards can never be maintained in any general

$$
\text { G } 2
$$


hospital, if cases of disease depending upon contagious poisons are also admitted. It is probable that if cases of surgical operations were placed in buildings apart from medical cases, the mortality from pyæmia and allied diseases, would be considerably reduced.

State of Vessels favouring the Entrance of Diseasegerms.-Admitting, then, that it has been proved that contagious poisons generally consist of minute particles of living matter or bioplasm, and that this living matter, to produce its characteristic effects upon the system, must enter the blood, let us inquire how the living particles gain an entrance into the vascular system in cases in which no wound is made, in which there is no solution of continuity in any part of the vascular walls. The fact that, of a number of persons equally exposed to the influence of contagium, some will contract the disease, while the majority will escape, may be accounted for by supposing either that in the latter case the particles do not really penetrate the vascular wall at all, or that, they are in some way destroyed as soon as they traverse the wall of the capillary and come into contact with the blood.

We must therefore enquire what circumstances would favour or assist the passage of the living particles of the contagious material through the vascuiar membrane into the blood. Thin-walled capillary vessels, as is well known, come very near to the free surface in many parts of the body, and if these capillaries are 
distended with blood, their walls are rendered still thinner, and they come still nearer to the surface. The capillaries of parts of the mucous membrane of the nose, mouth, fauces, and conjunctiva, even in a state of perfect health, are covered with a very thin layer of protective epithelium, while those of the aircells of the lung are practically bare. Through these, minute germs might readily pass. In many morbid states, the epithelial covering of the mucous membranes above enumerated, is very soft, and sometimes it is reduced to a thin layer of moist, pulpy mucous material in which any foreign particles would very readily become embedded. In such a material, contagious disease-germs would find a nidus suitable for their reception, and at the same time probably also soluble materials adapted for their nutrition. Having fallen into this, they would grow and multiply, and minute offsets from them might soon make their way to the external surface of the thin capillary walls.

When the capillaries are much stretched, as is always the case when they are fully distended with blood, the minute particles of living germinal matter or bioplasm of the blood, as well as diverticula from the white blood-corpuscles, readily make their way out of the capillaries through the walls with the blood serum, and grow and multiply in their new position. Even red blood-corpuscles, as is well known, often pass through the vascular walls under 
these circumstances. In many kinds of inflammation this commonly happens.

Every one who has been in the habit of making minute injections of the vessels of tissues must be acquainted with the fact that little longitudinal rents or fissures in the walls of the capillaries, quite wide enough for a red blood-corpuscle to pass through edgeways, are easily made. It is therefore quite certain that particles can pass from the interior of the capillary vessels outwards with the greatest readiness, and without the occurrence of any actual rupture of the vascular wall. There can, therefore, be no difficulty in explaining how the passage of disease-germs in the opposite direction in a similar state of the capillary wall takes place. These little particles, like other forms of bioplasm, possess inherent powers of movement, and would easily insinuate themselveș through any slight fissure which existed in the capillary wall. Such particles of living matter are even capable of passing considerable distances through the interstices of various tissues, like the living germs of some parasitic organisms, which, as is wcll known, often traverse a great extent of tissue before they arrive at the spot where they undergo development.

Again, it must be borne in mind that there are at. very short intervals in the capillary walls masses of bioplasm (nuclei), which increase considerably in size when supplied very freely with nutriment. These 
may divide and subdivide, and give rise to collections of little bioplasts "granular corpuscles," as seen in cases of inflammation of the pia mater, and also in cases of tubercular disease of the same membrane. The walls of the vessel are weak and liable to alterations in the situation of these nuclei, as the latter increase or diminish in size. Hence there is no difficulty in accounting for the passage of minute particles of the living contagious bioplasm in cases in which the capillary walls are diseased, and after they have been unduly stretched and have remained somewhat flaccid.

Now, the state of things referred to above-a soft moist state of the mucous surfaces, a dilated condition of the capillaries, combined with a weak, flaccid state of their walls, which always follows long-continued congesticn, and which is intimately connected with a weak heart's action and feeble condition of the nervous system, are the very conditions which would facilitate the passage of living germs,and is not this the state of things which exists in the organism about to be the victim of a contagious fever?

No doubt in these cases the composition of the blood is altered and its fluid constituents manifest a tendency to permeate the vascular walls more rcadily than in a perfectly healthy state. Such a state of blood would doubtless affect the action of the nervous centres presiding over the contraction of the arterial walls, and regulating the flow of blood through them, 
thereby influencing the nutrition of the part. In this way a relaxed state of the arterial walls and a congested state of capillary vessels might be induced, or already existing, might be increased. It is this low and but too often ill-defined weak state of health, which often persists for some weeks before the attack of contagious disease occurs, that we should endeavour to detect, and at once treat. Nay, it is almost certain that every serious acute disease dangerous to life to which we are subject is preceded by a condition of system which in many particulars is a departure from health. If this can be altered, the liability to the supervention of the acute attack no longer exists. It is in the direction of anticipating the occurrence of actual serious well-marked disease that those most earnest in advancing medicine may reasonably hope to do useful work. And it seems certain that the more minutely we investigate, the more likely shall we be to learn how to discover and to appreciate that slight departure from the healthy state which precedes, and often by some considerable time, the development of many of the most serious and most fatal maladies. Were our knowledge greater we might perhaps in many instances succeed in warding off altogether the threatened invasion of disease.

Minute investigation in connexion with disease has been most unwisely discouraged, by purely scientific men on the one hand, and by those who confine themselves to their practical medical duties on the 
other. By the first, because they think that medical practice affords occupation enough for one man; by the last, on the ground that scientific work unfits a man for the practical duties. It has too often happened that the very few who have devoted themselves to real medical enquiry, have been unfairly treated, and by the very persons who ought to have afforded them support. The time has now arrived when the incentives to this course should be openly condemned, as resulting from narrow ancient prejudice, which has long survived its allotted term. Every intelligent person will do his utmost to further those branches of investigation which have already exerted so great an influence upon the discovery of the wonderful changes which occur in man's body in health and disease, and therefore upon the progress of medicine.

Of the Presence of the Germs in the Capillaries.In every form of contagious disease, and during every period of its existence, the circulation through the capillaries is affected ; indeed, the essential phenomena of each special malady are due to changes in the quantity and quality of the contents of the capillary vessels. If recovery from the malady is rapid and complete, the capillary changes induced by the disease have been slight. If the disease terminates in death, th.e fatal result is occasioned by irreparable damage in and around the capillary vessels themselves, or it is occasioned by secondary changes in the tissues induced 
thereby. The character of the eruption is determined mainly, and in some cases entirely, by the abnormal state of the capillary circulation, and even in those instances in which local alterations in vascular tension are unquestionably associated with nervous disturbance, this is often induced indirectly by a primary change in the capillary circulation, by which the afferent nerve fibres passing to the ganglia, are influenced. Disturbance consequently occurs in the ganglion, and the central variation excited in the intensity of the current is conducted along the efferent vaso-motor arterial nerves. In consequence, many little arteries become dilated, and the vascularity of the area of tissue supplied by them is increased.

In all cases of contagious disease which I have examined, the same sort of living germinal or bioplastic matter has been discovered in the capillary vessels of many of the affected tissues of the body. In some parts the vessels appear to be quite filled with a "granular," more or less transparent material, which, when fresh, may be stained by the carmine fluid, and exhibits the characters of bioplasm, the particles of which are, however, exceedingly minute.

I cannot explain fully and satisfactorily why the contagious material collects principally in the capillaries of the skin and mucous membranes, but I would remark that the masses of bioplasm in connexion with the surface capillaries are large, and project into their interior, Plate XII, fig. 3I, p. 52 . Thus there are 
many little eminences by which the further passage of the germs might be interfered with. The vessels themselves change much in volume many times during every twenty-four hours; the canal being sometimes far too narrow to permit a red blood corpuscle to pass, Plate XXII, fig. 79, p. I04, while at others the tube is much dilated and filled with blood. Moreover, the capillaries often form loops, and sometimes little diverticula may be found here and there, in which particles might collect and accumulate to some extent, without the tube of the vessel being in any way obstructed.

The little particles of contagious matter having gained entrance into the blood and arrived at the superficial capillary, probably absorb nutrient material rapidly. It is possible that fibrin may become coagulated around these little bodies, just as if they were particles of pus, and the mass being too large to pass, may become impacted into some part of the capillary system. The large size of the white blood corpuscles in very many blood diseases is also a fact not generally known, although of great importance, which must not be lost sight of in considering this part of the question; but I cannot discuss it here. In those organs in which the circulation is slowest-as the spleen and liver - the conditions would be very favourable to the multiplication of such particles of living matter, and it is probable that in some cases the capillaries in these organs are principally affected in the 
early period of the disease. From the collections thus formed, particles may be carried to other parts.

State of Blood favourable to the Multiplication of Disease Germs. - No investigation is likely to be more fruitful in valuable results than a very careful inquiry into the microscopical and chemical characters of the blood just before its invasion by contagious disease germs, and the alterations effected by them during the period of incubation. There is much reason to think that certain states of blood are favourable to the multiplication of the poison, while others, perhaps, render its destruction almost certain.

It is at least doubtful if the growth and multiplication of every kind of disease germ will occur in perfectly healthy blood, even if introduced and mixed with it. Numerous facts, which will occur to every practitioner, render it far more probable that-at least in the case of the great majority of contagious fevers -a certain state of blood must be induced before the contagious poison can grow and multiply, and produce new germs. No one has, however, yet succeeded in ascertaining exactly in what particulars such altered blood differs from the perfectly healthy circulating fluid, but it is not a state of blood associated with a large number of red blood corpuscles, or with a highly active condition of the oxidizing processes ; nor is the condition under consideration brought about by living much in the open air, and by the plentiful supply of good wholesome food and water. 
Although little has been discovered concerning the state of blood favourable to the growth and multiplication of disease germs, it has long been known that when fever, inflammation, and other blood diseases have become established, the composition of the blood is altered, and even in a slight feverish attack which constitutes an ordinary cold, the chemistry of the blood is temporarily deranged. The extractive matters soluble in boiling water are present in undue proportion, and it is probable that this increase arises from insufficient oxidation. Various matters which in perfect health are very highly oxidized, so as to be eliminated in the form of carbonic acid, urea, and other substances which are readily excreted, remain in the blood unoxidized, or are very slowly and with difficulty eliminated in a suboxidized state. Thus there remains in the blood an excess of soluble material, which permeates the tissues much more readily than ordinary healthy serum. This transudes through the walls of the capillaries, and is appropriated by the bioplasm of the blood, of the vessels, and of the tissues. The bioplasts or masses of germinal matter invariably increase in size under these circumstances. By this increased growth of germinal matter, which invariably takes place in all inflammations and fevers, the close analogy existing between these two classes of diseases is clearly indicated.

One important change in the composition of the blood when fever has become established, may be 
demonstrated in a very simple manner. If the dried residue of the fever blood be extracted with boiling distilled water, it will be found that the proportion of matter dissolved out from the fever blood is much larger than that obtained from the healthy blood residue. Three specimens of blood taken from animals which died of the Cattle Plague, contained respectively, 2.9I, 2.22, and I.8I parts of soluble matter dissolved out by boiling water, or twice the quantity extracted from healthy ox blood. The exact amounts were as follows :-

\begin{tabular}{|c|c|c|c|c|c|}
\hline \multirow{3}{*}{$\begin{array}{l}\text { Solid matter obtained } \\
\text { by evaporating } 100 \\
\text { parts of blood } . . . .\end{array}$} & \multicolumn{2}{|c|}{ Healthy ox blood. } & \multicolumn{3}{|c|}{$\begin{array}{l}\text { Blood from Cattle } \\
\text { Plague. }\end{array}$} \\
\hline & I. & 2. & I. & 2. & 3. \\
\hline & 19.87 & $20 \cdot 63$ & $23 \cdot I$ & $22 \cdot 78$ & $24 \cdot 88$ \\
\hline $\begin{array}{c}\text { Substances soluble in } \\
\text { boiling water ...... }\end{array}$ & $\mathrm{I} \cdot 33$ & I'I I & $2 \cdot 91$ & $2 \cdot 22$ & $I \cdot 8 I$ \\
\hline
\end{tabular}

The solid matter of the two healthy specimens contained respectively 6.69 and 5.38 per cent. of matters soluble in boiling water, while the diseased specimens contained respectively $12 \cdot 62,9 \cdot 72$, and $7 \cdot 22$ per cent. So that not only is the percentage of the solid matters generally greatly increased in this form of fever, but the extractives and other substances soluble in boiling water are present in increased proportion. These substances probably constitute a pabulum, which is very readily appropriated by degraded forms of bioplasm.

Obstructicn of the Capillary Circulation.-In all 
diseases depending upon the presence of disease germs in the blood there is at length unmistakeable evidence of obstruction to the flow of blood through the capillary vessels of different parts of the body. If this obstruction is incomplete, and only affects a limited area of tissue here and there, the case terminates in recovery, but if, on the other hand, the capillaries of a considerable portion of the body are obstructed, and more especially if the heart's action in such a case should be weak, and the contractions of the left ventricle not sufficient to drive the blood forcibly towards those capillaries which may yet remain more or less pervious, the disease must be fatal, and probably during its early stage. It is therefore of the utmost importance in critical cases to excite the heart's action by giving remedies which are known to have this effect. See also page I4O.

The contagious disease germs in some instances, as has been already suggested, are perhaps enveloped in a coagulum of fibrin, and thus are formed little masses which would be too large to traverse the capillary vessels. Mr. Lee showed that if pus was injected into the blood of a living animal, coagulation of the fibrin of the blood immediately occurred. In the case of some contagious disease germs, it is possible that the coagulation of fibrin around the contagious particles may only increase the size to that of a white blood-corpuscle, or little larger, but a body even of this size would, under some circumstances, fail to pass, 
and being obstructed in its passage, further coagulation is necessarily occasioned, p. 9I. Thus many capillaries would be stopped up, and small patches of highly turgid and obstructed vessels would result. Soon the germs enveloped by the coagulum increase and multiply, and thus after a while the cavity of the capillary vessel appears to be entirely occupied by them, and no blood whatever can pass through. This often leads to complete disorganization, which will be again referred to.

In some cases the obstruction depends rather upon the increase of the bioplasm of the capillary walls, which occurs in all inflammations and fevers, Plate XXIV, p. I34, and is not due to the increase and accumulation of the contagious disease germs themselves.

But however the obstruction may be brought about, it is soon followed by most important changes, external to the vessels, in consequence of which the action of the tissues and organs involved becomes seriously deranged. It has been frequently proved that if, in certain states of the blood, particles of living matter allied to pus be introduced, phenomena which at length end in death, are occasioned. The blood cannot cease to circulate without the neighbouring tissues being deprived of nourishment, and if the obstruction remains complete for a few days, still more serious consequences ensue. Not only are the vessels themselves destroyed, but the adjacent textures are involved in the common ruin. Separation of the 
textures by the formation of sloughs not unfrequently occurs; but where neighbouring vessels and lymphatics remain healthy, the removal of disintegrated tissue is sometimes effected by absorption, in which case portions of the tissue or organ afterwards appear as if they had wasted.

With regard to the particular capillaries obstructed, it has been already remarked, that those of the cutaneous and mucous surfaces are most seriously involved in many contagious fevers, but these are by no means the only vessels affected. In some diseases the capillaries of the liver and spleen are the seat of change, while in certain forms, those of the lungs, kianeys, and other glands, and even those of the muscular and nervous tissues suffer to such an extent, that part of the organ may undergo most serious pathological change, or be completely destroyed.

Destruction of Vessels and Tissues.-Wasting of tissue, usually circumscribed, which not unfrequently follows a bad attack of contagious fever, is a direct consequence of the vascular changes which have been referred to. In such cases the organism is often seriously and permanently damaged, and the normal state can never be regained. There is not a tissue or organ in the body which is certain to escape the terrible consequences of a severe attack, but happily cases in which many organs in one individual are seriously damaged, are rare, for, as a general rule, when the disease is sufficiently severe to produce 
such a result, it ends fatally. Still, we meet with many instances, where serious local damage has happened, as, for example, where permanent local paralysis follows continued fever, diphtheria, and scarlatina, or destruction of the delicate textures which form the nervous portion of the organs of sight and hearing, especially as a consequence of the last condition. Nor is prolonged or permanent derangement of the health and imperfect nutrition an uncommon consequence of the changes effected in and around the capillaries in many cases of different kinds of contagious fever, which are due to the entrance of disease germs into the blood. A very good notion of the sort of change which occurs may be formed if the great alterations which are induced in the villi as a consequence of cholera, be carefully studied.

If such changes have affected an extensive tract of small intestine, it will be seen that the proper functions of this important surface can never again be properly discharged. Although, no doubt, in the healthy state there is a much greater extent of absorbing surface than is really required, it must be obvious that if this be very much reduced, as is the case after a. severe attack of cholera, the effective absorbing area will be too limited to take up the quantity of nutriment required to maintain the body in a state of health and vigour. Nor, after a careful consideration of the serious changes induced in the vessels and other tissues of the villi in cholera, shall we be surprised that serious 
attacks generally prove fatal. The obstructed vessels of the villi are represented in Plate XVII, figs. 52 to 59 , under a low magnifying power. The villi themselves are much smaller than in health, and some are completely disorganised (Fig. 57). Lieberkuhn's follicles are also seen to be shrunken, short, and wasted, and some have completely degenerated (Fig. 59). In Fig. 58 the narrow openings of wasted follicles are represented. These are very much smaller, and are separated from one another by a much greater distance than in health. Many of the vessels represented in these drawings are so changed and disorganised, that it is impossible they could ever again have transmitted blood. Had the patient recovered, many of the villi figured would have disappeared.

The capillaries in many of the villi have wasted in a manner and to an extent which is very remarkable. A specimen has been represented in Pl. XVII, fig. 55, which shows the alterations very distinctly, although they have not yet proceeded to an extreme degree. In Pls. XVIII, XIX, a more advanced stage of disorganisation, is represented. At the summit of the villus in Figs. 60, 61, p. 102, many of the capillaries have become reduced to mere lines, and the texture a short distance from the surface has wasted; indeed much of it had completely disappeared. In the intervals between the lines which mark the positions occupied by the capillaries is a little indeterminate tissue, in which several oil-globules are seen. 
In Figs. 55, 62, the vessels have not wasted to the same degree, but their outline is irregular, and they are filled with an almost colourless material. A greater quantity of the tissue of the villus remains in the meshes of the capillaries in Fig. 60 than in Fig. 63 . It is clear that the blood could not have circulated at all in these vessels for some time before death. Any blood that remained stagnant in the larger ones had become altered. Its colouring matter had disappeared, proving that many days had elapsed since the obstruction had first occurred. Those constituents of the tissues which were incapable of absorption have undergone great change. Among the resulting products is fatty matter in considerable quantity (Fig. 6I).

In some cases there was demonstrative proof that some time before death blood had actually passed through the capillary walls into the surrounding textures. Crystals of hæmatoidin, as well as oil-globules, were found in considerable number in this situation, as represented in Fig. 6I. This circumstance proves that the villus had not been in a healthy condition, even for some time before the attack.

Villi exhibiting the structural alterations described cannot be organs of absorption. Neither could secretion have taken place from the follicles. The passage of fluid out of the vessels must have ceased long before they became reduced to the state figured. They must now be regarded as mere processes of de- 
CAPILIARIES OF VILLI. CHOLERA.

Fig. 52.
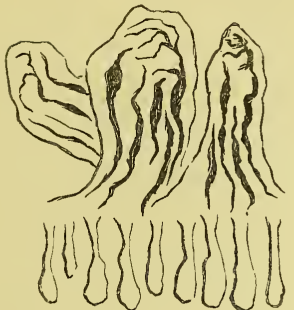

Fig. 53.
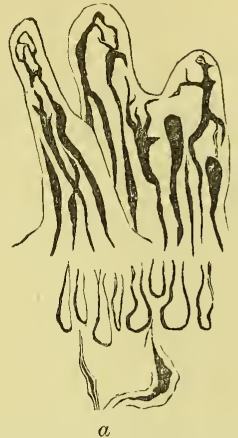

Fis. 54.

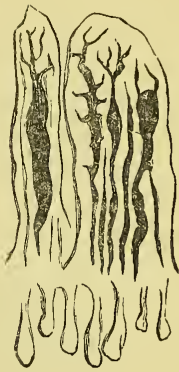

Tertical sections through mucous rnembrane of small intestives in cases of cholera showing Tessels of villi and wasted Lueberkubn's follicles $a$ small arteries in sub. mucous areolar tissue filled with clots. $\times 40$. p. 99 .

Fig. 55.

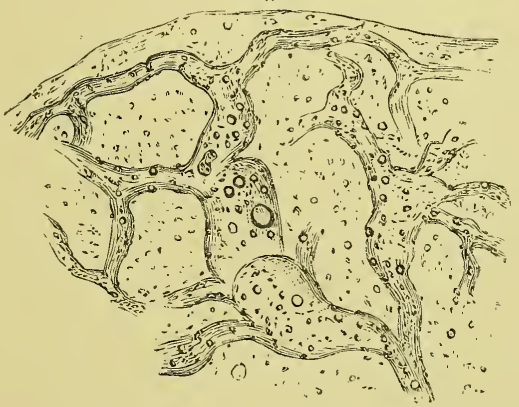

Fig. 56.

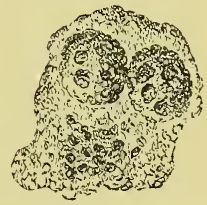

Cell-like mass represeented at $b$. Fir. 62. The dark bodies in tae lower part may be tactema $\times 1800$.

Vessel with bulgings consequent upon obstruction. From the surrumit of a villus, (Cholerd, case 4) $\times 215$. Oil globules are seen in sreat number in the vessel itself and in the tissue external to it. pp 99, 113.

Fig. $\dot{\text { if. }}$

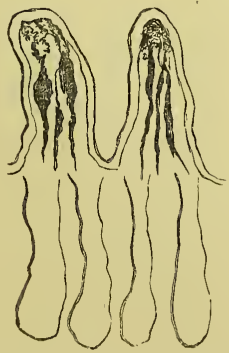

Villi of small intestine, cholera, sho ins distencled vessels of villi with complete disorgavitation of capillaries and tissues at the summit $\times 40$. $\mathrm{p}, 99$

$\frac{1}{10} \overline{0}$ of an inch

Fig. 53.

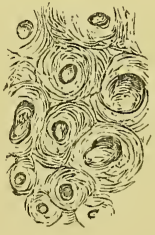

Orifices of Iieberkuhn's follicles of small intes tine-much wasted. $x \pm 0$ $\times 40$.
59.

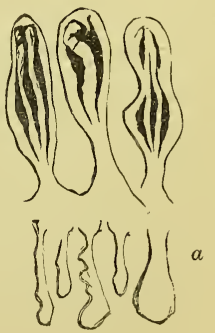

Irregular and much alterea villi. Cholera $a$. Jieberkukn's follicles, mich altered, warted and desenerated. $\quad x \neq 0 . \quad$ p 99. $\frac{1}{1000} \quad, \quad, \quad \times 215$. 

generated tissue, useless to the economy, and destined to be removed, and their place occupied by new organs, if life had been preserved.

The changes affecting the capillary vessels as they appear under high powers, will be understood by reference to Figs. 55, 60, to 67 . Fig. 64 shows the capillaries of the villus in an almost healthy condition.

It is quite certain that the morbid changes delineated in these drawings must have been progressing some time previous to the attack which destroyed life. It may be confidently affirmed that such changes as those described could not have taken place in a few days. There is sometimes evidence of alterations which must have been going on, even for weeks before death. The kind of degeneration which has been observed obviously requires some time for iis completion, although I have not the data to enable me to fix the precise period. The time requisite for the changes which occur in blood-clots can be ascertained accurately in some cases, and we have no reason for inferring that the red blood-corpuscles could be much more quickly disintegrated in the tissue of the villi, or hæmatoidin crystals formed in a shorter time, than in other situations.

In many of the specimens of small intestine from cholera cases I have found villi in every stage of wasting-the villus in which the change has only just commenced, and villi of which all that remained were little stunted elevations, projecting slightly from the surface of the mucous memprane $\mathrm{Had}$ the patient

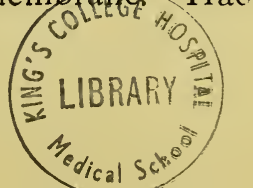


recovered, I am of opinion that new villi would have been formed, and to some extent have replaced those which had been removed. As I have already remarked, in a given area of intestine in cholera cases there are fewer villi and fewer Lieberkuhn's follicles than in health, and I believe that many victims of this disease had been suffering from degeneration of their villi for a long while before the occurrence of the attack of cholera, which proved fatal. The constant introduction of bad food and water, and in many instances terrible deficiẹcy of food of all kinds, will sufficiently account for the marked changes which have been described. I think the evidence advanced in favour of the view that healthy persons die of cholera is defective and inconclusive, and believe, if this scourge is ever to be prevented, it will be by constant and unremitting attention to the food and general habits of life of the poor, not merely while we are appalled by the actual presence of the scourge, but at all times. There seems reason for thinking that it is possible by good management to prevent people from being attacked hy cholera. Have we not reason to conclude that much may be done to prevent people from becoming subjects for the cholera poison? We know, alas! that we can do little, sadly little, to cure those attacked-though, perhaps, very much to improve the health of those liable to attack. We might thus mitigate to some extent the severity of the disease, and improve the patients' chances of recovery. I should waver in these views 
Fig. 60.

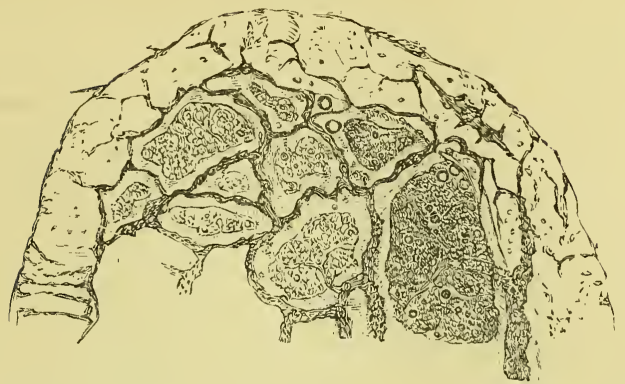

Shrunken and altered vessels from the summit of a villus Jejunum. (Cholera, case 5 .) Thickening of apparent 'basement membrane.' $\times 700$. p. 100.

Fig. 6l.

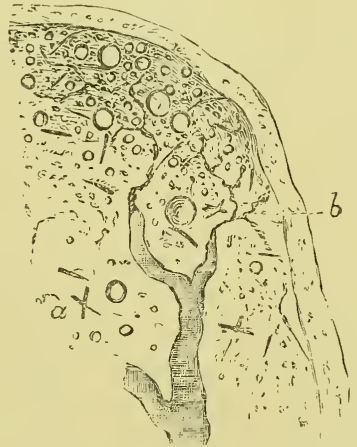

Part of the summit of a villus (Cholera, case 6.) $\boldsymbol{a}$, crystals of hæmatoidin. The vessel was pervious up to the point marked $b$ bevond which mere lines were discernible. The norma! tissue of the villus had completely disappeareu, and zumerous oil globules were disseminated through what iemained. $\times 700$. pp. 100, 113.

Fig. 6?.

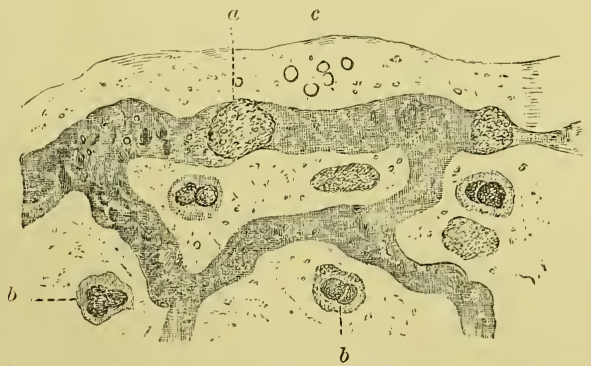

Altered capillaries, from the summit of a villus. (Cholera, case 1.) a represents a larke mass of germinal matter in the vessel, crobably an altered white blood corpuscle $b$ some cells appareutiy in the tissue of the villus, perhaps in the lacteal; one of these is represented more highly magnified in Fis. 56, Plate xvii. c, oil globules. $\times 700, \quad p .100$. 
(1) 


\section{VILLI IN CHOLERA.}

Fig. 63.

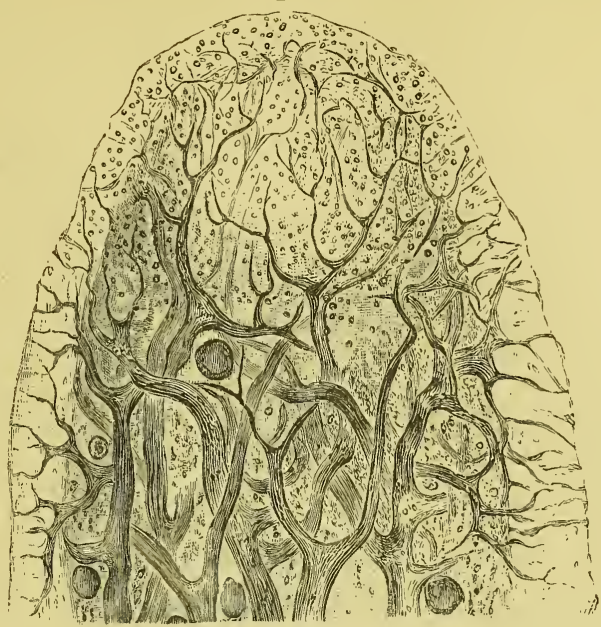

Summit of a villus. Jejunum. (Case 5.) Showing shrunken and wasted vessels and thickeniug of apparent 'basement membrane " of villus $\times 700$. p. 101.

Fig. 64.

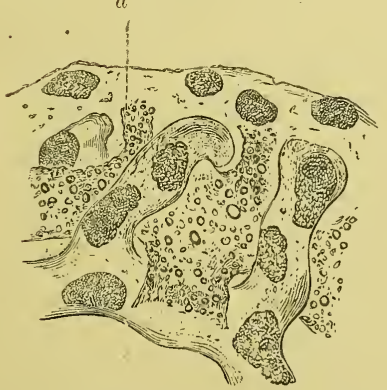

Summit of a villus from the jejunum. (Case 4.) Nearly healthy, $a$, lacteal. $\times 700$

Fig. 66.

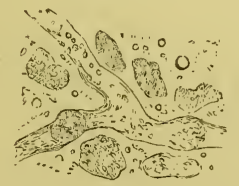

Capillaries and bodies external to the vessel. (Case 3.) $\times 700$. p. 101.
F1g. 65.

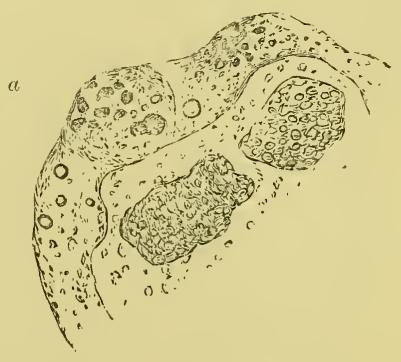

Capillary vessels, from the summit of a villus Containing a large mass with dark pigment granules and oil globuies in its interior. In various places very minute bioplasts are seen $\times 1,800$. p. 101 .

Fig. 67

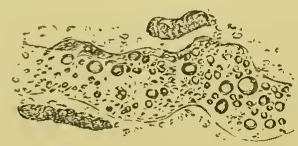

Vessels from the summit of a villus. Case 3.) Containing numerous oil slobules, $\times 700$, p. 101 . 

if I should obtain but a single specimen of small intestine in which I could not demonstrate diseased and altered villi. So far I have found them, without exception, in every case I have examined, and hence I have been led to form the above opinion, which becomes stronger as I work on.*

Multiplication of the Disease Germs in the Infected Organism.-From the observations already advanced concerning the size of the smallest living particles capable of growing and multiplying, it will be inferred that the actual quantity of contagious bioplasm sufficient to produce a contagious disease is wonderfully small, and that within the organism this minute particle multiplies a million-fold.

The contagious disease germs, like particles of germinal matter in inflammation, multiply enormously, not only in the blood vessels (Plates XX and XXI), but after having passed through the capillary walls, and gained the interstices of the tissues, Plate XXII, they grow there, and not only

* I regret to have to notice here that a distinguished pathologist has stated that he has failed to confirm my observations upon the villi. It would have been but fair had he taken the trouble to look at my specimens before condemning my statements. It is probable he did not employ a method of examination which would afford a chance of success - certain that he did not proceed as recommended. Such hasty and confident assertions are calculated to excite distrust in the minds of many, but this cannot be helped. The observer simply records the facts, and if others, who have not taken the trouble to ascertain whether they are true or not, think proper to contradict him positively, he cannot prevent the practice. Speaking solely from what he has actually observed, and delineating carefully what he has seen, he may safely leave to those who contradict his observations the satisfaction of registering their contradiction. 
appropriate the nutrient matter which is required by the bioplasm of the tissue, but they may even grow at the expense of the latter, Plates XXI and XXII.

The bioplasm of the tissue may be killed and the tissue completely destroyed. The latter very soon ceases to discharge its function, and gradualiy it deteriorates in structure, and at length undergoes disintegration. Bacteria may be developed in it, and its decomposition may even occur in consequence of the rapid growth and multiplication of the germs of some contagious fever. In Plate XXII will be found drawings which illustrate some of the remarks just made, and in Plate XXI, fig. 72, is a drawing which shows very well the vast growth of bioplasm amongst the vesicles of adipose tissue in ordinary inflammation.

We have now to inquire more precisely into the circumstances under which the wonderful increase of the poison is brought about. There are two views essentially different from one another, which may be supported by different arguments.

I. It might be maintained that the contagious material actually passing into certain portions of the living germinal matter of the organism excited in these new actions, and caused them to divide and sub-divide very actively, and communicated to them the same properties which the original particle possessed, somewhat in the manner in which the wonderful powers existing in connexion with the germinal matter of the spermatozoon are communicated to that of the ovum and affect to some extent every one 


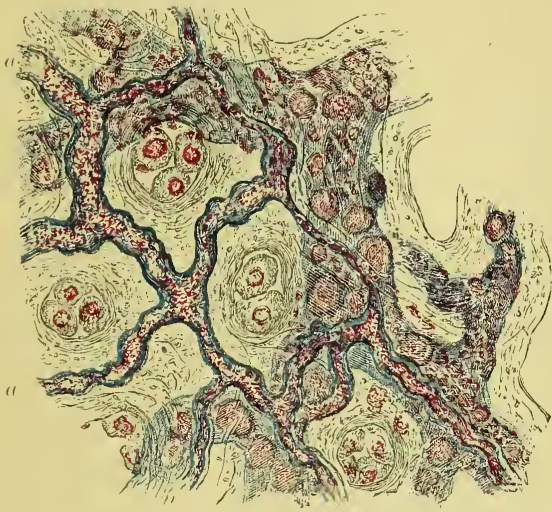

Surface of mucous membrane of founth stomach Cattle Plasue: corresponaing to a thin depressed circular spot like an vicer : $a$, stzperficial capillary vessels varyind very much in diameter, filled with (disease germs) miuute particles of serminal matter or bioplasm. The orifices of several bastric blands are seel il the spaces bounded by the vessels, and the deeper vessels on a lower plane are also delineated. $\times 300$. p. 103 .

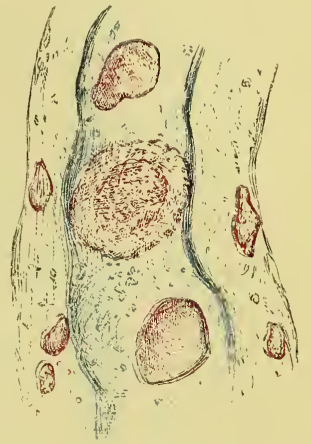

Portion of one of the larker vessels on the surface of the mucous membrane representer in Fí, 69, contanning masses $c$ bioplasm, $\times 1,800$

\section{Fig. 70}

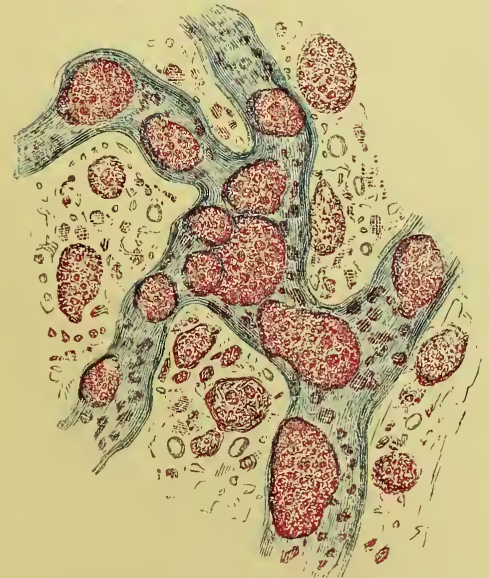

Capiliary vesse from the surface of a villus containinó larke masses of bioplasm and minute bioplasts (disease germs). $\times 700$. p. $10 t$
Fig. 71.

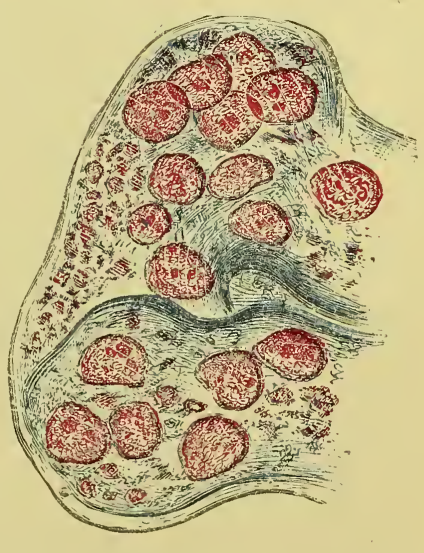

Capillary loop from Malpishian body of kidnez. Cattle plaśue. Containinǵs numerous white blood corpuscles and many minute kioplasts (disease germs). $\times 700, \mathrm{p}, 104$. $\times 700$. 

BIOPLASN-CATTLE RLA TUE.

Fig. 72.

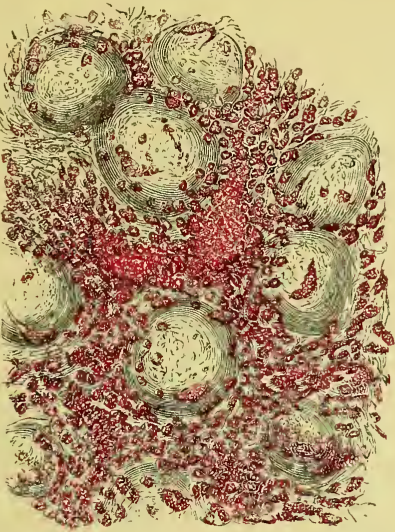

Lat vesicles and areolar tissue from exterual cout of vein of horse, three days alter it was opened by operation. Multitudes of bodies like white bloor corpuscles (broplasts), and probably direct descendants from them, are seen in the intervals between the fat cells which in some instances were dyed with the altered and dissolved colouring matter of the blood, the greater part of which had however been removed. The bioplasm represented in this fisure is harmless, but colxld not be clistiasuished from the contagious particles in other figures in this plate. $\times 215$ p. $10 \pm$.

F'ig. 74.

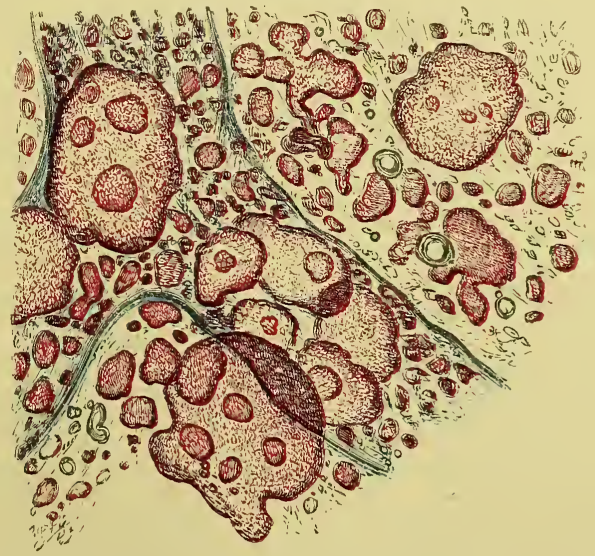

Citho of a capillary from the surtace ut a villus. small intestine from a very bad case of collo masses of the same character in their interior. Complete disorganization had occurred, $\times 2.800$ $\frac{1}{10 \overline{0}} \overline{0}$ of an inch $\times 215$.

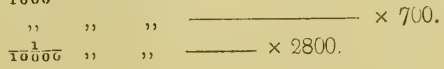



DISEAST GHRMS.-CATTLE PLAGUL.

Fig. 75 .

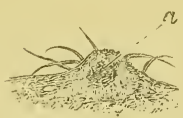

Vertical section through the centre of a well-marked papule (pustule ") from the udder of a cow, with cattie plasue, sent by Mr Ceely, January ltlk, 1866. The emption and roseoloid rash were well marked. There were also numerous scales; $\boldsymbol{a}$ is the central soflened portion of the papule. Natural size.

Fis. 77.

Fig. 76.

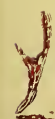
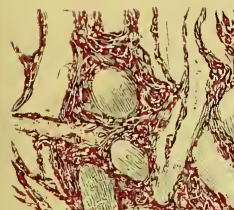

2.6
+1

1. 7
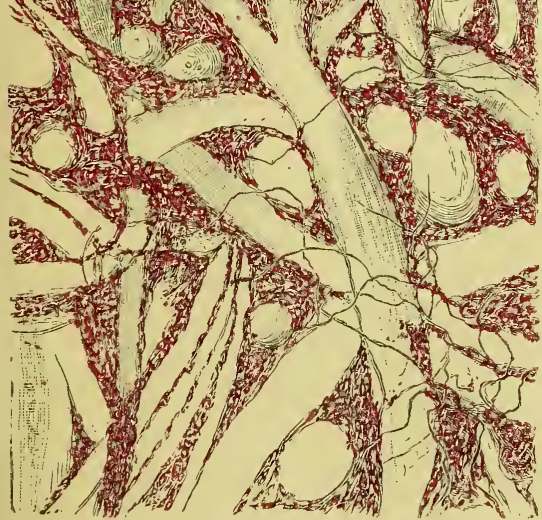

Tibrous tissue of the corium or true skin from the softened part of the papule. $\boldsymbol{a}$. Fis. 75. The intervals between the fibres occupied with bioplasm (disease ferms) growing and multiplyinś rapidly. $\times 215$. p. 104.

Fig. 73.

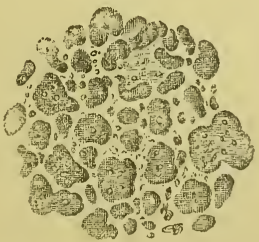

Minute particles of contagious bioplasm from the fibrous tissue of the skin, beneath the eruption. (Fig. 77.) $\times 1,800$.
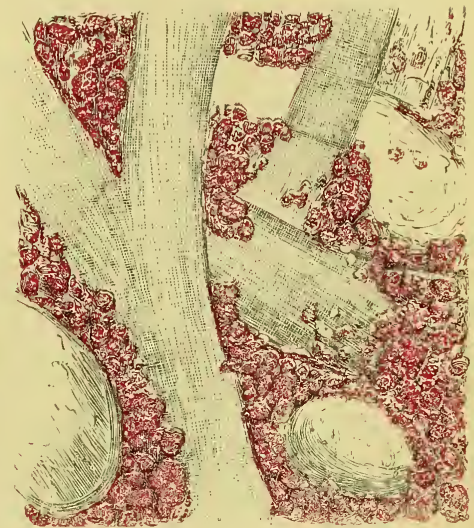

A portion of Fig. 76, magnifea 700 . The masses of contasious bioplasm can be seen dividing and subdividins into new portions which are growins rapidly and invading the bundles of white fibrous tissue. p. 101.

F1․ 79.

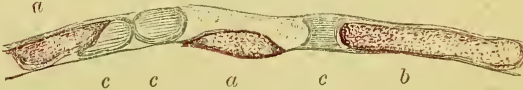

Capillary. Retina of calf (cattle plague) showing enlarped nuclei $a$, of the walls projecting into the interior of the vessel $b$, enlargad white blood corpuscle c, c, $c$, red blood corpuscles. $\times 700$

Fig. 80.

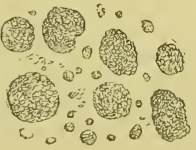

Masses of bioplasm from the excerna surface of a villus, cattle plaśue, $\times 7.0$

$\frac{1}{1000}$ of an inch $\times 215$. 

of the multitudes of living particles resulting from its division.

2. The contagious particle or particles having gained access to the fluids of the uninfected organism may absorb nutrient matter, grow and multiply, and give rise to a progeny very closely resembling the originals.

In the first case the actual living matter of a healthy organism is supposed to take upon itself a new and peculiar action in consequence of the influence of another kind of germinal matter upon it. In the second the contagious material simply grows and multiplies at the expense of the pabulum.

It is open to discussion which of these two views is supported by the greatest number of and most pregnant facts. I incline strongly to accept the latter as the more probable of the two.

It may, however, be fairly asked, when a pus corpuscle from the surface of the conjunctiva of a person suffering from purulent ophthalmia, or when a particle of gonorrhoal pus comes into contact with an uninfected conjunctiva and grows and multiplies, establishing a similar morbid condition to that in operation upon the surface where it grew,-whether the multitudes of resulting pus corpuscles are the direct descendants of the original specific pus corpuscle, or are derived from the bioplasm of the blood or of the cells of the conjunctiva, which is modified in consequence of its action upon it.

It seems to me probable that the corpuscles capable 
of exciting a new action upon an unaffected surface are the direct descendants of the original corpuscles which excited that action. Not only so, but I believe they take the nutrient material which was destined for the nutrition of the normal bioplasm, and live at its expense. Just as in the case of cancer, the adventitious rapidly growing germinal matter takes the nutriment destined for the normal tissue, and even feeds upon the latter in consequence of its powers of growth being much more active.

At the same time in the case of the specific puscorpuscles growing upon a mucous surface there is no doubt that the germinal matter of the normal cells increases and multiplies too. Indeed, in some instances I have proved that this is the case, so that there are two distinct processes going on- $\mathrm{I}$, the multiplication of the specific bioplasm, and, 2, the multiplication of the germinal matter of the normal cells modified by the altered circumstances to which it is exposed. And it therefore follows that not every one of the pus-like bodies formed is capable of exciting the specific inflammation, but the morbid bioplasts outstrip to so great an extent, in the rate of their multiplication, the masses of normal germinal matter, that the number of descendants of the latter would be comparatively insignificant, and would soon be completely overwhelmed by the former.

Upon the whole, then, I venture to conclude that the millions of contagious particles produced in the 
organism in an eminently contagious disease, are all the direct descendants of the very few, or perhaps even single particle first introduced; just as the millions of bacteria and fungi developed in certain decomposing organic matters in the course of a few hours may have been produced from one or at most a very few particles. And that although in the secretions upon the mucous surfaces, and in internal parts, there may be many masses of germinal matter resulting from the increased access of pabulum already many times referred to, these latter do not form the active elements of the contagious material or contagium.

Concerning the Possibility of Disease Germs passing into the substance of Normal Living Bioplasm.-It is true that in the substance of many masses of germinal matter found in the secretions and discharges of animals dying from cattle plague, and of many other diseases, some minute particles which would ordinarily be termed "granules," which refract the light very highly, and probably have been often mistaken for minute oil globules, may be invariably observed in great number. The nature of these particles is not known. They are met with in almost all kinds of living matter with which I am acquainted, and different forms are observed. In P1. XV, fig. 44, some are seen in masses of germinal matter from the milk. It seems to me probable that some of these particles have originated in the germinal matter itself, while others have passed into it from without. 
Now it is certain that such particles are very numerous, and are commonly found in masses of bioplasm so situated as to render their entrance from without not only possible, but probable. The fact of the amœba opening itself as it were, and then enclosing upon foreign particles, and embedding them in its very substance, is well known. Nor is this a phenomenon peculiar to the amœba, but it is possessed by other kinds of germinal matter. And now that the supposed importance and even the actual existence in many cases of the cell-wall has been disproved, and the active spontaneous movement which used to be called amobiform, because it was supposed to be peculiar to the amœba, has been proved to be common to living matter in general, it is probable that this and other vital properties, equally characteristic of all kinds of matter in a living state, will at last be admitted.

It must then be regarded as at least possible that particles of contagious living matter less than the Tơ $\frac{1}{1} \overline{0} \overline{0}$ of an inch in diameter might pass into the substance of a white blood, lymph, or chyle corpuscle, and thus embedded, the particle might be carried to all parts of the system. The matter itself might increase and multiply in the corpuscle, destroying it and living at its expense until the new collection attained a size larger than that of the corpuscle; or the foreign living particles in the white blood corpuscle might interfere with its division and sub- 
division, and the germinal matter of the corpuscle itself, attain a size larger than ordinary ; or the presence of the bodies supposed might cause the death of some of the particles of germinal matter and the formation of oil globules and other substances which might go on accumulating until the white corpuscle became too large to traverse the smaller capillaries. The phenomena above referred to would not only seriously interfere with the growth and nutrition of the white blood corpuscles, but would prevent the material undergoing conversion into red blood corpuscles; and in consequence of the diminution in number of the red blood corpuscles, and the reduction of the total quantity of blood in the system, various secondary phenomena would ensue.

But in whatever way the minute particles of germinal matter supposed to be included in the white blood corpuscle might cause their enlargement or interfere with their function, impediment to the free circulation of the blood in the capillaries must be induced. The minute particles now stationary would rapidly increase and multiply, and some might make their way through the vascular walls towards the surface, or into the surrounding textures.

The minute particles embedded in the germinal matter sometimes so closely resemble minute vegetable germs that in some cases it is difficult to believe they are not of this nature, and have gained access from without. In other cases these particles are of 
the nature of nuclei, and have originated in the germinal matter itself, while I am quite certain that some of the minute highly refracting particles embedded in the white blood-corpuscles, pus-corpuscles, and some other masses of germinal matter, result from changes occurring in the germinal matter itself, and are closely allied to fibrin.*

OF the Escape of THE Contagious Bioplasts FROM THE DISEASED ORGANISM.

There are three ways in which such minute particles of living matter as contagious disease-germs have been proved to be, might escape from the system in which they have been developed. These may be stated as follows :-

I. The living disease-germs might make their own way through small chinks or fissures in the capillary wall when it is overstretched.

2. They might be removed from the blood suspended in the fluid which is made to exude through the vascular wall.

3. It is supposed by many that disease-germs may be, as it were, attracted through the walls from the blood by the action of epithelial and secreting cells situated outside the vessels.

The view which has long been entertained and is

* "On the Germinal Matter of the Blood; with remarks on the Formation of Fibrin." Trans. Mic. Soc., Dec., I863. 
most in favour at the present time, is the last. The opinion seems generally held, that disease-germs, like urea, uric acid, and other poisonous matters present in the blood may be selected and separated from the normal constituents of the circulating fluid by the agency of cells situated external to the vessels, and thus "eliminated" from the organism. But there is no analogy whatever between non-living urea and uric acid, and living disease-germs, while it is an error to suppose that if fluid is discharged from the blood the process is invariably due to the influence of epithelial or other cells. The result is often, I believe almost invariably, dependent upon other circumstances altogether. So far from the epithelium taking an active part in the process, this structure is often damaged and sometimes destroyed and stripped off by the free escape of fluid from the blood, or before any discharge has commenced to take place.

The escape of the fluid is usually associated with a highly distended state of the capillary vessels. There have been stretching and consequent thinning of the capillary walls in these cases. Even after death fluid will transude through the capillary vessels which have been involved, with undue readiness. This I have frequently noticed in injecting the vessels of persons who have died of cholera. Although the fact has not been observed in every case, it has occurred too often to be regarded as a mere accident, and in many instances the phenomenon was so 
striking that it could not fail to excite immediate and careful attention.

In order to make a good artificial injection of healthy capillary vessels, it is necessary, as is well known, to employ some force in pressing down the piston of the syringe, and the injection is seen to spread very slowly from the points where it first appears. It is only after several minutes that the injection becomes complete. In many cases of cholera, however, the injection seemed to run into the most minute capillaries almost instantly, and under very slight pressure indeed. The capillaries seemed to be filled at once, and extravasation occurred, without any force having been exerted, within half a minute after the injection had been commenced. While injecting the vessels, one was forcibly reminded of what takes place when fine injection is introduced by the aid of very slight pressure into one of the large vessels of a mollusk-the force required to inject the smallest vascular ramifications, which in this class are very large, being so slight that the injection will pass freely into the smaller vessels, althouyh it runs out very fast through the opening made in the larger one, in which the pipe is placed without being tied.

I think there is little doubt that this increased facility of injection depends upon the extreme stretching to which the coats of the capillaries have been subjected during the course of the disease. The 
elasticity of the vascular walls had been much impaired during the progress of the disease, and I think it likely that in many instances the stretching had been carried to such an extent as to reduce the capillaries to a state of extreme tenuity, and to produce slight fissures in every part of the capillary wall through which the injecting fluid readily escaped after death. In some of these same cases we know blood-corpuscles had passed out during life.

Now there can be no question as to the extreme distension suffered by some of the capillary vessels in cholera. In Fig. 55, plate XVII, p. IOO, some capillaries are shown stretched to three or four times their ordinary diameter, and yet there is no evidence of actual rupture having occurred. It appears probable, however, that in many instances the distension is succeeded by the giving way of the capillary walls, when hæmorrhage takes place into the surrounding tissues. This appears to have occurred in the specimen from which Fig. 6I, plate XVIII, p. IO2, is taken. In various parts well-defined crystals of hæmatoidin were observed, as well as numerous oil-globules which have resulted from changes having taken place in matters which have extravasated from the blood. The tube of the capillary vessel may be traced up to a point indicated by the letter $b$, but beyond this the only indications which remain of its further course are a few irregular lines. This vessel was pervious, and was injected with fine Prussian blue fluid as far as the 
point marker. Below this point its walls were very permeable, and permitted the fine Prussian blue injection* to pass through them readily.

Capillary hæmorrhage, as is well known, although frequent in cholera, is by no means constant. It is probable that in many capillaries extreme distension is followed by cessation of the circulation and stagnation of the blood, which then undergoes change, much of it being re-absorbed. The vessel after shrinking very much gradually wastes, as has been already described.

It would seem, therefore, that in this case a free escape of fluid occurs, and any disease particles present would be removed in the blood. The circumstances, therefore, which gave rise to the stagnation of the blood and the distension of the capillary vessels must be regarded as the cause of the escape from the blood of fluid holding in suspension the disease-germs. Neither the epithelium which had probably been removed long before, nor other structure external to the vessels were actively concerned in the discharge of fluid or in the removal of the disease-germs.

As, however, it has been maintained that "elimination" performs a very active part in the removal of matters from the blood, and that living disease-germs

*For the composition of the Prussian blue injecting fluid, see "The Microscope in its Application to Practical Medicine," 3rd edition; or "How to Work with the Microscope," 4th edition. 
are "eliminated" from the infected organism, it is desirable to consider the nature of the process called "elimination" as it occurs in health and disease.

On Elimination.-The idea that poisons of all kinds are eliminated by a natural process, and that the operation is effected through the agency of the cells of certain tissues and organs, has of late years taken so firm a hold upon the mind as to be regarded by many writers as a well-established pathological fact. If, however, the view which is entertained be carefully analysed, and the supposed phenomena examined by the light of modern investigation, little indeed will, I think, be found to justify the doctrine that cells take an active part in removing poisons from the blood, or that it is part of their duty to "eliminate" such deleterious little particles as diseasegerms which have gained an entrance. Indeed if this were part of the work of these cells, we could not help acknowledging that they performed their duties most imperfectly, and failed more often than they succeeded in separating from the blood the poison which had entered. And it would certainly appear very strange that the cells did not "eliminate" the small amount of poison soon after it had entered, instead of remaining perfectly passive until it had accumulated to an enormous extent, jeopardized the life of the patient and seriously impaired the action of the very apparatus that was to take an active part in expelling it from the body. So far from the cells 
which are supposed to conduct this beneficial operation being active, it is probable they are perfectly passive, and have nothing to do with removing the disease-germs. So far from having any affinity for the particles they are supposed to eliminate, the secreting cells are damaged or destroyed by the latter, which may take up pabulum which the normal cells should have absorbed; or in their escape from the body the disease-germs may forcibly detach and destroy the healthy tissue supposed to be instrumental in elimination.

Let me now try to determine what is generally understood by this act of "elimination," which is supposed to play so important a part in physiology and pathology. By this process it is held that certain substances existing in the blood are removed from that fluid. The agents by which this removal is effected are the gland cells, and it is supposed that these possess an attraction for the particular substances which it is their duty to eliminate, by virtue of which they are enabled to select and draw towards themselves these special matters. It seems further to be generally concluded that the gland cells, after having taken up the particular substances in question, at least in some instances, produce in them important alterations and convert them into new compounds. When the change is complete and the gland cells have attained their mature state, it is supposed that they are cast off from the surface loaded with the materials they have 
modified and are about to eliminate. In short, the gland cell is supposed to take up certain matters as cells in general take up nutrient materials-to grow, to pass through certain phases of existence, and to die, its contents being set free at the time of its destruction. The place of this cell is then occupied by a new one which grows up. If this view is correct, it follows that numerous cells in every gland must grow, pass through their several stages of existence, and die in the course of a few hours at most; and necessarily the changes occurring in the cell must take place very quickly indeed.

Now what are the facts which lead us to conclude that in the ordinary process of secretion the cells are thus destroyed bodily? It is indeed quite true that cells occupying different positions in a gland follicle. exhibit different characters, the most mature cells apparently containing the perfectly elaborated secretion. But does this fact alone prove that these cells are removed and renewed as fast as the secretion is formed? Can the fact be only explained upon such a view? There is no doubt that the epithelial cells are gradually cast off bodily from the surface of the cuticle and mucous membranes and replaced by new ones, which grow up from below; and this is an argument in favôur of the occurrence of a similar process in glandular organs, but the analogy has surely been much overstrained. The rate of desquamation of cuticular epithelium for example is not very rapid, 
but it must be slow indeed compared with the desquamation of liver and kidney cells that must take place if the bile and urine discharged are set free by the rupture and destruction of epithelial particles. But what shall we say concerning the gastric juice, in which case many pounds of secretion are poured out in the course of twenty-four hours from glands which, with their vessels and other structures included, weigh but a few ounces? Does the formation of every drop of gastric juice necessitate the destruction of an equal bulk of gland cells? Is it not much more probable that the secretion filters away fully formed from the gland cell as fast as it is produced, while the latter remains apparently unchanged? In the case of the cuticular cell, it is necessary to inquire if the hard epithelial material is the only thing eliminated by its agency. Was it not very moist at an early period of its life, and is it not probable that much liquid holding various soluble substances in solution filtered through it and was carried off for a long time before the cell itself was cast away?

If the formation of a liquid secretion, like the bile, urine, or gastric juice, involved the growth and destruction of epithelial cells, the quantity of the secretion formed in these cases is so very great that the growth of the cells would take place very quickly. I think that we ought to be able to see, under our microscopes, the actual process of growth taking place-if not in man, at least in some of the lower 
animals-just as we can see the movements of the blood, lymph, and chyle corpuscles, and the wonderful alterations in form and size of the mucus and pus corpuscles and portions detached from them.

Many circumstances, however, render it far more probable that the act of secretion, and "elimination" of excrementitious substances from the blood, does not involve the destruction of the cell. That every cell grows old and dies is certain; but the process is much slower than it would be if the functional activity of the cell involved its death as a whole. The facts arrived at from a careful study of the cells at different stages of development lead me to ionclude that every cell, instead of secreting only its own weight of matter, elaborates and eliminates a hundred, or a thousand, or ten thousand times its weight of material in its lifetime. The doctrine generally entertained upon this point involves an extravagance of cell destruction which neither the results of anatomical observation nor the conclusions arrived at from physiological experiments permit us to entertain.

In secretion and elimination it is probable that the germinal matter of the cell absorbs the materials from the blood, and converts these irito matter like itself, while at the same time a portion of the germinal matter already existing dies, and undergoes conversion into those substances which constitute the secretion, according to the explanations given in my papers on 
nutrition, \&c., in the "Medical Times and Gazette," March, I865. The cell may thus take up a quantity of material, convert it into new constituents, and discharge these into its duct, without itself undergoing any appreciable alteration either in form or weight.

A large quantity of urea or uric acid may, I think, be "eliminated" from the blood without the destruction of a vast number of renal cells. Lactic acid, and lactates, and ammoniacal salts may be "eliminated" by the agency of the cells of the sweat glands without these cells being destroyed and replaced by new ones. Other lifeless soluble substances may be separated from the blood and eliminated in the same way, but it is very improbable that the cells of secreting organs should also attract towards them particles of living matter and afterwards "eliminate" these in an unaltered and living state.

I would remark here that when the eliminative act does undoubtedly involve the destruction of the organ of elimination, we have an arrangement very different from that observed in the permanent or true glands possessing ducts. The secreting organ in that case is a closed follicle, like the "solitary glands" and the glands constituting Peyer's patches in the alimentary canal. The little "cells" or masses of germinal matter, of which the gland is composed, grow and multiply, and retain in their substance at least a great part of the nutrient pabulum they take up. The mass 
composing the closed gland therefore increases in size, and approaches the surface of the mucous membrane; an opening is formed, and the contents escape. The walls of the old gland shrivel up, the wound in the mucous membrane heals, and probably a very slight cicatrix, with a little condensed areolar tissue beneath, is all that marks the seat of the gland. But even in this case we cannot affirm that the "cells" which have elaborated the secretion die and discharge their contents. They escape from the cavity in which they grew, but has anyone shown that they die and undergo rupture? We have much to learn concern"ing the destination of these "cells" in the closed glands which escape by rupture of the capsule of the gland. We know that "cells" of the same kind formed in the spleen have a very different office and destination. They seem to be but commencing their career when they become free, and I could bring forward several facts which justify me in expressing a strong opinion that the life of the cells does not cease when the temporary follicle in which they grew becomes ruptured and permits their discharge. On the contrary, it appears to me that at this very time they commence the really important part of their lifework, and they may now be only beginning to perform their active duty for the first time; so that neither in the case of the secreting glands with permanent ducts, nor in that of the temporary closed glands, can I admit that the doctrine which maintains that the 
formation of a secretion involves the detachment, death, and destruction of the cell which formed it, rests upon sound evidence.

We have now to inquire how far the term "elimination" is appropriate, when speaking of the removal of living disease germs from the blood. It is true we are told that the living self-propagating germs of scarlatina are "eliminated" by the skin and kidneys, but no evidence is adduced in favour of such a view. Like many doctrines, it is accepted as if it had been proved, although arguments have not been adduced in its favour. We may, however, now form a more exact notion of the kind of matter the poison in question really is, and of the way it escapes through textures from the blood and from the body, and we are, perhaps, for the first time in position to consider the question with advantage.

The desquamation of the cuticle, which almost invariably takes place after scarlatina, and the desquamation of renal epithelium, which not unfrequently occurs after this disease, as well as in acute dropsy, have been supposed to result from a tendency upon the part of the skin and kidneys to "eliminate" the scarlatina poison; and it has been held that these circumstances indicated an effort on the part of nature to remove or "eliminate" a noxious poison from the system. But it has not been shown whether the poison is capable of being eliminated, nor proved that it cannot make its own way out of the blood without the agency 
of any epithelial or other cells at all. On the other hand, I think it must be admitted that the facts, viz., the peeling of the cuticle and the removal of renal epithelium, might be exp,lained on the supposition that the "poison" had damaged the cutaneous and renal epithelium, as we know it often damages other tissues, and had afterwards made its own way out of the blood. Not only so, but if we accept this view we have a simple explanation why the injury done does not make itself evident till two or three weeks afterwards. The growth of the young cells, which were at the time of the fever near to the vessels, was affected, but the interruption of regular growth could not become manifest till the time had arrived when these celis should have considerably advanced in growth and reached the free surface of the body.

So far, therefore, from the desquamation of cuticle after scarlatina being due to an effort of nature on the part of the epithelial cells to eliminate poison, it is more probable that scaling results from the young cuticular cells having been damaged by the poison, as it escaped from the blood coming into contact with, and perhaps invading the structure of, these young cells.

But can the hypothesis which assumes that such poisons as those of small-pox and scarlatina are "eliminated" by the skin and kidneys, and that it is the business of the skin and kidneys to eliminate "poisons" of this class from the blood be sustained? If such a 
view is justifiable at all, it can only be on the ground that the "poisons" of small-pox and scarlatina are allied to the soluble excrementitious substances, which it is really the business of the secreting organs to "eliminate" from the blood. Recent researches here recorded, so far from favouring this view, lead us to a different conclusion. On the one hand, many things which were supposed to exist preformed in the blood, and to be "eliminated" by the agency of cells, are actually formed by the cells, and did not pre-exist in the blood; and, on the other hand, we have been led to the inference that the "contagious poisons" are totally distinct from excrementitious matters, that they are "living," and quite distinct in their nature from anything that can, as far as is known, be "eliminated." The term "eliminate" is therefore wholly inappropriate. If an epithelial cell can attract towards it, and then get rid of, any kind of living matter, it is an operation concerning which nothing whatever is known. It would not be more incorrect to talk of the "elimination" of ova or spermatozoa than it would be to speak of the elimination of living pus corpuscles or disease germs.

Although it has been asserted that pus corpuscles pass through epithelial cells, it need scarcely be said that the assertion has never been proved, while many arguments that might be advanced render such an hypothesis untenable. But even if the pus corpuscle did pass into an epithelial cell, it would not be correct 
to say that the epithelial cell eliminated it from the body, unless it had been shown that the epithelial cell in some way attracted or drew towards itself the corpuscle. But we know that the pus corpuscle is itself living ; it can destroy epithelium and normal textures, and can make its own way through tissues out of the body. It is opposed to all that we know of the changes effected by epithelium to conclude that it is capable of attracting or selecting particles of living matter from the blood and eliminating them.

Moreover, it has been established that living particles of the nature of pus may insinuate themselves into the interstices between epithelial cells, invade these, and ultimately destroy them. The epithelial cells of the mouth are invaded by vegetable germs, but it would surely be absurd to say that the latter organisms have been "eliminated" by the cells, for they simply make their way into the formed material, just as many of the lower animals bore their way into the old tissues formed by some of the higher animals and consume them. It would be as unreasonable to attribute destructive operations depending upon the invasion of the living particles to a tendency upon the part of the cells invaded to eliminate the particles, as it would be to argue that the invasion of the organism by the germs of entozoa was due to a tendency on the part of the body to attract these germs from other bodies, or eliminate them from the surrounding medium.

The term "elimination" has, then, been applied to 
two very different phenomena-the removal of nonliving excrementitious matter from the blood by the agency of epithelial cells, and the passage of living particles through the capillary walls, in which operation it has not been proved that the cells take any part whatever. In the first series of phenomena it is reasonable to conclude that the gland cells are the active agents, and not only take up but change materials which they have absorbed ; in the last it is much more probable that the particles of the poison or virus in the blood move themselves, and pass of their own accord through the vascular walls. So far from being selected or attracted by the epithelium, it is more likely that they bring about conditions which damage it, and in some cases lead to its destruction.

Indeed, when we examine the seat of actual change in small-pox, so far from finding the cells imagined to be the active agents in eliminating the poison in a condition such as we should suppose would be favourable to the operation, we find them terribly deranged, many of them completely destroyed, and the particles which are probably "contagious" amongst them, dislocating them from their natural positions and damaging them. It would seem that the epithelial cells had been destroyed by the poison, or by the conditions resulting from its presence, rather than that they had selected it from the blood and taken an active part in removing it from the system.

But if the passage of one kind of living matter 
through the vascular wall be due to an eliminative act, it is difficult to see why the passage of other kinds should not be due to elimination. If the escape of the virus of small-pox or scarlatina from the blood be an example of "elimination," surely the migration of an entozoon might be referred to the same process, and we might correctly speak of the "elimination" of a leaf from the branch, or the "elimination" of a hair from the hair follicle.

In the organism certain kinds of epithelium are concerned in absorption, and certain kinds in secretion and elimination. In the first the direction of the flow must be towards the blood, and in the last from the blood. It is obvious that if epithelium ordinarily concerned in absorption is to take part in eliminating matters from the blood, its action must be reversed. The columnar epithelium covering the villi is a remarkable instance of the first form of epithelium, and yet not only has it been inferred that this was concerned in eliminating poison from the blood in cholera, but that there was actually an increased formation of epithelium in this disease, and that the detachment of the epithelium was to be regarded as evidence of a tendency upon its part to separate a poisonous material which had been accumulating in the blood. It was shown, however, in the first part of this section, that epithelium usually eliminates without being detached or destroyed, and that we are not justified in inferring that such epithelium could 
under any circumstances increase so rapidly as has been supposed to be possible.

But is not cholera characterized by an almost complete cessation of the eliminative process? Is it not a fact that the organs which ought to be active in eliminating morbid materials are almost passive? So far from taking upon themselves increased duties, they do not even discharge their ordinary work. There is, as is well known, complete suppression of urine for a time, and, although there are often profuse perspiration and free discharge of fluid from the intestinal surface, it seems more probable that this increased pouring out of fluid is a physical process, than that it results from an effort upon the part of any cells connected with these surfaces to eliminate matters, noxious or otherwise, from the blood.

So far from the detachment of epithelium in cholera being evidence of an effort of nature to eliminate poison from the blood, it is more probable that it results from a destructive process altogether, and is due to morbid changes which have taken place in the blood in the subjacent capillaries (p. IOr). The villus is destroyed and incapable of absorbing or eliminating, and there is reason to think that before the epithelium is detached the circulation, but very imperfectly carried on for a long time previously, entirely ceases. Nothing, therefore, could be brought to the villus for elimination, supposing it were able to eliminate. 
I will now venture to state briefly the principal conclusions arrived at in this section:-

I. That the gland-cell is not, as a general rule, destroyed when it secretes.

2. That the poisons "eliminated" by the skin and kidneys are probably in a state of solution.

3. That the poisons of contagious diseases are not soluble, but consist of living germs which move of themselves, but which cannot be "eliminated" from the blood by epithelial or other cells.

4. That so far from there being any evidence of the epithelial cells eliminating contagious poisons, the living particles of the latter interfere with the action of the cells, and many are destroyed by them.

5. That the function of the columnar epithelial cells is to draw substances from the intestine and pass them on towards the blood, and that therefore it is most improbable that these cells should take part in "eliminating" anything whatever from the blood in health or in disease.

The passage of Disease Germs through the Vessels.The observations made in the preceding sections will prepare the reader for the remark that the minute particles of bioplasm which constitute disease germs, after having multiplied in the capillaries through which the circulation had completely ceased and made their way into the surrounding tissue and multiplied there, would easily pass in the intervals between epithelial cells and thus reach the free surface; 
or they might grow and multiply amongst the epidermic cells or epithelial cells of mucous membrane, and cause small collections or flakes of these to be detached from time to time. It is probably in this manner that the poison of scarlatina is discharged from the infected organism. Protected by the scales of cuticle amongst which it has grown, it may retain its vitality for a length of time.

From animals which have died of the cattle plague, I have been able to obtain specimens which show very conclusively the manner in which the escape of the particles of contagious bioplasm is effected. In Plate XXIII are represented several papillæ from the mamma of an animal which died of the disease. All the capiliaries contain the bioplasm which makes its way from them into the epithelial texture above, in the manner represented in the outline drawing, Fig. 83. In 86 many of the bioplasts are actually seen amongst the epithelial cells. The bioplasm of the cells is also enlarged from the accompanying fever and inflammation, and in some cases pus was almost produced, Fig. 84. See also pp. I06, I34. Among the softened and altered cuticular cells sporules of fungi may often be detected, Fig. 85 , but these have nothing whatever to do with the disease.

The constant phenomena of Fevers and Inflammations.-Although the subject of fever and inflammation is far too extensive to be discussed here, my work would be incomplete if I omitted to refer 
F1g. 81.

b)

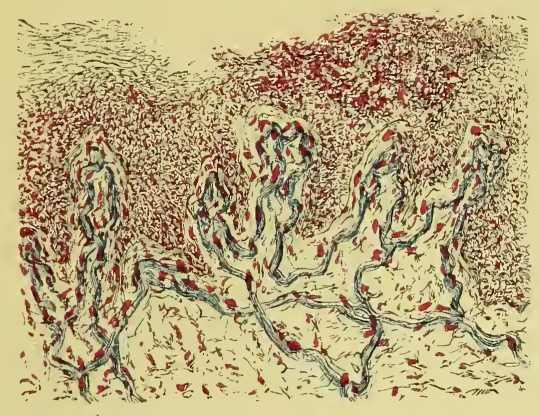

a

section through cuticle and cutis in the seat of the eruption, cattle plague, showing at $a$ a papilla, the cuticle over which is still in a healthy state, while that above the papillæ at $\boldsymbol{b}$ is undergoing disintegration caused by the growth and multiplication of contasıous bicplasm among the cuticular cells, as shown by the dark patches $\times 130, \mathrm{p}, 130$.

Fio. 83.

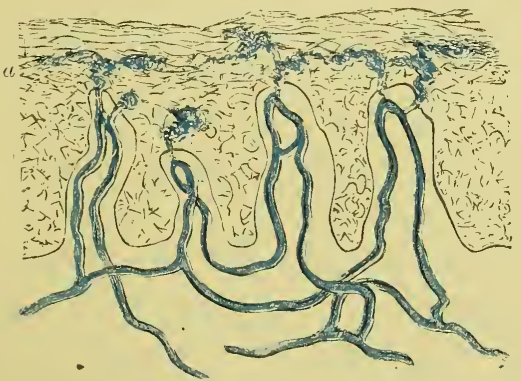

Outlicie plan showing how the contagious bioplasm nay pass from the capillaries and reach that part of the cuticle where the layers of cells are parallel. $a$ whence it spreads horizontally in trarious directions. and thus strips off the superf cial layers of the cuticle.
Fig. 82.

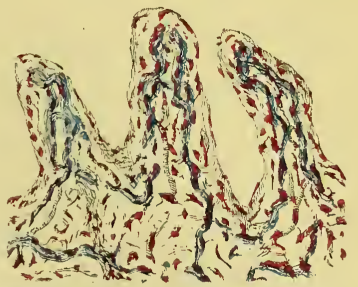

Papillæ from beneath the eruption. Cattle plasue. T'ke cuticle is much more easily detached from the cutis than in health. $\times 130$.

Fig. 84.

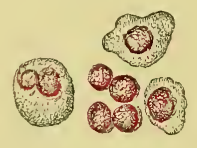

Young cuticular cells and masses of bioplasm growing and multiplying under scab. Cattle plague. $x$ 700 p. 130 .

Fig. 85.

$$
\left(\begin{array}{rr}
3 & 0 \\
0 & 0 \\
0 & 0
\end{array}\right]
$$

Minute sporules of fungi amongst the superficial cells of cuticle situated near the eruption. $\times 1,800$. p. 130.

Fig. 86.

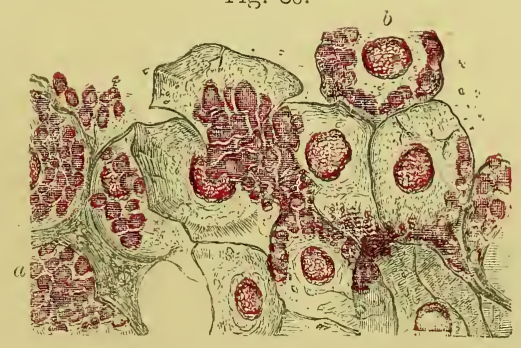

hul ular cells wuder scab. Cattle plaǵze. Eruption on mamma, showing how the rells are wvaded by the srowth and rulciplication of the minute particles of coutagious bioplasm $\times 700$. p. 130 . 

altogether to the febrile action which invariably follows the introduction into the system of every kind of contagious germinal matter, and is indeed a constantly attendant phenomenon.

But fever, as is well known, may be due to changes induced within the organism, and which do not depend upon the introduction into the body of disease germs or other particles from without. If in these cases of idiopathic fever there be a poison at all, the special morbid bioplasm must necessarily have been generated in the organism itself during or just previous to the illness. In the simple feverish state, and in febrile conditions induced by the introduction of contagious bioplasm from without, we find the essential phenomena identical. These are to be noticed: altered chemical changes, impeded capillary circulation, and elevation of temperature, which is maintained as long as the fever lasts. These phenomena cease when free action of the skin, kidneys, and bowels occurs. By this free action, is effected the removal of a large quantity of imperfectly oxidized compounds which had been accumulating during the continuance of the febriie condition. The escape of these substances is soon followed by complete disappearance of febrile symptoms and return to the healthy state. The most virulent and fatal fevers excited by the introduction of poisonous disease germs into the organism differ from the simple feverish condition only in degree, and in the immediate exciting cause of the early changes. 
Fever and inflammation are always characterized by an elevation of temperature varying from one or two, twelve, or even fifteen degrees, above the normal standard. If this is not, as I believe it to be, a consequence of the increase of bioplasm or living matter in the organism, the two phenomena are invariably associated. Principally and primarily there is increase of the bioplasm or germinal matter of the blood and of that in the capillary vessels, but afterwards that of the tissues undergoes the same change. This increase of germinal matter is itself due to the presence in the blood of pabulum, and its accumulation in undue proportion. The constituents of this pabulum ought to have been eliminated by various glands as fast as they were formed, or other compounds should have been produced instead, which being more highly oxidized would have been readily got rid of in the form of urea, uric acid, carbonic acid, and other substances easily excreted.

In a common cold, and in any slight feverish attack from which we may suffer, there is evidence of increase of the germinal matter in the blood, of consequent impairment of free circulation through the capillaries, and of increase of the bioplasm upon various mucous surfaces. These phenomena are accompanied by a temperature higher than the normal standard.

Congestion in many of the surface capillary vessels is invariable in all fevers. Upon local or general dilatation of the small arteries and capillaries of the 
cutaneous surface, the general redness, spots, or rashes, characterising various kinds of fever, depend. In some cases the dilatation and congestion of the capillaries pass on to actual rupture and extravasation of blood, and little ecchymoses result. In others serum, containing much red colouring matter of the blood, permeates the walls of the vessels and infiltrates the neighbouring tissues. In all febrile states the heart cannot drive the blood through the obstructed vessels fast enough to carry off the animal heat which is developed. The temperature of the whole body therefore rises, and the action of the various organs which are adapted to work perfectly at one fixed temperature is deranged.

In contagious fevers these same phenomena are observed, and are caused in the same manner, but the bioplasm matter (disease-germs) which increases has a definite rate of multiplication of its own. It goes on increasing for a time, and from its increase serious complications may result. Numbers of the germs produced may pass through the capillary walls into the tissues around, and many escape from the excreting surfaces into air or water, and thus the scourge is spread far and wide. When this has happened, under favourable circumstances the process stops. Products resulting from the death and decay of the specific contagious germinal matter which yet remain are removed by the increased activity of the organs of excretion, and health is gradually restored. 
If, on the other hand, the changes have proceeded to a degree sufficient to prevent the capillary circulation over a considerable portion of the body or throughout the greater part of one or more organs, the integrity of which is necessary to life, recovery is no longer possible, and death must result.

The actual changes which take piace in the vessels and tissues will be understood if the reader will attentively examine the drawings in Plate XXIV, which well illustrate the striking alterations which occur in the bioplasm or germinal or living matter of the tissues and vessels in fever. Figs. 87 and 88 represent respectively the bioplasm of connective tissue in health, and in fever. The amount in the diseased connective tissue is many times greater than in the healthy specimen. The masses of bioplasm of the capillary represented in Fig. 89, are more than three times as large as they would be in a state of health, and the same remark applies to the little artery represented in Fig. 90. In both these figures the bioplasm is already beginning to divide and subdivide, and had life been prolonged for a few days, numerous separate particles, like pus-corpuscles, would have resulted. In very bad cases of fever which are fatal, similar changes may be demonstrated in the textures in all parts of the body; and in every case of local inflammation precisely corresponding phenomena are found at the seat of pathological change.

The rise in temperature, be it restricted to a part 
INCRE $\triangle$ S
F19. 87 .

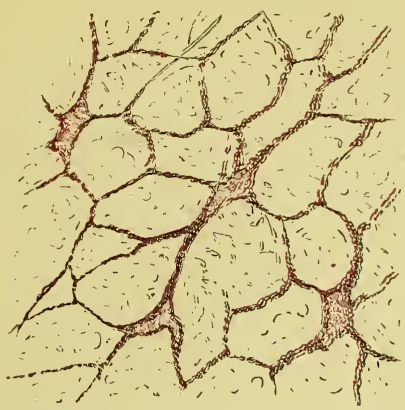

Connective tissue corpuscles. Surface of healthy mucous membrane over epislottis just beneath the epithelium. Ox. For contrasting with Fis 88. x 700. p. 134 .
IOPTASM-FEVEP.

Fig. 8?.

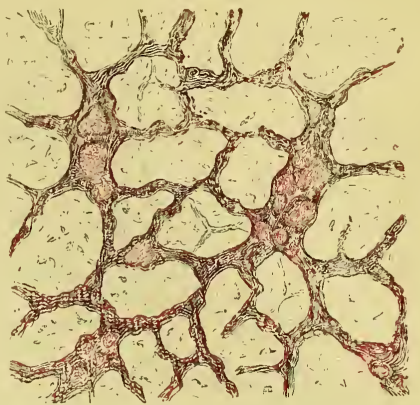

Enlarged connective tissue corpuscles. Burface of mucous membrare ovrr epislottis-cattle plague-just beneath epithelium $\times 700$. p. 131. Fid. 89.

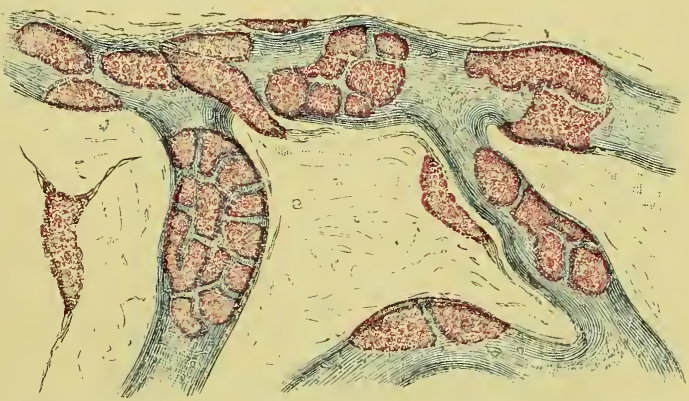

Capillary from same situation as the artery, Fis. 90. The masses of bioplasm of the capillary are very much enlarged, and are dividing and subäividing to form new masses. $\times 700$. $p .131$

Fig. 90.

\section{$b$}

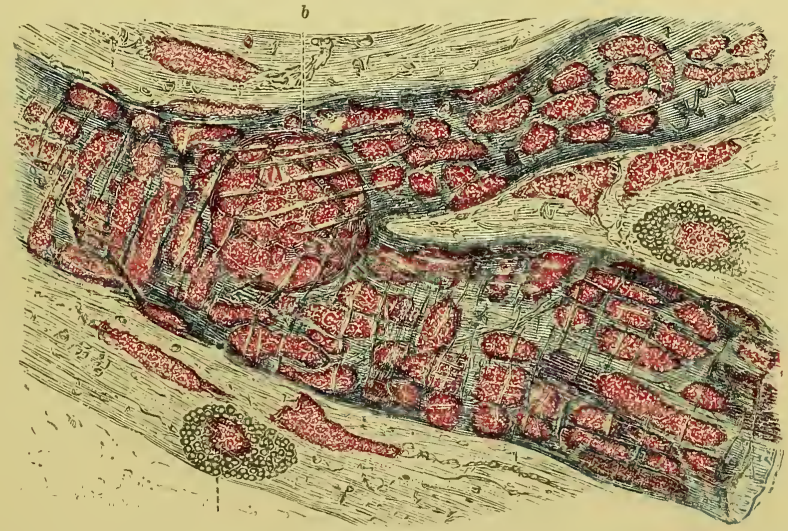

Small artery from connective tissue beneath depression of mucous membrane of fourth stomach Cattle plasue. a. small cells with numerous oil slobules in the external coat of the vessel; $b$, a Cattle plaǵue. a, larǵe mass of bioplasm obstructinǵ branch of artery. $\times 7 C 0 ., p, 131$. 

of the body, as in inflammation, or distributed over the entire organism as in fever, is invariably associated with the increase of bioplasm. The facts I have observed justify me, I think, in concluding that whenever bioplasm increases, the evolution of heat takes place. Normally the heat developed is very soon distributed over a wide extent. The arrangements for effecting the distribution, and thereby occasioning the equalization of the temperature in all parts of the body, notwithstanding considerable local variations are, in man and warm-blooded vertebrata, wonderfully perfect. In fever and inflammation the arrangements are much disturbed, or they are completely suspended for the time. In cases where the body-heat rises several degrees in the course of a few hours, the germinal matter or bioplasm increases with marvellous rapidity. The capillaries of a great part of the body are found to be gorged with particles of living matter, for the most part descended from the colourless blood-corpuscles, while the masses of bioplasm of the neighbouring tissues have increased to twice their normal size.

It has been affirmed, over and over again, that the elevation of temperature is invariably due to increased oxidation; but the state of things above referred to can hardly be favourable to this process. The oxidation theory is quite negatived by the fact that the temperature sometimes rises most rapidly for some hours after death has occurred, and when, 
it need scarcely be said, the organs concerned in effecting oxidation have completely ceased to act.

The development of animal heat probably occurs at the moment when non-living matter becomes living-when the elements of compounds are separated from one another to enter upon that state of suspended affinity or equilibrium in which they seem to be retained while the living state lasts.

It is of the greatest importance in treating cases of fever, to favour to the utmost the actions concerned in carrying off heat during the persistence of the febrile condition. Although direct cooling of the surface will bring down the temperature of the body, it must not be forgotten that the phenomena upon which the development of heat depends cannot be influenced by this proceeding. On the other hand, by keeping the surface of the body warm and well covered by light woollen things, the operation of the natural process for lowering the temperature is favoured; for when the surface is kept warm, the arteries of the skin are dilated and much blood is brought to the cutaneous capillaries where free evaporation takes place, and much fluid is in this way removed in the state of vapour charged with heat.

Mr. A. B. Garrod has shown that when the clothes are removed from the body and the surface chilled, the cutaneous arteries are caused to contract. The blood is thus diverted from the surface of the body to internal parts so quickly and so decidedly that its 
temperature rises, and the mercury in a thermometer placed in the axilla stands as much as two degrees of Fahrenheit's scale higher than it did immediately before the clothes were removed (Proceedings of the Royal Society, No. I I 2, I 869*).

We have seen, then, that in all feverish and inflammatory states, whether caused by changes commencing in the system itself, or by special living disease-germs introduced from without, important alterations are induced in the blood. An undue amount of nutrient matter is formed, and this is taken up by the bioplasm of the blood of the

* Mr. Garrod has more recently noticed the interesting fact that as the temperature of the external air increases, the rise in body heat on stripping off the clothes decreases. This is a necessary deduction from the theory that the temperature of the body is modified by alterations in the amount of blood distributed to the skin in consequence of alterations of arterial tension. Several observations have been made by him with the view of ascertaining the point at which no change in the internal temperature results from stripping, or what temperature of air causes no rise in the arterial tension. This point has been found to be $70^{\circ} \mathrm{F}$., above which, the first effect on becoming nude is a slight fall from the evaporation of accumulated surface moisture, this soon ceases, and the temperature returns to near its previous height. By means of an hygrometer, constructed for the purpose, Weyrich (Die unmerkliche Wasserverdunstung der Menschlichen Haut. Von D. Victor Weyrich, Leipzig, 1862), has found that from many degrees below, up to $70^{\circ} \mathrm{F}$. of the external air, the amount of moisture exhaled from the skin does not vary; but above $70^{\circ} \mathrm{F}$. it commences rapidly to increase, -in other words, from that point the sweat glands commence more active secretion. This fact tallies exactly with that ascertained by the use of the thermometer internally. And it is interesting to notice that by these two very different methods of investigation, entirely independent of one another, results are obtained which do not differ by as much as $\mathrm{I}^{\circ} \mathrm{F}$. 
vessels and of the tissues, as well as by the contagious bioplasm when this exists in the system. The. increase of the bioplasm in the blood (white bloodcorpuscles and minute particles of bioplasm) has been already described in Page 39, plates VIII, IX, et seq.

The above changes are invariably associated with increased development of animal heat, which in its turn further favours the growth of the bioplasm.

This interesting subject will be further discussed in a work "On Inflammation and Fever," which will be published shortly.

The manner in which Disease Germs may occasion Death.-The observations already made in this work will have prepared the reader for the inference that disease germs, consisting of living germinal matter, or bioplasm, may be instrumental in causing death in different ways, and in different periods of time, but that in all cases the fatal result is brought about by changes in the composition of the blood, and by serious disturbances in the circulation thereby resulting. The manner in which death begins at the head, at the heart, and at the lungs has been well described; but death may really be said to begin more frequently at the capillary vessels than at any higher texture.

Complete interruption, or sudden cessation of the circulation, from any cause whatever, may produce almost instant death. Fainting, as is well known, results from a more or less sudden reduction of the 
impelling, force by which the blood is driven into the capillary vessels, and this may end fatally. Any local. disturbance of the capillary circulation gives rise to various phenomena according to the precise seat of the change. Interruption of the capillary circulation, over even a small area, in part of a tissue or organ, may lead to the death of that part. In this way boils, and carbuncles, and sloughs are produced, and when the area is extended, mortification of a considerable portion of tissue, it may be of a considerable part of a limb, is occasioned. Partial interr'sption of the capillary circulation may give rise to inflammation only, as has been described in pages 38,39; and in many cases, even though a considerable portion of tissue may be affected, if only a few capillaries here and there continue to transmit blood, mortification is averted, though inflammation very damaging to the part may result.

In fevers, as has been already mentioned on page 95, the degree of severity of the attack is determined by the extent of capillary circulation which is implicated, and the force of the heart's action. The capillary circulation being equally involved in two cases, in one the force of the heart being very good, in the other very weak, death may result in the latter and complete recovery in the former. The heart's action being weak, it is reasonable to suppose that if by artificial means its force could be increased for the time, the prospects of recovery would thereby be- 
come much enhanced. In certain fevers the disease germs may increase in the blood to such an extent during the period of incubation, that the rigors and vomiting which mark the commencement of the actual fever may be followed by death in a very few hours. In some of these terribly fatal cases, it is possible that the capillaries of the nervous centres may be the seat of obstructed circulation; in others the fatal result may be occasioned by rapid chemical changes set up in the blood, and an indirect effect upon the nerve centres produced through the nerve fibres distributed to the capillaries; but in some instances the state of the capillary circulation in all parts of the body justifies the inference that the fatal result is actually due to the cessation of the circulation in the obstructed capillary vessels distributed everywhere.

In fatal contagious fevers, death more commonly occurs some days after the commencement of the dttack, and may be ascribed to the obstruction to the circulation caused by gradual plugging of capillaries in every part of the body, consequent upon the multiplication of the contagious bioplasm, and the changes resulting from this phenomenon. The process has been already described in pp. 37 to 42,95 et seq, and the indirect consequences have been referred to. In many instances I have carefully studied the several changes in the capillaries of various tissues of the body, and in a most instructive case of glanders, I 
had an opportunity of demonstrating every degree of capillary obstruction in the pulmonary tissue. In the early stages of this most fatal form of fever, boils and other evidences of complete capillary obstruction over a limited extent of tissue are often observed, but these are too frequently followed by more extensive general capillary plugging, which is necessarily fatal.

Of the manner in which an Organism may be "protected" from other attacks of the same Contagious Disease.-Of all the problems I have ventured to touch upon in my book, this is by far the most difficult. It is one which has been as yet little considered. Indeed, until a clear idea of the nature and mode of action of disease germs had been formed, the consideration of such a question could not have been undertaken with much prospect of success.

Certain physicists and chemists, satisfied that all the phenomena of the universe are to be explained by physics and chemistry, would, of course, dismiss this and other such questions in a sentence or two about collocations and physical attractions, molecular properties and evolutional heterogenity, and assure the public that they understood all about it, although they are quite unable to explain what they mean by the long words they employ. A phraseology which is eminently fitted for conveying information about the actions and reactions of lifeless particles upon one another may become utterly devoid of meaning when applied to living things. As long 
as such persons hold, contrary to all reason, that the living differs only in degree from the non-living, in fact deny that there is any absolute difference between a thing living and the same thing dead, they will fail to appreciate or to understand vital phenomena ; and, so far from assisting the progress of biology their misdirected efforts only too effectually retard it.

The action of disease germs in the organism is in every essential particular, utterly unlike the action of any non-living substance whatever, for there is no example of the non-living growing and multiplying a million fold, and leaving a state of things totally different from that which existed before the remarkable changes induced by its presence commenced. A living disease-germ of a certain kind is introduced into a healthy organism. It grows and multiplies freely, and in the process causes derangement of most of the normal phenomena, and brings about a state of disease more or less serious. After a definite time, the countless multitudes of germs cease to multiply further. Many of them die, and the products of their decay are eliminated from the body, while many may escape in a living state from the organism and gain access to other living beings. But the remarkable fact is that after an organism has been the seat of these changes, its state is everywhere completely altered, inasmuch as similar disease germs, and in some instances germs of another kind, will no longer grow and multiply. The living particles may get 
into the blood, or they may be forced into it, but they will not excite any changes, or at any rate they will not give rise to disease. The organism which has already been diseased and has recovered, may be afterwards inoculated to any extent, but the living particles will not grow and multiply in it. They will die, or if they do not die they remain in the body without inducing any change. The organism which may have been scarcely deranged or nearly destroyed by the first invasion is by that operation rendered proof against a second attack, but this protection is not, at least in many cases, necessarily permanent. After the lapse of a certain period of time, further change occurs, and the organism again becomes fitted for the growth and multiplication of the same kind of disease germs, in fact susceptible to another attack. This period of protection varies in duration, but is probably pretty constant for each particular kind of disease germ.

Some forms of disease germs not only "protect" the organism from a second invasion of the same kind of germ, but the change induced is an efficient "protection" against allied forms. And there is indeed reason to hope that means may be discovered, perhaps by passing it through the bodies of animals, or in some other way, of rendering the poison milder, without destroying its efficacy as a protecting agentin fact, that we may produce a mild and harmless disease, in order to "protect" the organism from the chance of suffering and being destroyed by a most 
virulent and very fatal form of the same malady. This, thanks to Jenner, we have been able to do daily, as regards the most loathsome of all contagious diseases, for the last seventy years. Would that I could say there was great hope that we should soon be able to discover as efficient means of protecting ourselves from the ravages of scarlatina, measles, whooping cough, and other scourges, as, by vaccination, we protect ourselves from the ravages of small-pox. But although all attempts to find out how this great object is to be achieved have failed, we may feel sure, not only that this is possible, but that it will be done. In this direction our work should be unremitting. The secret may be found out any day by the sagacity of a Jenner, or it may not be discovered until long series of carefully devised scientific experiments have been performed, and have for years proved so barren of results that persons well versed in knowledge ridicule those who persist in making them, while the public scoffs at the sacrifice of labour, and becomes indignant at what in their eyes is a most unjustifiable waste of money.

But who would not be struck at the discovery of the fact, if a few animals in a herd were found to be proof against the poison of cattle plague? And who acquainted with such a circumstance would not desire to learn the cause of this immunity from a disease which seizes upon almost every individual animal exposed to its influence? One cow lived a mongst the cattle plague 
poison for weeks, and was inoculated with it, but never took the disease. Whether this animal had had a mild attack before, or whether her escape was due to some other circumstance, was not determined. But ought we not to work to find out how to induce such a disease mildly in other animals? Will the public neither supply us with the means to discover, on condition that if the discovery be made it be given freely to the world, nor offer a reward sufficiently large to encourage an observer to risk all he has, and spend many years in the prosecution of what may turn out to be an absolutely barren investigation? Many a scientific man would work for the best years of his life for the value of one monster gun, and many valuable investigations might be conducted for a sum equal to that spent upon a single discharge.

In cases where "protection" has been obtained, the change effected in the organism, it may be remarked, is general and complete. The entire mass of the blood is in some way altered, and there is not the smallest particle of the body which is not efficiently "protected" against invasion by certain special disease.germs. The result may be explained by supposing that changes have occurred in the blood only, without any alterations having been necessarily effected in the solid tissues. All contagious fevers are, in fact, essentially blood diseases, so that in discussing the nature of the changes which may be instrumental in effecting "protection," we may con- 
fine ourselves to the consideration of the manner in which the blood is probably altered. Although the precise nature of the alteration induced cannot be determined, it may be worth while to consider which of several changes that may be caused by the growth and multiplication of the disease germs is most likely to be the actual change which is occasioned.

In the first place, some substance existing in the blood prior to its infection may be taken up, assimilated, and thus removed by the growth and multiplication of the germs. This matter being necessary to their growth, it follows that by its removal from the blood further growth of the germs, should more be introduced, would be prevented, or, in other words, a second attack of the disease becomes impossible.

Secondly, it is possible that by the growth and multiplication of the disease germs in the blood, some new material may be produced which is destructive, and thus, as long as this material remains, further growth is prevented.

Neither of the above suggestions is, however, satisfactory, because the materials supposed cannot be proved to exist chemically; and in order to account for "protection" only being temporary, we must further suppose that the material which we know nothing about, may according to the first hypothesis, recur at a future time, and according to the second disappear.

But, thirdly, it may be supposed that from the par- 
ticles of bioplasm which induced the first attack of disease, bioplasts are produced, which continue to give rise to others. As long as this production of new germs by descent proceeds, the bioplasts must take up pabulum, which other disease germs in their absence might appropriate. In this way we can account for "protection" lasting only for a time. When these germs cease to produce descendants, or, producing descendants whose properties gradually change, the state of "protection" ceases. Upon the whole, then, I incline to the view that "protection" is due to the presence of bioplasts in the blood, which have directly descended from those introduced. These, growing and multiplying in the blood, take up the pabulum suitable for the nutrition of disease germs, and the growth and multiplication of the latter and of germs allied to them in character is prevented, should any such gain access to the blood.

While "protection" lasts, we may infer that the growth and multiplication of the protecting particles interferes with the growth and multiplication of the virulent disease particles. After a time, however, the descendants of the first becoming exhausted, the last may then be victors in the struggle for existence. 


\section{OF THE NATURE OF THE CONTAGIOUS DISEASE GERM.}

Contagious Disease Germs not Parasites.-Many different things, the characters of which are not very clearly defined, and not to be easily determined, are often called by the same name, and it is perhaps not to be wondered at, considering the serious difficulties encountered by scientific investigators in their attempts to discover the real nature of the contagious disease germ, that this virulent particle should, as it were, by common consent, have received the reproachful designation, "parasite." But it is much easier to call a thing a name, and to assert that it belongs to a particular order or class of things, than it is to demonstrate its affinities, and assign good and sufficient reasons for the nomenclature and classification adopted. There are some objections to the view of regarding disease germs as parasites, which do not appear to have presented themselves to many of those who have used the word. Some have indeed tried to give to it a wider and more extended meaning than can be justified, and thus have included in the parasitic class many living organisms that ought not to have been consigned to so questionable a position.

The doctrine of the parasitic origin of contagious disease has no doubt received some support from the circumstance that certain morbid affections have 
undoubtedly been shown to be associated with the presence and vigorous growth of organisms belonging to the class of parasites; but of late the term parasite has been used far too freely, and the word has been employed without due consideration. Not only have the living particles of mucus and pus been thus designated, but the highest living cells in the body of man himself have been called parasites.

Scientifically speaking, a parasite is an organism which lives upon another organism. The organism does not evolve the parasite any more than the latter produces its host. The organism may live in the absence of the parasite, though for the latter to exist the first is a necessity. The parasite is a descendant of a pre-existing parasite-not an emanation from the being upon which, and perhaps by which, it lives. A vegetable or animal organism dependent for subsistence upon the juices or secretions of another vegetable or animal organism much higher in the scale is a parasite. But it is as wrong to speak of the constituent living growing cells of the human body as parasites, as it would be to assert that the complex individual compounded of them was a parasite.

Every cell of the organism has been formed by direct descent from the original embryonic mass of bioplasm. The bioplasm of each cell is capable of growth and multiplication, but it cannot be looked upon as parasitic upon other cells, for its parentage is the same as theirs. For the same reason abnormal cells cannot be 
regarded as`parasitic upon healthy cells, although many forms of abnormal bioplasm, like pus, cancer, \&c., maybe transferred from animals to man, or vice versâ, and grow and multiply. All such forms have, however, been derived from normal cells, which perhaps would not grow and multiply if transferred from one organism to another, though all have descended from the same primitive bioplasmic mass. As the bioplasm retrogrades it acquires the power of -living upon less elaborate pabulum than normal bioplasm, and may even appropriate different kinds of pabulum. Its rate of growth and multiplication is far greater than that of the normal bioplasm from which it came, and it retains its vitality under circumstances which would certainly have ensured the destruction of the latter. Nor must the fact be lost sight of that the development of the abnormal forms of bioplasm tends to degradation and destruction. The bioplasm of vaccine, although conservative in effect, is damaging in its action. Its growth is the lesser of two evils. But these and allied forms of bioplasm cannot be considered parasites on account of their derivation.

The true parasite is as much a species as is the being upon which it feeds. The masses of living matter developed from the living matter of one of the higher organisms have descended from a specific living mass. In no sense can such bodies be regarded as species. Never do they regain the properties and powers of the living matter from which they were 
derived-never do they give origin to-descendants having such properties and powers. On the other hand, every parasite is complete as an organism, and gives rise to organisms like itself, which may repeat its life history. A parasite possesses individuality, but a disease germ can no more be regarded as an individual than a white blood corpuscie, or a pus corpuscle, a nail, a hair, or a gland follicle can be so considered; for, from any of these, under no known circumstances can a complete individual organism be developed. If such bodies as mucus corpuscles, pus corpuscles, cancer cells, tubercle corpuscles, and disease germs generally, be termed parasites, the nails, or hairs, or glands, or limbs might with equal propriety be regarded as of this nature. Even the brain cells have been spoken of as parasites, but one would have thought. that if any part of the body of a man belonged to him his brain cells were certainly his own, and therefore could not be parasites living upon him. Such confusion has resulted, that it is really difficult to decide what is a parasite; and it seems almost vain to hope to restore the scientific meaning of a term which has been entirely metamorphosed by the sparkling wit and keen satire of transcendent literary genius.

Nature of Contagious Disease Germs.-Although many diseases are caused by the action of noxious gases, fluids, and solids of various kinds, every one will agree that the particular forms of disease now under 
consideration-the contagious fevers-result from the introduction of living particles of some form or other. But of the nature and origin of this living matter opinions differ, and the differences are very decided, and oftentimes are expressed energetically. The subject is intensely interesting, and not second in importance to any kind of enquiry whatever. The view to which my investigations have led me will have been already gathered by the reader (see p. 65), but in the present section I propose to recapitulate some of the evidence which has already been adduced, and to reply to some objections which have been raised.

In the first part of this work I have encleavoured to show that the doctrine of the vegetable nature of disease germs must be abandoned. No one has succeeded in proving that any form of contagious living matter can be traced to a microscopic fungus or other low vegetable organism. Nevertheless, in opposition to all that has been urged to the contrary, but without a reply to one of the many arguments advanced against the doctrine, we find the vegetable nature of disease germs, and the prejudicial disease-carrying properties of vegetable fungi, taught and advocated in "The Twelfth Report of the Medical Officer of the Privy Council." As the Report has been published since the first part of this work was printed, I propose to offer a few more remarks upon this doctrine which seems to have a warm supporter in Mr. Simon. I was much surprised to find a general 
assent to the views of Hallier, which have not been confirmed and which few who have carefully studied the matter are inclined to accept.

In his report the Health Officer of the Privy Council makes the following remarks upon this subject :- " Knowing that all contagia (as such) are distinct from one another, and believing that each of them has its essence in the so-called microzymes which it contains, we by implication impute to the microzymes that in different diseases they are not identical; and as we affirm them to be dynamically different, so also we assume that under well devised differential experiments, other signs of their specificity may be brought to light, and for each sort of them a definite genesiology be written." Athough many objections have been raised to these and allied views, they appear to be regarded with especial favour in the Government Report. More than a dozen closely printed pages have been devoted to an exposition of Hallier's strange doctrines, and several of his drawings have been repeated in the Introductory Report by Dr. Burdon Sanderson.

Figures of the supposed contagious microzymes have been given, which refute themselves. The drawing given by Dr. Sanderson in his Report (Fig. I, p. 232), and described as groups of particles in fresh vaccine, conveys no idea of the actual appearance of the matter represented. A few minute circles may be made to indicate very fairly the appearance of 
microscopic fungi, but they are no more like the particles of vaccine lymph, or any contagious poison, or any kind of living matter known, than an oil globule or an air bubble is like a white blood corpuscle, or a pus corpuscle. Such illustrations only help to retard investigation and convey erroneous ideas regarding the character of the matters referred to ; nor is it right to lead the reader to suppose that nothing more has been made out concerning the little particles of vaccine than is represented in the drawing referred to, considering the particles in question were described and figured under a much higher magnifying power several years ago.

But strange to say, Dr. Sanderson remarks that the presence of these particles is in itself a fact of little importance (!), because "many transparent organic fluids, as, e.g., the liquor sanguinis, are found when examined under high powers, to contain particles of about the same size as those which exist in vaccine." Now it is quite certain that the fact is of the very highest importance, as showing that living particles, having precisely the same characters, may differ remarkably in powers and properties, and that therefore these last cannot be attributed to chemical composition, or to anatomical structure. But the same writer intimates that the opinion may be fairly entertained that bioplasm might exhibit structure if subjected to more perfect investigation, and then remarks that the resemblance between different kinds of germinal matter 
"relates rather to those properties of which we can judge by anatomical means, than to those of chemical composition, or even organic form." Such a remark indicates that the writer does not understand the view he thus attempts to criticise. Neither he nor any one else knows anything about the composition of living matter. Dr. Sanderson's remarks clearly show that he is opposed to the views advanced by me, but if he noticed them at all, in common fairness he ought to have stated exactly what they were. He may do his utmost to make people believe in the old notion that the properties of various kinds of living matter are due to chemical composition, or to organic form, but the facts of the case render such a view absolutely untenable, nor could it have been made to appear plausible had the objections which have been urged against it been stated. No wonder that innocent fungi are again made to do duty for the active particles of contagium, ordinary bacteria, called " microzymes in vaccine" and "crypto-coccus cells" obtained by the "cultivation of vaccine;" for Hallier's "Micrococci" are still regarded as disease-carrying particles, and readers are entertained with the ofttold story of the "rice parasite." Several of Hallier's untenable theories are minutely discussed, whilst the mass of evidence against his conclusions is almost entirely passed over.

If such a subject as the "intimate pathology of contagion" be discussed at all in a Government report, 
it is only right that a fair and clear statement of the views of those who have investigated the subject should be given, accompanied by references to the original memoirs. Otherwise by these reports particular theories are promulgated as it were by authority, and instead of the public being furnished with a comprehensive view of what is known at the time regarding questions of the deepest scientific interest, as well as of great importance, they are led to accept inferences which perhaps have long been actually proved to be erroneous. Competent observers have indeed rejected Hallier's conclusions as based upon inconclusive evidence. Moreover the arguments advanced against the notion that the contagious poison consists of vegetable particles are so conclusive, that the abandonment of the theory is probably only a question of time.

It has been shown that the contagious poison of contagious fevers and allied affections is not volatile, nor composed of mere albuminous matter capable of being dissolved in fluid. It consists of minute particles of soft matter in a living state, and as was stated in my Report, printed in 1856 , this material increases and multiplies, and behaves in a manner peculiar to matter which is alive. Though the contagious disease germ consists of living matter, and is formed in a living organism, and lives and grows in the body, it cannot properly be regarded as parasitic. Any one who had studied the germinal matter of 
the lower simpler creatures, or that of man and animals at an early period of development, or had only cursorily glanced at that which can be seen and studied so readily in the developing textures of a young embryo, or in an inflamed tissue, or in a rapidly growing morbid growth, as cancer, would have been quite prepared for the observation that the living bioplasm of contagious disease presented nothing more remarkable than was to be observed in connection with any other kind of living germinal matter.

In my Report to the Cattle Plague Commissioners these arguments were set forth, and the observations were illustrated with numerous drawings. The contagious material was represented in several of these, and some general conclusions were arrived at, which it is believed were fully justified by the facts and observations recorded. I was therefore disappointed when I read the comments of the Commissioners, and I believe that any one who reads the observations in my Report, and then refers to the remarks of the Commissioners, will come to the conclusion that the writer of this part of the Report was either prejudiced against my conclusions, or that he had not read the observations on which they were based. Although the living poisonous germinal matter had been described and figured, the public were told that I had "found no definitely formed substance that can certainly be said to be the cause of cattle plague," and that I had discovered "granular matter." Not 
only were my conclusions misinterpreted, but it was asserted that the method I pursued was not likely to succeed, and that the poison was of a kind which " is and will always be undiscoverable by the microscope."

The suggestion of the Commissioners is that the poison consists of some complex albuminoid matter, in a state of rapid chemical change, which causes "an increased zymotic action in the blood and in the textures," but the complex chemical substance has not been discovered, and nothing is known of the rapid chemical changes it is supposed to undergo. A "zymotic action in the slood" requires explanation, while a zymotic action in the textures is simply as inconceivable as fermentation of skin and bones and muscles. The opposition to the use of high magnifying powers which had shortly before been introduced and much employed by me, was very strong at the time the Report was published, and many did not hesitate to insinuate that the conclusions arrived at were due rather to the imagination than to investigation. Since that time, however, so many twenty-fifths have been employed, that it is quite needless to defend their use, while some of those who insisted so much upon the results of physical and chemical experiments have been forced to appeal to the fancy for evidence in support of their theories which were not based upon facts.

The characters of the actual contagious material having been demonstrated in several instances, I do 
not think any one will urge as an objection to the general application of the doctrine here taught that these same characters ought to have been proved in the case of every contagious malady known to us. As well might it be argued that we cannot accept any conclusions as to the nature of pus until the pus produced under all possible kinds of pus formation, and in every part of the organism has been submitted to investigation. Knowing what we do of the several diseases, it would not be reasonable to infer that the poison of small-pox consisted of matters in an essentially different state from that of vaccine poison, or that the poison of typhus, typhoid, relapsing fever, scarlet fever, and measles, consisted of matter in very different physical states,-in one fever being a gas, in another a liquid, in one an alkaloid, in another a protein substance, and so on. Such a doctrine would be absolutely untenable. It may, however, be urged by dissentients, that the evidence I have adduced in favour of the contagion of all contagious fevers being a form of bioplasm, is not conclusive, because every individual contagious fever has not been subjected to precisely the same course of minute investigation.

The minute contagious bioplast is less than the $\overline{1} \frac{1}{0}, 0 \overline{0} 0$ th of an inch in diameter, and often so very clear and structureless as to be scarcely distinguishable from the fluid in which it is suspended. Such a minute particle may readily be transferred from the affected organism to an apparently sound organism. 
It may be carried a considerable distance from its source without losing its marvellous power of causing in the organism invaded a series of changes resembling, and often in very minute particulars, the phenomena which have occurred in the organism from which it was derived.

And it is established that there exist different kinds of contagious living bioplasm, each capable of occasioning specific phenomena which distinguish it. The poison of small-pox will produce small-pox, not typhus fever, or measles, \&c., nor will any of these produce small-pox.

Without therefore pretending to identify the actual particles of the living bioplasm of every contagious disease, or to be able to distinguish it positively from other forms of bioplasm, healthy and morbid, present in the fluids, on the different free surfaces, and in the tissues in such vast numbers, I think the facts and arguments I have advanced prove-first, that the contagious virus is living and growing matter; secondly, that the particles are not directly descended from any form of germinal matter or bioplasm of the organism of the infected animal, but that they have resulted from the multiplication of particles introduced from without; thirdly, that it is capable of growing and multiplying in the blood; fourthly, that the particles are so minute that they readily pass through the walls of the capillaries, and multiply freely in the interstices between the tissue elements or epithelial cells; 
and lastly, that these particles are capable of living under many different conditions--that they live and grow at the expense of various tissue elements, and retain their vitality, although the germinal matter of the normal textures after growing and multiplying to a great extent, has ceased to exist.

But the reader will ask which of the particles seen in the secretions from the nose and eyes, intestines, vagina, and in the tissues, are the particles of contagium, for it has been proved that in matter from all these situa. tions, at least in cattle plague, the contagious property resides. He will probably have gathered from the statements made that I regard some of the most minute particles present to be alone the active agents, while the epithelial cells, the fungi and bacteria, are probably as passive as the oil globules or crystals of triple phosphate commonly met with. Particles which I believe to be contagious are represented in Plates $\mathrm{XX}$ to XXIV, figs. $68,70,73,74,78,80,81,86$, and the bioplasm amongst the bundles of fibrous tissue, represented in P1. XXII, figs. 76, 77, I think consists entirely of particles, the smallest of which would induce the cattle plague, if introduced into the blood of an uninfected animal. Figs. 68, 70, 74, represent particles of the supposed contagium or active contagious matter in the vessels. It would, I think, be quite possible to devise experiments which would determine positively which is the real contagious matter. The real contagious material has passed unnoticed, 
having been included in the collection of substances which have been denominated débris and granular matter. By the carmine fluid we can, however, distinguish particles of germinal matter from fat granules, myelin particles, and débris. Nor are observations and experiments upon this most interesting question concerning the nature of contagium limited to cattle plague. Although this disease affords in very many ways advantages for study far above many other contagious maladies, and deserves on many grounds the most thorough and extended scientific investigation, no doubt many of the questions of the greatest general interest may be successfully worked out by studying other contagious maladies affecting man or animals.

No Difference to be detected in the Appearance of different kinds of Living. Matter.-I have shown that even with the aid of the highest powers of the microscope no differences can be discerned between bioplasm from the cell or elementary part of the highest organism at any age or period of development, and bioplasm of which the lowest simplest being in existence is composed. A minute particle of the germinal matter of an amœba could not be distinguished from a portion of a pus or mucous corpuscle, or white blood-corpuscle, \&c. Compare Figs. 3,5 , p. $16 ; 25,27 *$, p. $46 ; 36,37$, p. 64 .

It will probably strike many as very remarkable that the highest magnifying powers hitherto placed at 
our disposal serve but to convince us that a minute particle of the bioplasm of the most malignant tumour, or the most rapidly growing pus corpuscle, resembles in every particular that we can ascertain by observation or experiment, a minute particle of healthy living bioplasm, from the blood or from any tissue; and it is proved beyond a doubt by the same means of enquiry, that the living particles of bioplasm in vaccine lymph cannot be distinguished from those present in normal lymph or chyle. In short, that no differences exist in colour, form, density, chemical composition, or movements, between living particles producing the most diverse results, and giving rise to the production of the most different substances (formed material). I think we shall find ourselves compelled by the necessities of the case to refer the properties of these different substances to what must be termed a difference in vital power. To this we may attribute the different relations of the elements, which must be brought about immediately before they combine to form the different chemical compounds. Any argument against my conclusions, based upon the circumstance that no special germ can be detected in any contagious diseases, can therefore have no force, and will not be advanced by any one who has made himself acquainted with the facts of the case. All the contagious fevers have many points in common, and for this reason we should naturally infer that the poisons which give rise to them, although distinct 
from one another, belong to one class or order of living matter or bioplasm.

As every known living thing consists at one period of a little, clear, transparent, structureless, living, moving matter, which exhibits precisely the same characters in every case, though possessing powers so wonderfully different-as the various tissues and organs of man and animals all result from masses of living matter not to be distinguished from one another except in the results of their life-there is nothing, regarding the matter from this point of view, to deter us from accepting the conclusion to which we are led by actual observation, that the poisons of the different contagious diseases could not be distinguished from one another by microscopical examination or by chemical analysis.

Disease Germs may long remain Dormant, though alive.-Just as a seed may remain perfectly quiescent, but nevertheless in a living state, for a long period of time, without growing or giving any evidence of vitality, so, there is reason to think, many kinds of bioplasm may remain in a living, but almost dormant state, in the system, ready to spring into active existence should the conditions favourable to their existence be brought about, and the pabulum adapted for their nutrition be at hand. Unquestionably the morbid bioplasm of certain kinds of tubercle and syphilis may exist for years in a quiescent state. The development of the forms of disease characteristic 
of its presence being determined by the state of the system and the conditions to which it is exposed. So that of two persons equally infected, but living under very different, and, in some respects, opposite conditions, the germs in one, after remaining dormant for a long while, may at length die and become extinct, while in the other organism, being placed under conditions favourable to their activity, the germs grow and multiply, and perhaps even destroy the body, it may be at a very early age. And it is possible that in one organism more than one kind of morbid bioplasm may be dormant, the conditions favourable to the growth of one being unfavourable to that of another. So that of many kinds present, one or more may become active. The careful consideration of facts of observation in connection with the subject of contagious diseases, leads to the conclusion that in all cases where disease is developed two things are necessary- $I$, the presence of the living disease germ ; 2, the external conditions favourable to its growth and multiplication. It seems to me, therefore, that if every disease germ were destroyed to-morrow, the result would probably be far less favourable to humanity than if every organism could be placed under the conditions most favourable for resisting attack, and therefore under circumstances which would interfere with the growth of the disease germ, which at length would die. And for this reason-that in the latter case the extinction of disease germs, although more gradual, would not 
be less certain, while the probability of invasion would grow less as time advanced, and the development of new germs would become impossible.

It will probably be noticed that the above remarks are as applicable to the development of normal, as to that of abnormal forms of bioplasm. For multitudes of the lower forms of life spring into activity whenever the conditions favourable to their growth prevail. They may remain so quiescent for months, that no one would believe that their germs were in existence, but in a night the air or water of a district may become peopled with countless multitudes of beings, not one of which was to be found a few hours previously. No wonder the air or the water was supposed to create them, and that the doctrine of spontaneous generation was the belief of the vulgar. It is not a little remarkable that such a view, driven as it has been from one position to another during the last two hundred years, should yet find advocates among the most active intellects of these days. Instead of despairing, its advocates still keep up such a show of vigorous resistance, that the public, judging only from the information afforded by warm advocates of heterogenesis, is led to believe that although a horse, a mouse, a maggot, a worm, a rose, and even a mushroom unquestionably came from living things of the same kind which lived before them, very low microscopic forms, which are only to be seen with difficulty under the highest powers, spring direct from the non- 
living, without being indebted for existence to a previous generation.

On the Origin of Disease Germs. - We have now to try to find an answer to some very important questions, among which are the following:-Have disease germs always existed? Is their origin contemporaneous with that of life, or is it more probable they are of more recent date? Could they have existed before man, and independently of man, or is their production necessarily associated with human beings? If the latter appears to be the most probable view, we may enquire further whether there were contagious disease germs in the prehistoric epoch, or if their evolution is in some manner dependent upon civilization. The thoughtful student naturally desires to know if disease germs of each special kind known to us at this time, always retained the characters they now possess, or if their properties have become modified from time to time as external circumstances have changed. Are disease germs ever developed anew in these days? Do generations of disease germs die out and give place to others allied to them, but not identical? And, lastly, the important practical question which has been already referred to in page 165 presents itself. Supposing it were possible to extirpate entirely all disease germs now existing, is there reason to think that new forms of precisely the same kind would be reproduced, or that more or less closely allied forms would be developed anew? 
It is not, I think, possible in the present state of knowledge to reply definitely and conclusively to many of these enquiries; but it is well that they should be made. And in considering the mode of origin of contagious living matter, to which subject the present section is devoted, it will be my duty to lay before the reader, as simply as I can, the grounds upon which are based the views I have been led to adopt.

The facts that the living matter of the blood of one individual will live in the blood-vessels of the organism of another; that skin, periosteum, and other tissues may be transplanted and grafted, prepare us for the acceptance of the remarkable circumstance demonstrated by experiment that living pus bioplasts which have indeed been derived from normal bioplasm, may traverse long distances, free and independent, and then, gaining access to another organism, may live, and grow, and multiply in it, and establish changes of the same kind as those which were taking place at the seat of its origin.

Many of the lower and simpler forms of life, as is well known, may continue to grow and multiply as larval or imperfectly developed forms, and attain, under altered conditions, a higher and altogether different state of existence, during which the process of multiplication in that way ceases. It is possible that the exceedingly minute living particles which constitute the "contagium" of contagious 
diseases, may be the degraded offspring of some kind of normal living matter or bioplasm, which originally possessed comparatively exalted tissue-forming or other formative powers.

A consideration of many different circumstances leads me to suggest the possibility of the origination of the contagious fever poison in the matter which grows and multiplies in the capillaries in the feverish state. It is not improbable that in certain states of system the minute particles of bioplasm in the blood may grow and multiply enormously, without ever being developed into white blood-corpuscles, just as many of the lower organisms multiply infinitely without one of the offspring necessarily attaining the highest state of perfection possible. The surrounding conditions may be adverse to the individual particles attaining their perfectly developed form, though favourable to their growth and multiplication in an immature state.

The phenomena which occasion the formation of ordinary pus, may, if they continue to occur for a long period of time, determine the development of a specific pus, which has still more marvellous powers of vitality. So it may, I think, be reasonably argued that if the ordinary feverish state be prolonged for a considerable time, and be severe in degree, it is likely that the bioplasm in the blood collected in the capillaries may give origin to bioplasm with marvellously increased powers of retaining its vitality, of growing 
and multiplying. The particles of this, making their way through the vessels, and escaping, may live for a considerable time, and having entered the blood of another person, may excite in it changes which accompanied their own development.

Now, an organism which is about to be the subject of an ordinary feverish attack, would probably, if exposed to the influence of contagious disease germs, become the seat of development of a specific and perhaps fatal contagious fever. - It is only reasonable to infer that a state of things favourable to the rapid growth and multiplication of disease germs, is not very different from the conditions favourable to their origin.

It has been already shown that the living puscorpuscle and the living disease germ, like every other kind of living bioplasm, have been derived from preexisting living matter, and it would not be difficult to suggest certain "laws" by which the retrograde evolution of the bioplasm might be said to be governed. But of late so many "laws" have been made, that it is not desirable to attempt to make any new ones. If, at this present time, there is an intelligence sufficiently perfected to reveal to us what kind of new disease germs evolved under the then altered conditions of society will afflict civilized man three centuries hence, and what sort of new contagious diseases they will necessarily excite, it is doubtful if, with the limited powers of understanding with which most of us are 
endowed, we should be able to recognize the importance of the discoveries of a scientific imagination so exalted, or appreciate the "laws" it had evolved for our instruction. Without, therefore, venturing to state positively from what particular kinds of germinal or living matter of the body the germs of contagious disease are actually derived, or attempting to decide definitely whether they come from the very minute blood bioplasts, or from ordinary white blood-corpuscles, or lymph corpuscles, or mucus, or epithelial or other particles, I think I am justified in advancing the doctrine that the germs originate in man's organism, and that they have descended from the normal bioplasm of his body.

In ordinary febrile states, the bioplasm of the blood is increased, and it is not improbable that from the growth and multiplication of this bioplasm, under certain circumstances, contagious bioplasm of various kinds may result.

It would seem, then, arguing from the facts referred to when discussing the inflammation of the peritoneum, in which process a very highly contagious form of bioplasm is developed in the course of a few hours, that there can be little doubt regarding the origin of the poison in this particular case. The minute particles of bioplasm or living matter produced in such great numbers as the inflammation advanced, are the actual agents, and it is by their rapid growth and multiplication in the lymph, and afterwards in the blood, 
particularly in the capillaries in various parts of the body, that the dreadful effects exerted by these particles in an organism into which some have been introduced by inoculation, must be attributed.

It seems, then, that every stage in the production of at least this particular virulent poison, may be watched and studied, and from the facts ascertained a connected history of its development may be compiled. We have seen that the first particles of bioplasm resulted directly from the bioplasm of the blood. In consequence of continued free access of nutrient material, series after series, generation after generation, of new particles was produced; each series degenerating in formative power, and acquiring new powers, but of mere growth and multiplication, and a capacity for living upon materials which would not have been appropriated by the bioplasm from which it originated.

The following diagram may perhaps assist in rendering my meaning clearer :-

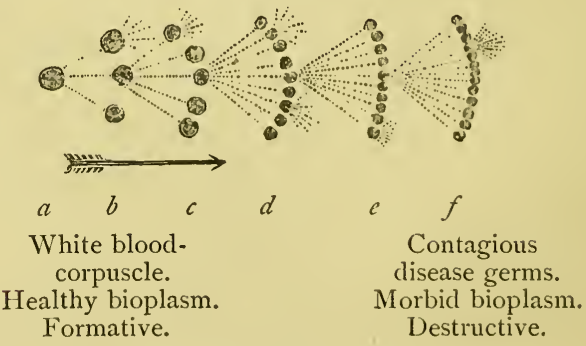

Successive series of living particles resulting from the growth and 
multiplication of a single white blood-corpuscle. Each series grows faster than the one from which it originated. In the plan, the process of multiplication is represented as if it only occurred in the case of one particle in each series ; but in order to afford an accurate conception of the process, similar radiating lines must be supposed to diverge from every part of the circumference of every particle. $a$ is a white bloodcorpuscle ; $b, c, d$, and $e$, successive series of particles which produce others, until at last contagious disease germs, $f$, result. In this particular instance we seem to almost succeed in demonstrating the manner in which a very highly contagious bioplasm originates in hospital and camp fever.

In certain forms of erysipelas, purulent ophthalmia, and analogous contagious diseases, which sometimes originate in an isolated population living under certain conditions adverse to health, it is almost impossible to doubt that the living germs are developed in the same manner as the virulent pus bioplasts produced in peritonitis from the bioplasm which was once in a normal healthy state. And the same reasoning leads to the inference that the generation of the poison of many. contagious diseases, and all contagious fevers, occurs in the same way. It is certain that many cases of blood-poisoning, and various forms of idiopathic fever, depend upon the passage into the blood, and its dissemination through the system, of a poisonous bioplasm which has been generated in the body, the virulent bioplasm itself having resulted from the growth and multiplication of generations of particles derived by continuous succession from the normal bioplasm of the organism.

In some cases the morbid living matter found in 
man will live in the higher animals, and that produced in the latter propagates itself in the human body. As bioplasm becomes more degraded, it acquires an -increased capacity of retaining its life under a greater variety of conditions. Pus which is derived from normal germinal matter by direct descent is not so easily destroyed as the germinal matter from which it proceeded; and special kinds of pus, which are separated from the bioplasm of health by a vast number of intervening generations, possess, if not a still more remarkable tenacity of life, at least the power of living under a greater variety of conditions. It is therefore possible that means may be discovered of destroying the life of these different forms of adventitious bioplasm. Being naked, that is, unprotected by any cell wall or formed material, these bioplasts are exposed to the direct influence of any vapours or fluids which may be brought to bear upon them, while, on the other hand, the bioplasm of the tissues would resist the action of these same agents, in consequence of the efficient protection afforded by the formed material around it. The naked germinal matter of the healthy blood is probably acted upon by many poisonous substances which do not affect the living matter of the tissues of the body, and there is reason to think that certain poisonous agents, the action of which is exceedingly rapid, destroy life by instantaneously killing the germinal matter of the blood, and thus leading to stoppage of the circulation. 
It is from researches in this direction that we may hope to gain knowledge which may lead to the discovery of means of destroying the contagious germinal matter while in the blood, and of preventing the influence of poisons of another kind upon the living bioplasm of the blood, capillary vessels, and of that of the tissues immediately adjacent.

A careful study of the course and symptoms of the various fevers which have been prevalent at different periods, leads to the suggestion of the probability that from time to time new germs are produced, and that old ones deteriorate and disappear. The new forms may be closely allied to already existing forms, and to forms which have existed previously, but nevertheless the results occasioned by their development are so peculiar that we cannot but suppose they are occasioned by a poison of a special kind. It is even possible to discern differences between cases of the same type of contagious fever, which are sufficient to justify us in arranging them as species of a genus, or as varieties of a species.

It is not probable that disease germs have sprung from insects or animalcules, or any kind of vegetable organism, neither have they originated in the external world, and seized upon man, but they have been derived by direct descent from the normal living bioplasm of the organism. They have originated in man, and if man is not indeed responsible for their origin, he has certainly himself imposed the conditions 
favourable to their production and dissemination. Human intelligence, energy, and self-sacrifice may succeed in extirpating them, and may perhaps discover means of interfering with the origin of new forms not known to exist at this time. 


\section{deter cielorks bu the same Anthor.}

\section{Now ready, 8th Thousiand, 2Is. \\ HOW TO WORK WITH THE MICROSCOPE.}

The Fourth Edition, very much enlarged.

This work is a complete manual of microscopical manipulation, and contains a full description of many new processes of investigation, with directions for examining objects under the highest powers.

With Seventy Plates, including many new Figures, some of which are coloured.

\section{CONTENTS :-}

I. The Simple and Compound Microscope-Choice of a MicroscopeTravelling and Dissecting Microscopes-Clinical, Pocket, and Class Microscope.

II. Examination of Objects by Reflected, Transmitted, and Polarized Light-Dark ground Illumination-Illumination-On Drawing and Measuring Objects-Ascertaining the Magnifying Power of Object Glasses.

iIII. Instruments required for Dissection-Valentin's Knife, \&c.-Cements -. Preservative Solutions.

IV. On making Cells-Brunswick Black, and different forms of Glass and other Cells for preserving Specimens.

V. On examining objects in the Microscope-Muscular Tissue-Of making Minute Dissections-Hardening Textures-Of examining Objects in Air, Water, and Canada Balsam.

VI. Of Preserving different Structures permanently-Of separating Deposits from Fluids.

VII. Of Injecting-Apparatus, \&c.-Of Natural and Artificial InjectionsOf the advantages of Transparent Injections-Of the Prussian Blue Injecting Fluid-Injecting Mollusca, Insects, \&c.

VIII. Of the use of Chemical Reagents in Microscopical InvestigationFallacies to be guarded against--Presence of Extraneous Substances.

IX. Of taking Photographs of Objects.

X. New method of preparing all Tissues for Microscopical Investigation.

XI. On the use of very high Magnifying Powers.

XII. Of making and recording Microscopical Observations.

Tables for practising the use of the Microscope and Manipulation.

A pparatus required in Microscopical Investigation.

Microscope Makers, Preparers of Specimens, Artists, Printers, Lithographers, \&c.

"The Author, both in the text and in the explanations of the engravings, has endeavoured to restrict himself, as far as possible, to giving hints and directions which may be practically useful to the studen t while he is at work." - Extract from the Preface. 


\section{THE PHYSIOLOGICAL ANATOMY \& PHYSIOLOGY OF MAN.}

By ROBERT B. TODD, WILLIAM BOWMAN, \& LIONEL S. BEALE, Fellows of the Royal Society.

Being a New Edition, by Dr. BEALE, of Vol. I. of the original Work of Messrs. TODd and Buwsan. Part I., with Plates, now ready, $75.6 d$. Part II., nearly riady.

LONGMANS \& Co.

Nowe Ready, Is., Free by Post.

ON MEDICAL PROGRESS. IN MEMORIAM : ROBERT BENTLEY.TODD.

$$
\text { Cloth, 8vo., I6s. }
$$

\section{CLINICAL LECTURES,}

By the late ROBERT B. TODD, M.D., F.R.S., formerly Physician to King's

College Hospital, and Professor of Physiology and of General and Morbid Anatomy in King's College, London.

Second Edition. Edited by Dr. Beale.

Now ready, fourth Thousand, I6s.

THE USE OF THE MIGROSCOPE IN MEDIGINE. FOR PRACTITIONERS AND STUDENTS.

3rd Edition.

This Work contains $5^{8}$ Plates, containing many new Figures, now published for the first time.

Now ready, 25s.

KIDNEY DISEASES, URINARY DEPOSITS, AND CALGULOUS DISORDERS;

Including the Symptoms, Diagnosis, and Treatment of Urinary Iiseases. IVith full Directions for the Chemical and Microscopical Analysis of the Urine in Health and Disease.

The Plates separately, 4I 5 figures, I $2 s$. The Text, pp. 500, I 5 s.

Uniform with "The Microscope in its application to Practical Medicine."

\section{THE ARCHIVES OF MEDICINE.}

A Record of Practical Olsservations and Anatomical and Chemical Researches connected with the Observation and Treatment of Disease.

Erdited by Dr. BEALE.

3.s. each number.

Vols. I., II., III., and IV. Vols. I. and II., I5s. each; III., IIs. ; and

IV., 13s. Subscription for four numbers, constituting a volume, Ios.

The first number of Vol. V. now ready. All Communications to be addressed to the Editor.

JOHN CHURCHII, \& SONS. 
Now Ready, Second Edition, very much enlarged, 6s. $6 d$.

LIFE, MATTER, AND MIND; OR PROTOPLASM.

With Original Observations on Minute Structure and numerous New Coloured Drawings.

*** This.work is partly original and partly controversial.

\section{Four Coloured Plates, $3,6 d$.}

DISEASE GERMS: THEIR SUPPOSED NATURE.

An Original Investigation with the aid of the Highest Powers yet made.

Uniform with the present Volume.

[Now Ready.

Recently Published,

I.-ON THE STRUGTURE.AND FORMATION OF GERTAIN NERVOUS CENTRES,

Tending to prove that the Cells and Fibres of every Nervous Apparatus form an uninterrupted Circuit.

Quarto, 8 Plates, containing 46 Figures, 5 s.

II.-INDIGATIONS OF THE PATHS TAKEN BY THE NERVE GURRENTS

As they traverse the Caudate Nerve Cells of the Cord and Encephalon.

One Plate and 4 Figures, Is. $6 d$.

\section{NEW WORKS PREPARING.}

ON DISEASES of the LIVER and their TREATMENT.

A Second Edition, much enlarged, of the Author's Work on the Anatomy of the Liver. Numerous Plates.

[The First Part shortly.

DISEASE : ITS NATURE AND TREATMENT.

New Researches. With Observations on the Cattle Plague and on Cholera. Numerous Coloured Plates. Based on the Third Course of Lectures delivered at Oxford by direction of the Radcliffe Trustees.

[Preparing.

ON E:OPLASM, OR THE LIVING MATTER OF THE TISSUES AND FLUIDS OF LIVING BEINGS.

With Numerons Coloured Plates. An Introduction to the Study of Physiology and Medicine. Being the first Course of Lectures delivered at Oxford by direction of the Radcliffe Trustees.

ON INFLAMMATION: ITS NATURE AND THE PRINCIPLES WHICH SHOULD GUIDE US IN TREATMENT.

[Preparing.

** All these Works contain the results of the Author's original investisa. tions. They are illuslrated with upwards of 2,000 Engravings, copied from the actual objects, all of which have been drawon on roood by the Author himself or under his immediate superintendence.

London : JOHN CHURCHILL \& SONS.

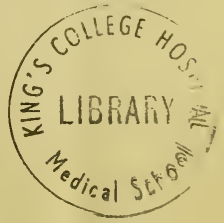


ON: HARRISON AND SONS, ST. MARTINS LANE,
PRINTERS IN ORDINARY TO HER MAJESTY.

20 

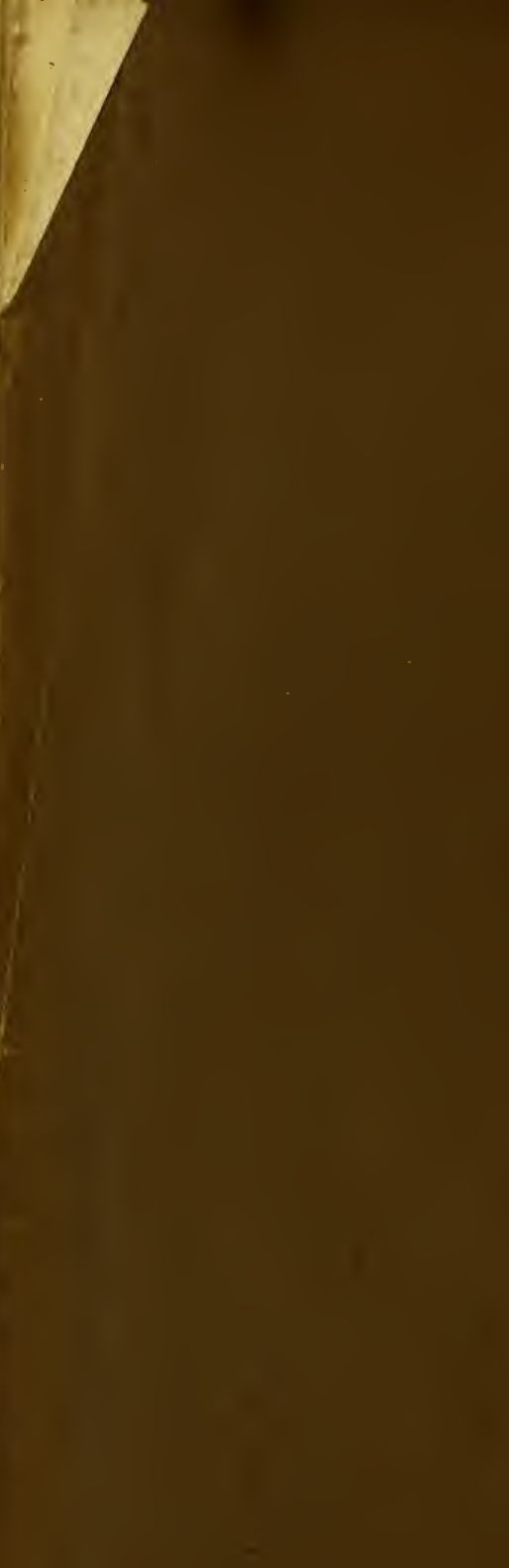


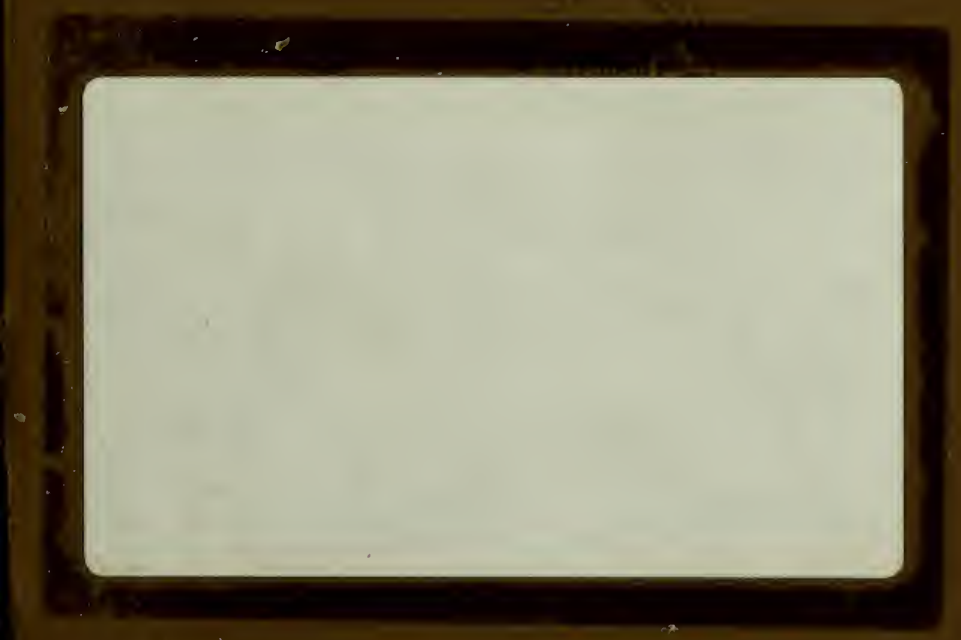

ह 
